Universidade de Brasília - UnB

Instituto de Ciências Biológicas

Programa de Pós-Graduação em Zoologia

Polinização da aboboreira (Cucurbita pepo L.): um estudo sobre a comunidade de abelhas em sistemas orgânicos e convencionais de produção no Distrito Federal

Karoline Ribeiro de Sá Torezani

Orientador: Dr. Raúl Alberto Laumann Co-orientadora: Dra. Carmen S.S. Pires 
Universidade de Brasília - UnB

Instituto de Ciências Biológicas

Programa de Pós-Graduação em Zoologia

\title{
Polinização da aboboreira (Cucurbita pepo L.): um estudo sobre a comunidade de abelhas em sistemas orgânicos e convencionais de produção no Distrito Federal
}

\author{
Karoline Ribeiro de Sá Torezani \\ Orientador: Dr. Raúl Alberto Laumann \\ Co-orientadora: Dra. Carmen S.S. Pires
}

\begin{abstract}
Dissertação apresentada ao Programa de Pós-graduação em Zoologia do Instituto de Ciências Biológicas da Universidade de Brasília (UnB), como requisito parcial à obtenção do grau de mestre em Zoologia.
\end{abstract}

Brasília, 2015 


\section{AGRADECIMENTOS}

Agradeço primeiramente a Deus por ter me dado forças para superar os obstáculos encontrados no decorrer deste trabalho, pois somente Ele me acompanhou durante cada segundo desta caminhada e viu todos os meus momentos de desespero.

À minha família pela compreensão da minha ausência em alguns momentos e pelas palavras de incentivo; em especial à minha mãe, por ter acreditado neste sonho e por todo o carinho e amor, ao meu pai que mesmo distante sempre me apoiou, e aos meus irmãos, Bárbara, Shayder e Stefhany que tiveram muita paciência comigo nos momentos de stress.

Aos meus orientadores, Raúl Laumann e Carmen Pires, pela dedicação, amizade, confiança e seus conselhos que foram essenciais para o meu crescimento profissional. Muito obrigada por toda a contribuição à minha formação acadêmica!!!!

Á Capes pela bolsa concedida e ao Laboratório de Ecologia e Biossegurança da Embrapa Cenargen pela estrutura fornecida.

Ao professor Antônio Aguiar da Universidade de Brasília (UnB) pelas identificações das espécies de abelhas.

Ao amigo Sérgio Noronha, analista da Embrapa Cenargen, pela grande ajuda com os dados da caracterização da paisagem e por ser prestativo e paciente.

A todos os motoristas da Embrapa que me acompanharam nas coletas de campo, e que tiveram que acordar bem cedo, mas sempre com muito bom humor, em especial, ao seu Mendonça por todo o carinho.

Aos moradores das propriedades dos núcleos rurais que sempre me recebiam com toda a atenção e permitiram que o estudo fosse conduzido.

A todos os companheiros de laboratório do Cenargen pela amizade, apoio, e troca de experiências, em especial a Mayra, Alex, Miniarê, Michely, Isabel e Yumi que tornaram os meus dias mais felizes.

A todos os profissionais que generosamente contribuíram com este trabalho, seja por meio de artigos científicos, livros e boletins de pesquisa.

E todas as outras pessoas que de alguma forma me ajudaram, seja dando apoio, animando ou tirando dúvidas. 


\section{SUMÁRIO}

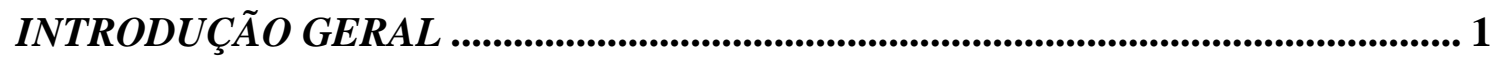

CAPÍTULO 1 ..................................................................................................... 3

1. INTRODUÇÃ

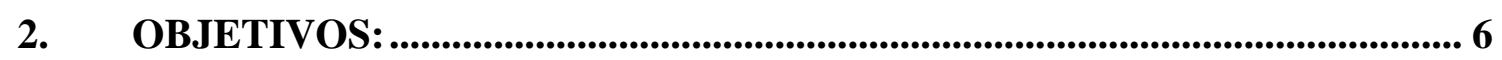

3. MATERIAL E MÉTODOS …........................................................................ 7

3.1. Áreas de estudo ..................................................................................... 7

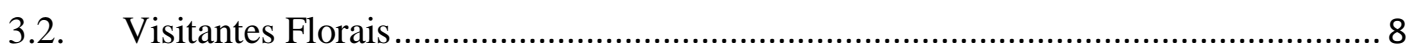

3.3. Caracterização das paisagens do entorno dos cultivos ......................................... 10

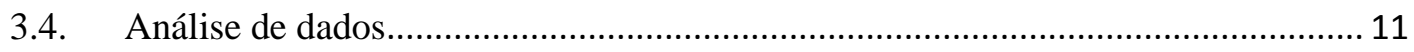

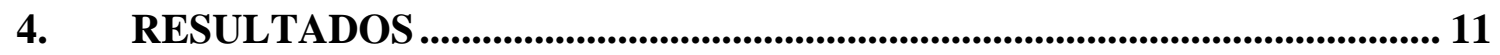

4.1. Comunidade de abelhas visitantes florais .......................................................... 11

4.2. Caracterização das paisagens do entorno dos cultivos ......................................... 19

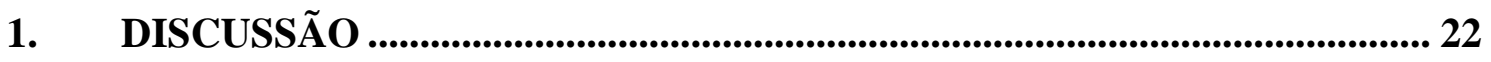

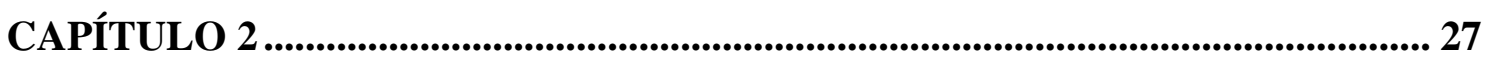

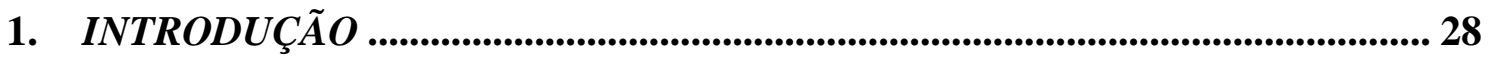

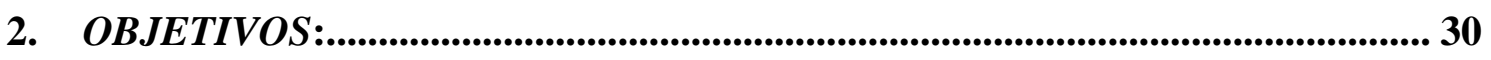

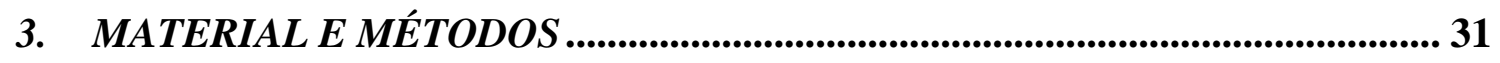

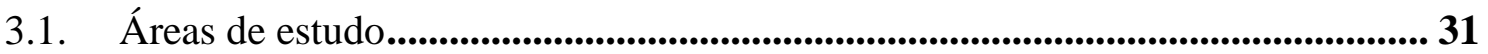

3.2. Comportamento de forrageamento ....................................................................................... 31

3.3. Avaliação do déficit de polinização................................................................................. 33

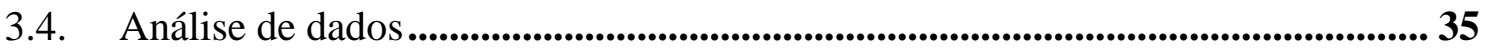

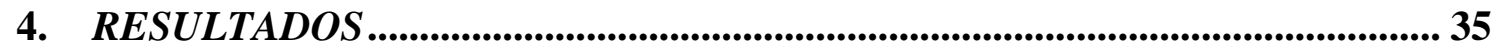

4.1. Longevidade das flores de Cucurbita pepo L. ............................................... 35

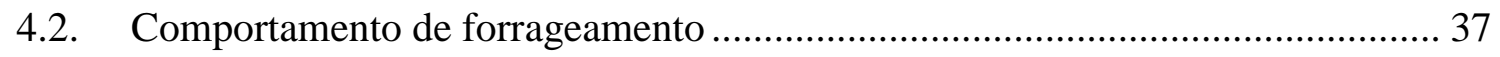

4.3. Avaliação do déficit de polinização................................................................. 43 


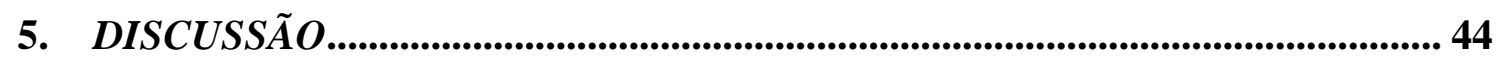

6. CONSIDERAÇ $\tilde{O} E S$ FINAIS .............................................................................. 48

7. REFER $\hat{E} N C I A S$ BIBLIOGRÁFICAS .................................................................... 49

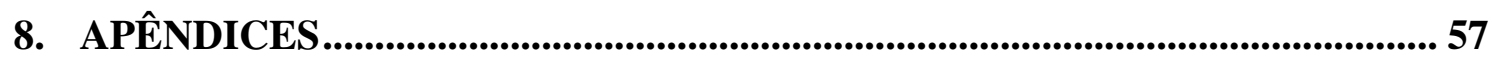




\section{RESUMO}

Dentre os insetos, as abelhas são consideradas os principais visitantes florais e agentes polinizadores da aboboreira Cucurbita spp. Os objetivos deste estudo foram estudar a comunidade de abelhas visitantes florais de Cucurbita pepo L. em sistemas orgânicos e convencionais de produção e avaliar a influência da paisagem do entorno dos cultivos sobre a riqueza e abundância de abelhas. Além de identificar, entre os visitantes florais de $C$. pepo, quais são seus prováveis polinizadores, e se existe um déficit de polinização desta cultura na região. $\mathrm{O}$ estudo foi conduzido em plantios de $C$. pepo, abobrinha italiana, nos dois sistemas de produção localizados no Distrito Federal nos anos de 2013 e 2014, entre os meses de julho e outubro. As abelhas foram coletadas diretamente nas flores de C. pepo com auxílio de frascos plásticos e feitas observações sobre o comportamento de forrageamento. No experimento do déficit de polinização foram marcadas 30 flores femininas/propriedade e avaliados a porcentagem de frutificação e parâmetros de qualidade dos frutos. Para cada propriedade foi feita a caracterização da paisagem em um raio de $2 \mathrm{~km}$ e gerados mapas de uso e ocupação da terra. Nos dois anos de amostragem foram coletados 3.879 indivíduos nas flores de $C$. pepo, distribuídos em duas famílias (Apidae e Halictidae), 23 gêneros e 35 espécies. As quatro espécies mais abundantes foram: Apis mellifera, Trigona spinipes, Trigona hyalinata e Partamona combinata. A abundância total de abelhas foi significativamente maior para o sistema orgânico $(\mathrm{p}<0.001)$ em relação ao convencional, porém a riqueza não diferiu entre os dois sistemas de produção $(\mathrm{p}=0.5)$. A presença de áreas com vegetação nativa no entorno dos cultivos de $C$. pepo tiveram uma influência positiva sobre a riqueza de espécies de abelhas. A partir das observações do comportamento de forrageamento dos visitantes florais mais abundantes, os agentes polinizadores mais importantes de C. pepo em propriedades orgânicas e convencionais de produção no DF, foram: Apis mellifera, Trigona spinipes e Trigona hyalinata. No experimento de déficit de polinização houve $100 \%$ de frutificação, indicando que as propriedades de produção de hortaliças, orgânicas e convencionais, localizadas no Distrito Federal não apresentaram déficit de polinizadores na cultura da aboboreira para este período que foi conduzido o experimento.

Palavras-chave: polinização; sistemas de produção; paisagem; Cucurbitaceae; aboboreira. 


\section{ABSTRACT}

Among insects, bees are considered the main floral visitors and pollinators of squash Cucurbita spp. The objectives were to study the community of floral visitors Cucurbita pepo in organic and conventional production systems and evaluate the influence of the surrounding landscape of crops on the richness and abundance of bees. Moreover to identify, between the floral visitors of $C$. pepo, what are their likely pollinators, and if there is a deficit of pollination of this crop in the region. The study was conducted in C. pepo L. crops, "abobrinha italiana", in both production systems in the Federal District in the years 2013 and 2014, between the months of July and October. Bees were collected directly in C. pepo flowers using of plastic bottles and made observations on the foraging behavior. In the pollination deficit experiment were marked 30 female flowers/property and evaluated the percentage of fruit set and fruit quality parameters. For each property was characterized landscape in a distance of $2 \mathrm{~km}$ and generated using maps and land occupation. In two years of sampling were collected 3.879 individuals in the flowers of $C$. pepo, distributed into two families (Apidae and Halictidae), 23 genera and 35 species. The four most abundant species were: Apis mellifera, Trigona spinipes, Trigona hyalinata and Partamona combinata. Bee abundance was significantly higher for the organic system $(\mathrm{p}<0.001)$ compared to the conventional, but the richness did not differ between the two production systems $(\mathrm{p}=0.5)$. The presence of areas with native vegetation surrounding the $C$. pepo crops had a positive influence on the species richness of bees. Regarding the foraging behavior of the most abundant floral visitors, the most important pollinators of $C$. pepo in organic and conventional production properties were: Apis mellifera, Trigona spinipes and Trigona hyalinata. In the pollination deficit experiment we observed $100 \%$ of fruiting, indicating that both production systems located in the Federal District have no pollinators deficit in C. pepo squash for this period the experiment was conducted.

Key-words: pollination; production systems; landscape; Cucurbitaceae; squash. 


\section{INTRODUÇÃO GERAL}

Cerca de $87 \%$ das angiospermas são dependentes em algum grau da polinização realizada por animais (Ollerton et al., 2011). Os insetos são o grupo de maior destaque, como polinizadores, sendo as abelhas os agentes polinizadores mais eficientes. Muitas características morfológicas de alguns tipos de flores refletem uma especialização para a polinização realizada por abelhas, tais como simetria bilateral, filamentos dos estames alongados, deiscência poricida, grãos de pólen políades (formas com mais de 4 grãos), néctar e resina como recompensas, entre outros (Crepet, 1996).

Das mais de 20 mil espécies de abelhas no mundo (Eardley et al., 2006), 1.700 espécies ocorrem no Brasil, mas estima-se que a riqueza de espécies no país esteja perto de 3.000 (Faria \& Gonçalves, 2013). Muitas dessas espécies estão sob crescente ameaça advinda das atividades antrópicas e a redução, ou até mesmo a perda regional de populações de abelhas e outros insetos tem-se intensificado em áreas agrícolas.

A maior parte dos estudos que avaliam a importância de insetos polinizadores sob uma perspectiva econômica tem sido realizada em agroecossistemas (Gallai et al., 2009; Losey \& Vaughan, 2006; Ricketts \& Lonsdorf, 2013). Uma avaliação recente tomando como base estudos realizados em diversas partes do mundo com 41 espécies cultivadas, dentre elas a aboboreira, estimou o valor dos serviços ecológicos de várias espécies de polinizadores silvestres, incluindo as abelhas, e comprovou que espécies de abelhas silvestres são mais eficientes na polinização do que a abelha européia, $A$. mellifera (Linnaeus, 1758) isoladamente (Garibaldi et al., 2013). Por ser uma espécie mais generalista, A. mellifera poderia atuar de maneira complementar aos outros polinizadores silvestres, e assim contribuir para aumentar a eficiência da polinização (Coffey \& Breen, 1997; Garibaldi et al., 2013; Blüthgen \& Klein, 2011).

Muitos cultivos figuram entre os mais vulneráveis à perda de polinizadores (Gallai et al., 2009), sendo vários os estudos sobre a eficiência de abelhas como seus polinizadores e práticas agrícolas amigáveis a fauna polinizadora como, por exemplo, no cultivo de pepino (Smith et al., 2013), tomate (Santos et al., 2009; Greenleaf \& Kremen, 2006), pimenta malagueta (Macias-Macias et al., 2009), berinjela (Montemor \& Souza, 2009) e abobrinha (Petersen et al., 2013; Julier \& Roulston, 2009). A polinização por abelhas melhora a qualidade dos frutos formados, devido à polinização cruzada promovida por elas, como no caso da berinjela onde a média do peso, diâmetro 
e comprimento dos frutos foram maiores em flores visitadas por abelhas (Patricio et al., 2012) assim como o número médio de sementes (Gemmill-Herren \& Ochieng, 2008) quando comparados a frutos cujas flores não receberam a visita desses insetos.

Um dos grandes objetivos da agricultura moderna é a maximização da produção de alimentos. Aproximadamente um terço da alimentação humana provem de plantas dependentes da polinização animal para a formação de frutos e sementes (Klein et al., 2007). Tal dependência vai além da formação de frutos ou sementes, uma vez que a qualidade nutricional de tais alimentos é maior quando originados de plantas devidamente polinizadas (Aizen et al., 2009). Entretanto, a grande diversidade de espécies agrícolas requer uma adequada diversidade de polinizadores (Westerkamp \& Gottsberger, 2000). Por esses motivos, a presença de elementos nas áreas rurais que permitam a existência de populações de abelhas é de fundamental importância para a manutenção dos serviços de polinização.

Visto o papel fundamental que as abelhas desempenham na polinização, a identificação de fatores que ameaçam a manutenção das populações silvestres é objeto de estudo de vários grupos de pesquisa em todo o mundo.

Este trabalho visa o estudo de polinizadores de abóbora (Cucurbita pepo) em sistemas de produção convencionais e orgânicos do Distrito Federal visando estabelecer a diversidade de espécies, a influência dos sistemas de produção na estrutura das comunidades e a relação entre o comportamento das espécies mais abundantes e a polinização da cultura. 


\section{CAPÍTULO 1}

Diversidade de abelhas em cultura de aboboreira Cucurbita pepo L. no Distrito Federal: influência do sistema de produção e da paisagem 


\section{INTRODUÇ̃̃O}

As hortaliças da família Cucurbitaceae estão entre os cultivos de relevante valor econômico e alimentar na América tropical. Entre elas destacam-se as abóboras (Cucurbita spp.), que ocupam o $7^{\circ}$ lugar entre as hortaliças mais cultivadas no Brasil (Filgueira, 2003) e possuem grande importância pela variabilidade genética que apresenta e vasta área em que é plantada.

Existem 32 espécies do gênero Cucurbita, sendo que, cinco espécies são cultivadas: C. fiscifolia, C. maxima, C. argyrosperma, C. moschata e C. pepo (Hurd et al., 1971). Entre as espécies de abóbora, Cucurbita pepo, está entre as dez hortaliças de maior produção e maior valor econômico no Brasil, principalmente no centro e sul do país. Também conhecida como abobrinha italiana, abóbora de moita ou de árvore, originou-se na região central do México (Filgueira, 2003).

O potencial de produtividade de C. pepo varia entre 8 e 10t/ha (Brito, 2005). Os produtores optam por cultivar essa espécie por ser de ciclo curto (até 120 dias) e com a colheita iniciada aos 45-60 dias após a semeadura (Orozco, 1997). Outra vantagem da cultura é que exige poucos tratos culturais, o que a torna uma hortaliça com ótimo custo-benefício (Souza et al., 2002). A colheita é feita em dias alternados, uma vez que estimula a formação e o desenvolvimento de novos frutos.

A cultura da abóbora é totalmente dependente da polinização entomófila (Passarelli, 2002), necessitando de um agente para realizar a polinização cruzada e garantir a formação de frutos de melhor qualidade. Dentre os insetos, as abelhas são consideradas os polinizadores mais eficientes das aboboreiras (Free, 1993).

Dentre as espécies de abelhas polinizadoras de Cucurbita spp., destaca-se a espécie Peponapis fervens (Smith, 1879) (Apidae). No Brasil, P. fervens foi registrada em cultivos de abóbora por Weiss \& Melo (2007) no Paraná e por Krug et al. (2010) em Santa Catarina. Essa abelha possui dependência dos recursos florais da aboboreira para a procriação, visitam as flores com alta frequência e são responsáveis por carregarem uma grande quantidade de pólen aderido ao seu corpo (Krug et al.,2010). Peponapis fervens é a única espécie do gênero que ocorre no sul da América do Sul e dentre os trabalhos realizados no Brasil somente o de Krug (2007) relatou alguns comportamentos de $P$. fervens em flores de Cucurbita spp. Porém, estudos conduzidos na região de produção dos estados de Alagoas e Minas Gerais mostraram que as abelhas Trigona 
spinipes e Apis mellifera foram os visitantes mais frequentes em Cucurbita spp. (Serra, 2007; Mélo et al., 2010).

A presença de polinizadores silvestres em áreas de cultivo está associada à vegetação natural nas adjacências, que fornecem locais de abrigo, nidificação, reprodução e recursos para forrageamento (Kremen et al., 2007). Foi observado em áreas de produção na Califórnia/ EUA uma relação positiva entre os serviços de polinização e a proporção da vegetação natural nas proximidades dos cultivos, tanto em sistemas de produção orgânico como convencional (Kremen et al., 2002b e 2004).

As culturas dependentes de polinização animal têm crescido acima de $300 \%$ desde 1961, ocupando, em nível mundial, cerca de 6,1\% das terras agricultáveis em uso (Aizen \& Harder, 2009). As intervenções humanas modificaram as paisagens naturais através da fragmentação, degradação e destruição dos habitats e da criação de novos habitats antropogênicos. No mundo as estimativas de conversão de habitats naturais variam por bioma de $0,4 \%$ (tundra) para 48,5\% (florestas tropicais/subtropicais) (Sanderson et al., 2002; Hoekstra et al., 2005). No Brasil a expansão da agricultura tem levado a perda de grandes áreas de vegetação natural. Somente nos biomas Cerrado, Pampas e Caatinga a perda foi de pelo menos $50 \%$ nos últimos anos, gerando sérios impactos sobre a biodiversidade (Ferreira et al., 2012; MMA, 2012).

Mudanças no uso e ocupação da terra e estrutura da paisagem do entorno dos plantios influenciam os polinizadores, plantas-alvo e suas interações em escalas individuais, da população e da comunidade. Portanto, a adoção de práticas de manejo que visem assegurar uma polinização adequada para diversas culturas agrícolas deve incluir a manutenção de áreas com vegetação natural ao redor de campos de cultivo (Vaughan \& Skinner, 2008).

No Distrito Federal, a abóbora (Cucurbita spp.) é cultivada tanto em sistemas de produção orgânico quanto convencional. O sistema orgânico é caracterizado pela substituição de fertilizantes químicos e de agrotóxicos por adubação orgânica e pelo manejo de pragas e doenças através da utilização de controle biológico e métodos culturais (Darolt, 2003). O sistema convencional baseia-se em práticas agrícolas de manejo de pragas e doenças com o uso intensivo de agrotóxicos, o que ameaça várias espécies de abelhas nativas (Freitas \& Pinheiro, 2010), bem como o manejo mecanizado do solo que reduz os locais de nidificação das abelhas.

Considerando-se a importância da polinização para o sistema de abastecimento de alimentos e manutenção da biodiversidade, tornam-se necessárias mais informações 
sobre a dependência das culturas agrícolas em relação aos seus polinizadores. Dentre essas informações, podemos destacar: conhecer a diversidade dos visitantes florais e dentre esses, avaliar quais espécies são polinizadoras efetivas, avaliar a eficiência da polinização entomófila, e conhecer o papel das plantas espontâneas para a manutenção da fauna de polinizadores nas áreas de cultivo. Além disso, informações sobre o manejo das propriedades agrícolas que possam favorecer esse grupo de organismos são escassas para os ambientes tropicais. Tais informações poderiam trazer benefícios à agricultura tropical, considerando a alta riqueza de espécies encontradas nesses ambientes. Esses conhecimentos poderiam ser usados para melhorar os níveis de produtividade, muitas vezes baixos devido à subpolinização como consequência da redução, inadequação e/ou ausência de polinizadores eficientes nas áreas agrícolas.

\section{OBJETIVOS:}

Objetivo Geral: Estudar a comunidade de abelhas visitantes florais da aboboreira $(C$. pepo) na região do Distrito Federal, em função dos sistemas de produção e da paisagem do entorno dos cultivos.

\section{Objetivos Específicos:}

i) Estudar a riqueza e abundância de abelhas visitantes florais de Cucurbita pepo em sistemas orgânicos e convencionais de produção;

ii) Avaliar a influência da composição da paisagem do entorno das áreas de cultivo sobre a riqueza e abundância da fauna de abelhas.

\section{Hipóteses:}

i) A riqueza e abundância das espécies de abelhas visitantes florais da aboboreira são maiores em sistemas orgânicos do que em convencionais.

ii) A área e qualidade dos fragmentos de vegetação natural no entorno de cultivos de aboboreira influenciam a riqueza e abundância da fauna de abelhas visitantes florais nessa cultura. 


\section{MATERIAL E MÉTODOS}

\section{1. Áreas de estudo}

Os dados foram coletados em plantios comerciais de C. pepo em dez propriedades pareadas e localizadas no Distrito Federal (Figura 1.1). As propriedades foram classificadas em orgânicas $(n=5)$ e convencionais $(n=5)$, sendo de pequenos produtores rurais (manejo familiar), com exceção da Fazenda Malunga (O1) (Tabela 1.1).

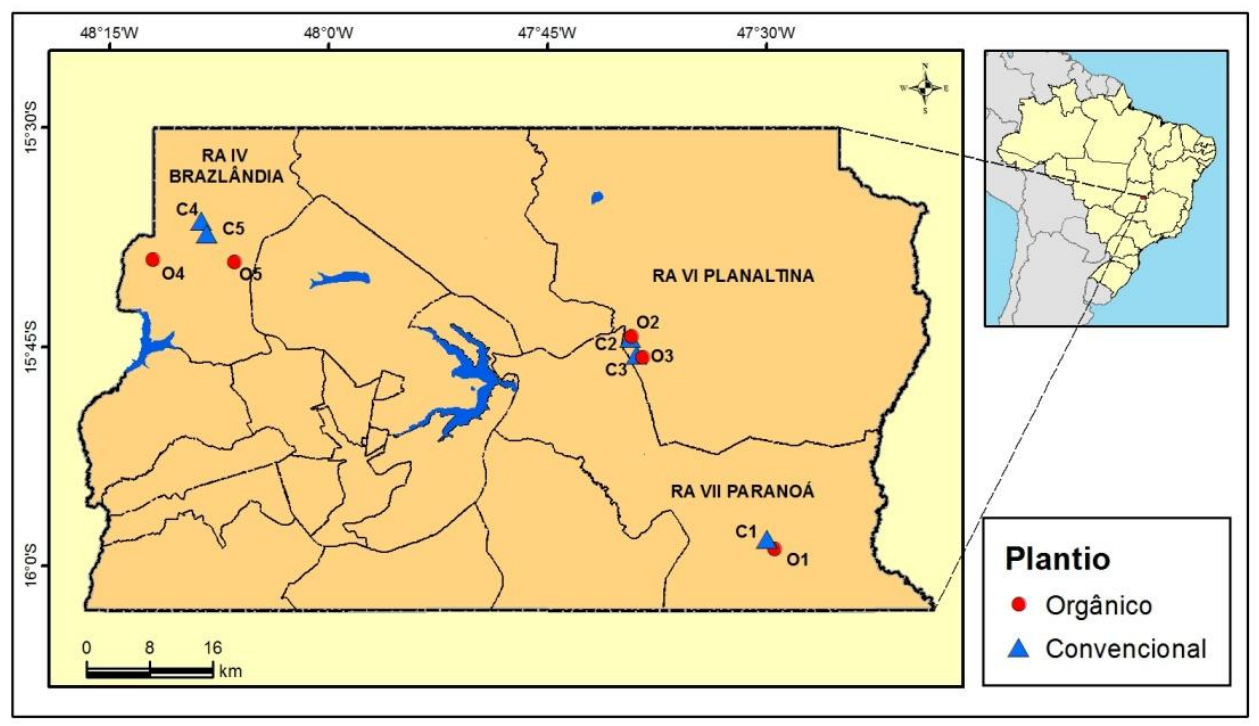

Figura 1.1 - Mapa do Distrito Federal com a localização das propriedades com plantios de abóbora (Cucurbita pepo L.) onde foi conduzido o estudo. Os círculos em vermelho representam as áreas de produção orgânica (O1 a O5), e os triângulos em azul representam as áreas de produção convencional $(\mathrm{C} 1$ a $\mathrm{C} 5)$.

Tabela 1.1 - Localização geográfica das áreas de estudo no Distrito Federal.

\begin{tabular}{|c|c|c|c|c|}
\hline \multirow{2}{*}{ Propriedade* } & \multirow{2}{*}{$\begin{array}{c}\text { Região } \\
\text { Administrativa } \\
\text { (RA) }\end{array}$} & \multirow{2}{*}{ Localidade } & \multicolumn{2}{|c|}{ Coordenadas Geográficas } \\
\hline & & & Latitude & Longitude \\
\hline $\mathrm{O} 1$ & Paranoá & PAD-DF & $15^{\circ} 58^{\prime} 49.44^{\prime \prime S}$ & $47^{\circ} 29^{\prime} 27.41^{\prime \prime O}$ \\
\hline $\mathrm{O} 2$ & Planaltina & Núcleo Rural Rajadinha & $15^{\circ} 44^{\prime} 17.38^{\prime \prime} \mathrm{S}$ & $47^{\circ} 39^{\prime} 13.48^{\prime \prime O}$ \\
\hline $\mathrm{O} 3$ & Planaltina & Núcleo Rural Rajadinha & $15^{\circ} 45^{\prime} 43.35^{\prime \prime S}$ & $47^{\circ} 38^{\prime} 30.02^{\prime \prime O}$ \\
\hline $\mathrm{O} 4$ & Brazlândia & Núcleo Rural Bucanhão & $15^{\circ} 39^{\prime} 5.12^{\prime \prime S}$ & $48^{\circ} 12^{\prime} 3.78^{\prime \prime O}$ \\
\hline O5 & Brazlândia & Núcleo Rural Rodeador & $15^{\circ} 39^{\prime} 10.84^{\prime \prime} \mathrm{S}$ & $48^{\circ} 6 ' 29.22^{\prime \prime O}$ \\
\hline $\mathrm{C} 1$ & Paranoá & PAD-DF & $15^{\circ} 58^{\prime} 175^{\prime \prime S}$ & $47^{\circ} 29^{\prime} 919^{\prime \prime} \mathrm{O}$ \\
\hline $\mathrm{C} 2$ & Planaltina & Núcleo Rural Rajadinha & $15^{\circ} 44^{\prime} 420^{\prime \prime S}$ & $47^{\circ} 39^{\prime} 284^{\prime \prime O}$ \\
\hline $\mathrm{C} 3$ & Planaltina & Núcleo Rural Rajadinha & $15^{\circ} 45^{\prime} 558^{\prime \prime S}$ & $47^{\circ} 38^{\prime} 886^{\prime \prime O}$ \\
\hline $\mathrm{C} 4$ & Brazlândia & Assentamento Betinho & $15^{\circ} 36^{\prime} 22.96^{\prime \prime} \mathrm{S}$ & $48^{\circ} 8^{\prime} 45.77^{\prime \prime O}$ \\
\hline $\mathrm{C} 5$ & Brazlândia & Assentamento Betinho & $15^{\circ} 37^{\prime} 15.3^{\prime \prime S}$ & $48^{\circ} 08^{\prime} 20.4^{\prime \prime O}$ \\
\hline
\end{tabular}

* $\mathrm{O}=$ sistema de produção orgânico; $\mathrm{C}=$ sistema de produção convencional 


\subsection{Visitantes Florais}

As amostragens foram realizadas para conhecer a comunidade de visitantes florais da aboboreira (C. pepo) em plantios orgânicos e convencionais de produção (Figura 1.2). Em 2013 foram amostradas dez propriedades, enquanto que em 2014 foi feita em apenas sete propriedades. Isto foi devido à ausência de plantio nas demais áreas e também porque não foram localizadas outras propriedades com os mesmos sistemas de produção nas proximidades. Assim, em 2014 foram avaliadas quatro propriedades convencionais $(\mathrm{C} 1, \mathrm{C} 2, \mathrm{C} 3$ e C4) e três orgânicas $(\mathrm{O} 1, \mathrm{O} 2$ e O3).

Em 2013 foram realizadas três amostragens em cada propriedade entre os meses de julho e setembro. Este período foi definido por representar os meses de maior atividade de plantio desta espécie de abóbora na região. As coletas foram realizadas entre as 09:00 h e 11:00 h, porque após este horário há uma tendência ao fechamento das flores e à torção em espiral da parte apical da corola, dependendo das condições climáticas. As fileiras do plantio foram percorridas em caminhamento lento, até o fim do horário de coleta e a presença de abelhas foi verificada em cada flor (Figura 1.3). O esforço de coleta, expresso em horas, foi calculado multiplicando o número de horas de amostragens pelo número de coletores, representando assim um esforço de amostragem de 12 horas em cada propriedade.

A amostragem de 2014 teve o objetivo de avaliar a diversidade de visitantes florais nos sistemas de produção, e para isso, o tamanho da área amostral foi padronizado e em todas as propriedades foram selecionadas e demarcadas áreas de 30x15m nos plantios de abóbora. Em cada propriedade foram realizadas três amostragens entre os meses de julho a outubro. A área experimental (30x15m) foi dividida em seis parcelas de $15 \times 2 \mathrm{~m}$. Nessas parcelas, as amostragens foram realizadas entre o período de 06:00 e 12:00 h, em seis intervalos: 6:00-7:00h; 7:00-8:00h; 8:009:00h; 9:00-10:00h; 10:00-11:00 h e 11:00-12:00 h. Em cada intervalo, durante cinco minutos em cada parcela, as abelhas foram coletadas diretamente nas flores com auxílio de frascos plásticos, totalizando 30 minutos por intervalo e um esforço total de coleta de 3horas por data de amostragem. Este método de amostragem em parcelas foi adaptado a partir do protocolo da FAO (Vaissière et al., 2010).

No Laboratório de Ecologia e Biossegurança (LEB) localizado na Embrapa Recursos Genéticos e Biotecnologia, as abelhas foram transferidas para câmaras mortíferas contendo acetato de etila. Este método foi preferido à câmara fria (freezer ou 
congelador), pois, sob efeito do acetato de etila, as abelhas expõem as maxilas, o que facilita sua identificação. Posteriormente, os insetos foram colocados em sacos de papel que foram acondicionados no interior de recipientes de alumínio (tipo marmitas), e depois mantidos no freezer. Em seguida, as abelhas foram montadas em alfinetes entomológicos e colocadas em estufa a $40^{\circ} \mathrm{C}$ por $48 \mathrm{~h}$ para secagem. Após a montagem, elas foram triadas e identificadas por comparação com exemplares da Coleção de Referência do LEB, e alguns espécimes foram enviados para o Laboratório de Entomologia/Departamento de Zoologia da Universidade de Brasília para confirmar a identificação pelo professor Antônio J.C. Aguiar. As abelhas foram depositadas na Coleção de Referência do LEB localizada na Embrapa Recursos Genéticos e Biotecnologia. A classificação das abelhas empregada neste estudo foi aquela apresentada por Silveira et al. (2002).

Em 2014, os dados de aplicação de produtos fitossanitários (data, período de aplicação, produto e dosagem) usados em cada propriedade foram obtidos a partir de consulta direta aos produtores no decorrer das amostragens (ver Tabela 3.2 Apêndice).
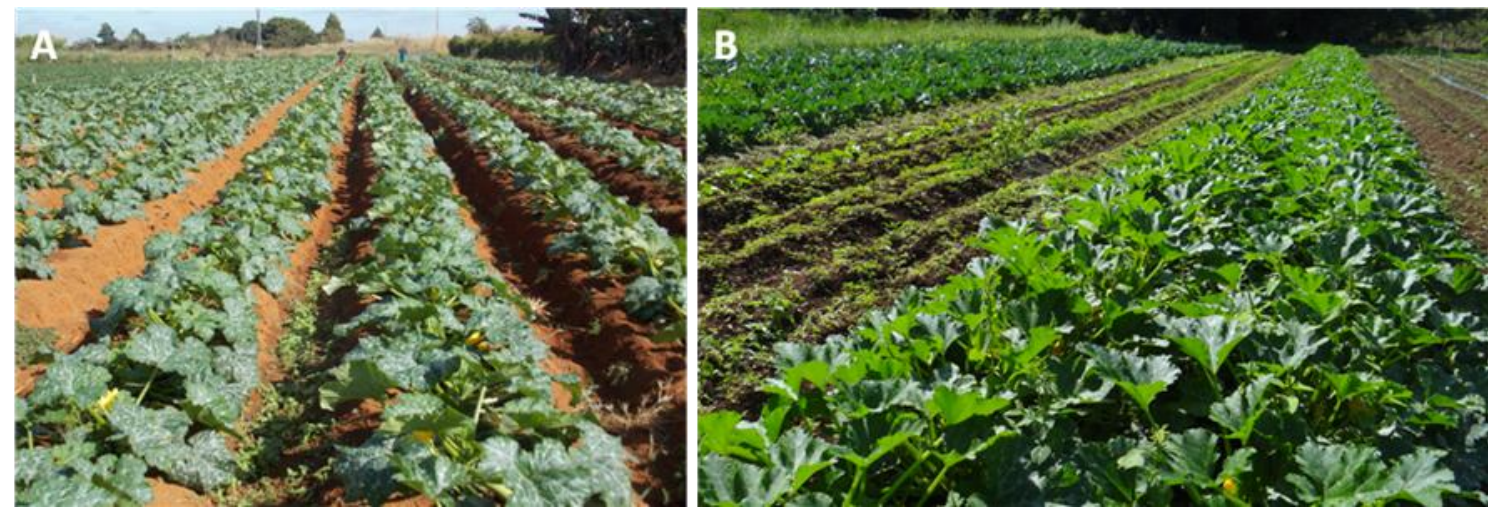

Figura 1.2 - Vista geral das áreas cultivadas com Cucurbita pepo. A) Plantio convencional da propriedade C2; B) Plantio orgânico da propriedade O3. Áreas localizadas no Núcleo Rural da Rajadinha, DF em 2014.

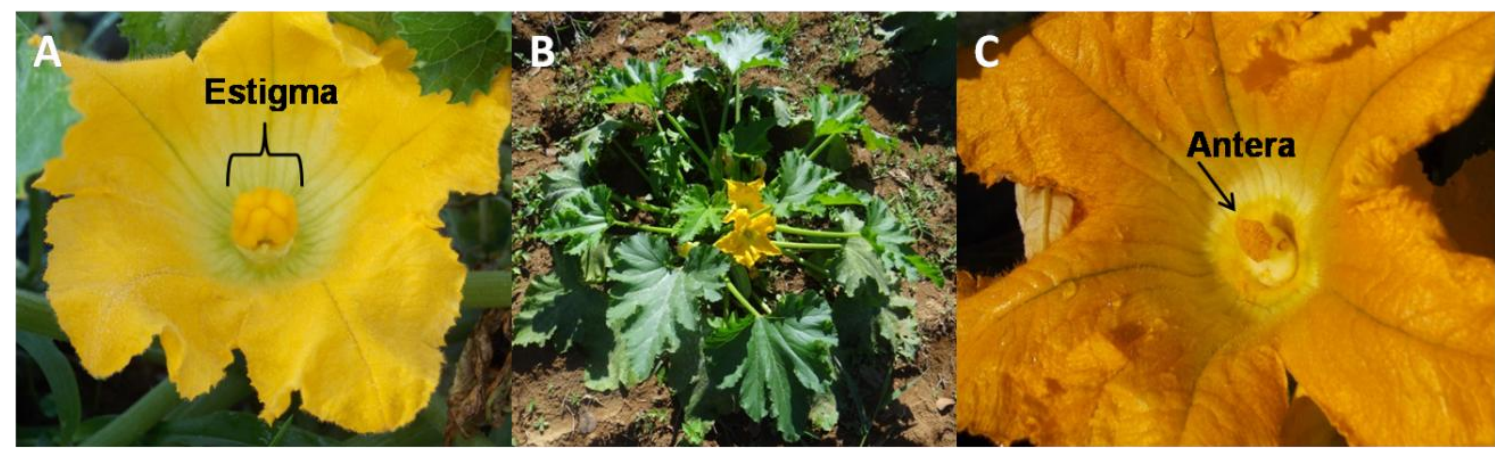

Figura 1.3 - Estruturas reprodutivas da abóbora Cucurbita pepo. A) Flor feminina (pistilada); B) Um indivíduo de C. pepo florido; C) Flor masculina (estaminada). 


\subsection{Caracterização das paisagens do entorno dos cultivos}

A caracterização da paisagem de cada propriedade foi feita a partir de marcação de pontos de referência com GPS no ponto central de cada área de produção, posteriormente projetado em imagens de satélite do Google Earth.

Para estabelecer a área de influência (buffer) foi considerado um círculo de raio de $2 \mathrm{~km}$ a partir do ponto central marcado em cada área produtiva. A demarcação da área buffer baseou-se em Kremen et al., (2004). Estes autores mostraram que para garantir níveis de polinização adequados pela comunidade de abelhas nativas, as fazendas dos produtores de melancia (Citrullus lanatus - Cucurbitaceae) devem estar situadas em áreas que contenham $>40 \%$ de habitat natural em um raio de 2,4 km.

Utilizando a ferramenta de digitalização do Google Earth "adicionar caminho", foram traçados os limites de 11 classes de habitat previamente estabelecidas: área de plantio/hortaliça, área de plantio/monocultura, área de pastagem, área urbana, corpos d'água, formação campestre, formação florestal, formação savânica, reflorestamento, setor de chácaras e área degradada em recuperação.

Para a validação das fitofisionomias presentes foram feitas observações "in loco", procurando relacionar os padrões das imagens disponíveis com a caracterização da vegetação (nativa e antrópica) encontrada, seguindo a classificação proposta para as áreas nativas segundo Ribeiro \& Walter (2008).

Posteriormente, foi feita uma sobreposição entre a área de influência e os limites das classes estabelecidas. Esse conjunto de dados foi exportado para o programa ArcGis 9.3 onde foram feitos os cálculos das áreas classificadas e a percentagem de cobertura de cada uma em relação a área total de influência. Após identificar e quantificar as diferentes classes de uso e ocupação da terra foi gerado mapas de uso e ocupação para cada área.

Para melhor compreender a influência das características da paisagem do entorno sobre a comunidade de abelhas, as 11 classes estabelecidas foram reclassificadas de acordo com a qualidade do habitat, ou seja, foram definidos habitats capazes de oferecer locais de nidificação adequados e recursos para forrageamento das abelhas. Deste modo, foram propostos três grupos: vegetação nativa (VN), onde agrupamos as formações campestre, savânica e florestal; área antropizada de alta qualidade (A1): agrupamento de áreas de plantio de hortaliça, reflorestamento e área degradada em recuperação e área antropizada de baixa qualidade (A2): plantio de 
monocultura com práticas agricolas intensivas, corpos d'água, área urbana, setor de chácaras (pequenas propriedades rurais) e área de pastagem.

\subsection{Análise de dados}

Para avaliar se o esforço de coleta foi suficiente para amostrar a riqueza de espécies foi gerada uma curva de acumulação de espécies pelo Programa Estimates. Para avaliar se houve diferença na riqueza e abundância de abelhas/propriedade entre os sistemas de produção foram utilizados modelos lineares generalizados (GLM) e Análise de Deviança, o modelo de análise utilizou função de distribuição de erros de Poisson e $\log$ como função de ligação. Tomando como referência as espécies mais abundantes, comparou-se a abundância de cada espécie entre os sistemas de produção com uma análise de modelo linear generalizado (GLM). O modelo de análise utilizou função de distribuição de erros de Poisson e $\log$ como função de ligação. Com os dados da caracterização da paisagem de cada propriedade foi realizada uma Análise de Componentes Principais (ACP) para confirmar se os pareamentos formados entre os sistemas de produção compartilhavam paisagens similares e identificar as componentes da paisagem que melhor representam cada região. Os três grupos propostos (vegetação nativa (VN); área antropizada de alta qualidade (A1); área antropizada de baixa qualidade (A2) gerados de acordo com a qualidade do habitat foram submetidos a uma Análise de Componentes Principais (ACP) para melhor compreender a influência da paisagem sobre a comunidade de abellhas. Foi utilizada análise de regressão simples para investigar a influência da vegetação nativa (\% de área) em relação à riqueza e abundância de abelhas nas áreas de produção agrícola. O programa $\mathrm{R}$ ( $\mathrm{R}$ Core Team 2013) foi utilizado para realizar as análises estatísticas.

\section{RESULTADOS}

\subsection{Comunidade de abelhas visitantes florais}

O levantamento das abelhas somou um esforço total de coleta de 104 horas em 2013, e de 63 horas em 2014. 
Considerando os dois sistemas de produção coletaram-se 3.879 indivíduos no total, sendo 2.345 em 2013 e 1.534 em 2014. Em 2013, a riqueza de abelhas foi de 18 gêneros e 28 espécies e em 2014, 14 gêneros e 21 espécies (Tabela 1.2). A riqueza total de abelhas em flores de C. pepo, considerando os dois anos de coleta, foi de 35 espécies pertencentes às famílias Apidae e Halictidae.

Em 2013 foram coletados no sistema convencional 1.177 indivíduos em 21 espécies, e em 2014, 768 indivíduos distribuídos em 18 espécies. Enquanto que no sistema orgânico foram coletados 1.168 indivíduos em 23 espécies (2013) e, 766 indivíduos em 13 espécies (2014).

Nos dois anos de coleta a família Apidae foi a mais diversificada e abundante, em 2013 com 13 gêneros e 18 espécies, representando 98,03\% dos espécimes coletados (n=2.299), e em 2014 com 15 gêneros e 13 espécies, representando 97,65\% dos espécimes coletados $(n=1.498)$. Halictidae foi representada em 2013 por 5 gêneros e 10 espécies, correspondendo a 1,96\% $(\mathrm{n}=46)$ do total de exemplares, enquanto em 2014 por 5 gêneros e 8 espécies, correspondendo a 2,34\% $(n=36)$ do total de exemplares.

Em 2013 Trigona spinipes foi à espécie mais abundante (46,65\%), seguida de Apis mellifera (19,70\%), Trigona hyalinata (17,69\%) e Partamona combinata $(4,73 \%)$. Em 2014 Apis mellifera foi à espécie mais abundante (29,0\%), seguida de Trigona spinipes (27,83\%), Trigona hyalinata (25,23\%) e Partamona combinata (9,32\%) (Tabela 1.2). Estas mesmas espécies foram coletadas com maior frequência e abundância na maioria das propriedades (Tabela 1.3). Estas espécies são sociais, com colônias populosas, perenes e ativas o ano todo. Com exceção de A. mellifera as outras espécies são meliponíneos (abelhas sem ferrão). Dentre as demais espécies coletadas em 2014 com poucos representantes, Melipona quinquefasciata merece destaque com 62 indivíduos coletados.

A curva de acumulação de espécies para os dois anos de coleta (Figura 1.4A) e considerando apenas o ano de 2014 não estabilizaram (Figura 1.4B), indicando que caso fossem efetuadas mais coletas na área, seria muito provável a coleta de novas espécies. 
Tabela 1.2 - Diversidade e número total de indivíduos de diferentes espécies de abelhas coletadas em flores de aboboreira (Cucurbita pepo) em propriedades de cultivo orgânico e convencional de hortaliças, localizadas no Distrito Federal, em 2013 e 2014.

\begin{tabular}{|c|c|c|c|c|}
\hline \multirow{3}{*}{ TÁXON } & \multicolumn{2}{|c|}{2013} & \multicolumn{2}{|c|}{2014} \\
\hline & \multicolumn{4}{|c|}{ Sistemas de produção* } \\
\hline & $\mathbf{O}$ & $\mathbf{C}$ & $\mathbf{O}$ & $\mathbf{C}$ \\
\hline \multicolumn{5}{|l|}{ APIDAE } \\
\hline \multicolumn{5}{|l|}{ APINAE } \\
\hline \multicolumn{5}{|l|}{ Apini } \\
\hline Apis mellifera Linnaeus, 1758 & 223 & 239 & 109 & 336 \\
\hline \multicolumn{5}{|l|}{ Bombini } \\
\hline Bombus atratus & 7 & 2 & 0 & 1 \\
\hline Bombus morio & 2 & 3 & 1 & 1 \\
\hline \multicolumn{5}{|l|}{ Centridini } \\
\hline Epicharis sp. & 0 & 0 & 2 & 0 \\
\hline \multicolumn{5}{|l|}{ Eucerini } \\
\hline Peponapis fervens (Smith, 1875) & 1 & 9 & 0 & 0 \\
\hline Thygater analis & 1 & 0 & 0 & 0 \\
\hline \multicolumn{5}{|l|}{ Euglossini } \\
\hline Eulaema sp. & 0 & 0 & 1 & 0 \\
\hline \multicolumn{5}{|l|}{ Meliponini } \\
\hline Frieseomelitta sp. & 0 & 0 & 0 & 2 \\
\hline Geotrigona mombuca (Smith, 1863) & 2 & 6 & 5 & 7 \\
\hline Melipona (Melikerria) quinquefasciata Lepeletier, 1836 & 12 & 35 & 34 & 28 \\
\hline Melipona seminigra Friese, 1903 & 4 & 0 & 0 & 0 \\
\hline Tetragona sp. & 14 & 3 & 0 & 0 \\
\hline Trigona hyalinata (Lepeletier, 1836) & 268 & 147 & 199 & 189 \\
\hline Trigona spinipes (Fabricius, 1793) & 497 & 597 & 322 & 105 \\
\hline Paratrigona lineata (Lepeletier, 1836) & 62 & 44 & 6 & 2 \\
\hline Partamona combinata Pedro \& Camargo, 2003 & 47 & 64 & 77 & 66 \\
\hline Schwarziana mourei Melo, 2003 & 0 & 0 & 0 & 5 \\
\hline \multicolumn{5}{|l|}{ XILOCOPINAE } \\
\hline \multicolumn{5}{|l|}{ Ceratinini } \\
\hline Ceratina sp. & 1 & 0 & 0 & 0 \\
\hline \multicolumn{5}{|l|}{ Exomalopsini } \\
\hline Exomalopsis auropilosa Spinola, 1853 & 0 & 2 & 0 & 0 \\
\hline Exomalopsis sp.1 & 0 & 1 & 0 & 0 \\
\hline Exomalopsis sp.2 & 0 & 3 & 0 & 0 \\
\hline \multicolumn{5}{|l|}{ Xylocopini } \\
\hline Xylocopa grisescens Lepeletier, 1841 & 1 & 2 & 0 & 0 \\
\hline \multicolumn{5}{|l|}{ HALICTIDAE } \\
\hline \multicolumn{5}{|l|}{ HALICTINAE } \\
\hline \multicolumn{5}{|l|}{ Augochlorini } \\
\hline Augochlora sp. 1 & 7 & 1 & 0 & 2 \\
\hline
\end{tabular}


2013

TÁXON

Sistemas de produção*

\begin{tabular}{lcc|cc} 
& O & C & O & C \\
APIDAE & & & & \\
HALICTIDAE & & & & \\
HALICTINAE & & & & \\
Augochlorini & 1 & 0 & 0 & 0 \\
Augochlora sp. & 0 & 0 & 0 & 1 \\
Augochlora sp. 3 & 2 & 0 & 0 & 0 \\
Augochloropsis sp.1 & 0 & 1 & 0 & 0 \\
Augochloropsis sp.2 & 0 & 0 & 0 & 1 \\
Augochloropsis sp.3 & 3 & 0 & 0 & 1 \\
Pereirapis sp. & 0 & 1 & 0 & 0 \\
Pseudaugochlora sp. & & & & \\
Halictini & 6 & 4 & 2 & 2 \\
Dialictus sp. 1 & 2 & 7 & 0 & 3 \\
Dialictus sp. 2 Dialictus sp. 3 & 3 & 6 & 7 & 16 \\
Dialictus sp.4 & 2 & 0 & 0 & 0 \\
Gnathalictus sp. & 0 & 0 & 1 & 0 \\
TOTAL DE INDIVÍDUOS & $\mathbf{1 1 6 8}$ & $\mathbf{1 1 7 7}$ & $\mathbf{7 6 6}$ & $\mathbf{7 6 8}$ \\
\hline
\end{tabular}

*O=sistema de produção orgânico; $\mathrm{C}=$ sistema de produção convencional

Tabela 1.3 - Porcentagem de indivíduos para cada espécie de abelha coletada em flores de aboboreira (Cucurbita pepo L.) em propriedades de produção orgânica e convencional de hortaliças, localizadas no Distrito Federal em 2014.

\begin{tabular}{|c|c|c|c|c|c|c|c|}
\hline \multirow{2}{*}{ TÁXON } & \multicolumn{7}{|c|}{ Porcentagem de indivíduos (\%) por propriedade* } \\
\hline & 01 & $\mathbf{O 2}$ & $\mathbf{O 3}$ & C1 & $\mathbf{C 2}$ & $\mathbf{C 3}$ & $\mathbf{C 4}$ \\
\hline Apis mellifera Linnaeus, 1758 & 27,41 & 5,86 & 8,77 & 27,65 & 11,04 & 29,05 & 92,92 \\
\hline Bombus atratus & & & & & & & 0,44 \\
\hline Bombus morio & & & & 0,59 & & & \\
\hline Epicharis sp. & & 0,90 & 0,35 & & & & \\
\hline Eulaema sp. & & & 0,35 & & & & \\
\hline Frieseomelitta sp. & & & & 0,59 & 0,61 & & \\
\hline Geotrigona mombuca (Smith, 1863) & 1,54 & & 0,35 & 0,59 & 2,45 & 0,95 & \\
\hline $\begin{array}{l}\text { Melipona (Melikerria) quinquefasciata } \\
\text { Lepeletier, } 1836\end{array}$ & & 15,32 & & & 17,18 & & \\
\hline Trigona hyalinata (Lepeletier, 1836) & 34,36 & 49,55 & & 58,82 & 1,84 & 40,95 & \\
\hline
\end{tabular}




\begin{tabular}{|c|c|c|c|c|c|c|c|}
\hline \multirow{2}{*}{ TÁXON } & \multicolumn{7}{|c|}{ Porcentagem de indivíduos (\%) por propriedade* } \\
\hline & $\mathbf{O 1}$ & $\mathbf{O 2}$ & $\mathbf{O 3}$ & C1 & $\mathbf{C 2}$ & C3 & $\mathbf{C 4}$ \\
\hline Trigona spinipes (Fabricius, 1793) & 19,31 & 20,72 & 79,30 & & 55,83 & 2,86 & 3,54 \\
\hline Paratrigona lineata (Lepeletier, 1836) & 1,16 & 1,35 & & & & & 0,88 \\
\hline $\begin{array}{l}\text { Partamona combinata Pedro \& Camargo, } \\
2003\end{array}$ & 15,83 & 3,60 & 9,82 & 8,24 & 6,75 & 19,05 & \\
\hline Schwarziana mourei & & & & 2,94 & & & \\
\hline Augochlora sp. 1 & & & & & & & 0,44 \\
\hline Augochlora sp. 3 & & & & & 0,61 & & \\
\hline Augochloropsis sp. 3 & & & & & 0,61 & & \\
\hline Pereirapis sp. & & & & & 0,61 & & \\
\hline Dialictus sp.1 & & 0,90 & & 0,59 & & & 0,44 \\
\hline Dialictus sp. 2 & & & & & 2 & & \\
\hline Dialictus sp.3 & & 1,80 & 1,05 & & 0,61 & 6,67 & 0,88 \\
\hline Gnathalictus sp. & 0,39 & & & & & & \\
\hline
\end{tabular}
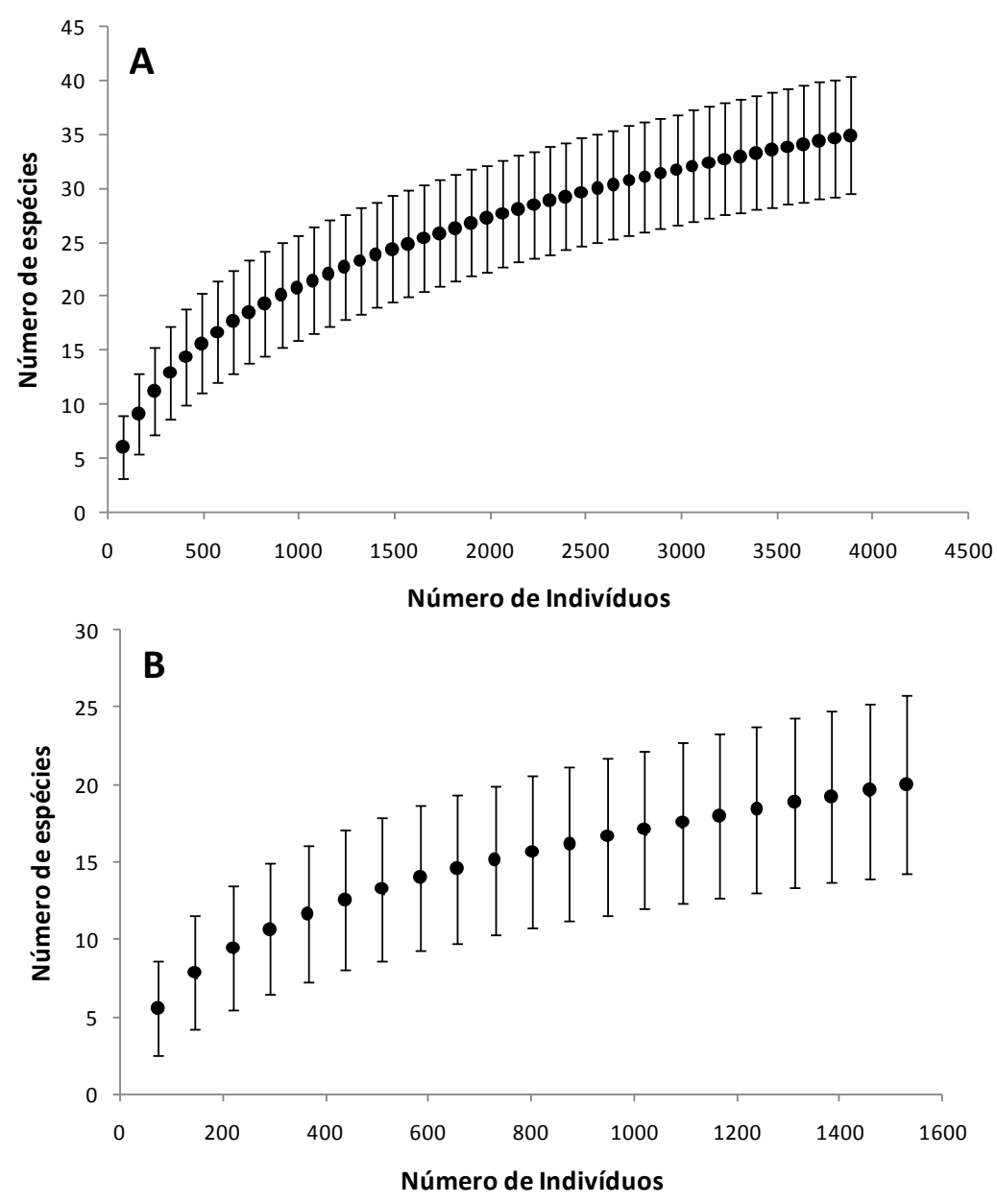

Figura 1.4 - A) Curva de acumulação de espécies de abelhas e indivíduos coletados em flores de aboboreira (Cucurbita pepo) nas propriedades agrícolas de cultivo de hortaliças por número de dias de amostragem $(\mathrm{n}=47)$, localizadas no Distrito Federal, em 2013 e 2014. B) Curva de acumulação de espécies de abelhas e indivíduos coletados 
em flores de aboboreira (Cucurbita pepo) em sete propriedades agrícolas de cultivo de hortaliças por número de dias de amostragem $(\mathrm{n}=21)$, localizadas no Distrito Federal, em 2014.

A abundância total de abelhas/propriedade em 2014 foi significativamente maior no sistema orgânico comparando-se ao convencional (GLM e Análise de Deviança $\chi^{2}=29.93$, g.l=1, p <0.001; Figura 1.5), porém a riqueza não diferiu entre os dois sistemas (Deviança $\chi^{2}=0.30$, g.l $1=1, \mathrm{p}=0.5$ ).

Em todos os pareamentos formados (orgânico vs. convencional) a abundância total de abelhas foi diferente estatisticamente entre os sistemas de produção, (GLM e Análise de Deviança O1vs.C1: $\chi^{2}=18.14$, g.l=1, p<0.001; O2vs.C2: $\chi^{2}=9.07$, g.l=1, p <0.01; O3vs.C3: $\chi^{2}=10.53$, g.l=1, p<0.01; Figura 1.6).

Quando as quatro espécies mais frequentes foram consideradas separadamente, foi observado que a abundância foi influenciada pelo sistema de manejo. $\mathrm{O}$ número de indivíduos foi maior nos sistemas orgânicos (Figura 1.7) para as espécies: Partamona combinata (Deviança $\chi^{2}=8.40$, g.l $=1, \mathrm{p}=0.003$ ), Trigona hyalinata (Deviança $\chi^{2}=11.46$, g.l=1, p<0.001) e Trigona spinipes (Deviança $\chi^{2}=186.82$, g.l=1, p<0.001). Apis mellifera foi a única espécie mais abundante no sistema convencional (Deviança $\left.\chi^{2}=65.30, \mathrm{~g} .1=1, \mathrm{p}<0.001\right)$.

Durante o período de estudo foram encontrados nas áreas de vegetação natural adjacentes aos plantios três ninhos das espécies Trigona spinipes (2 ninhos) nas propriedades C2 e O3 e Trigona hyalinata (1 ninho) na propriedade O3 (ver Figura 3.1 no Apêndice). Foram também localizadas quatro caixas de criação da espécie exótica Apis mellifera nas propriedades $\mathrm{O} 1$ e C1 (ver Figura 3.2 no Apêndice). 


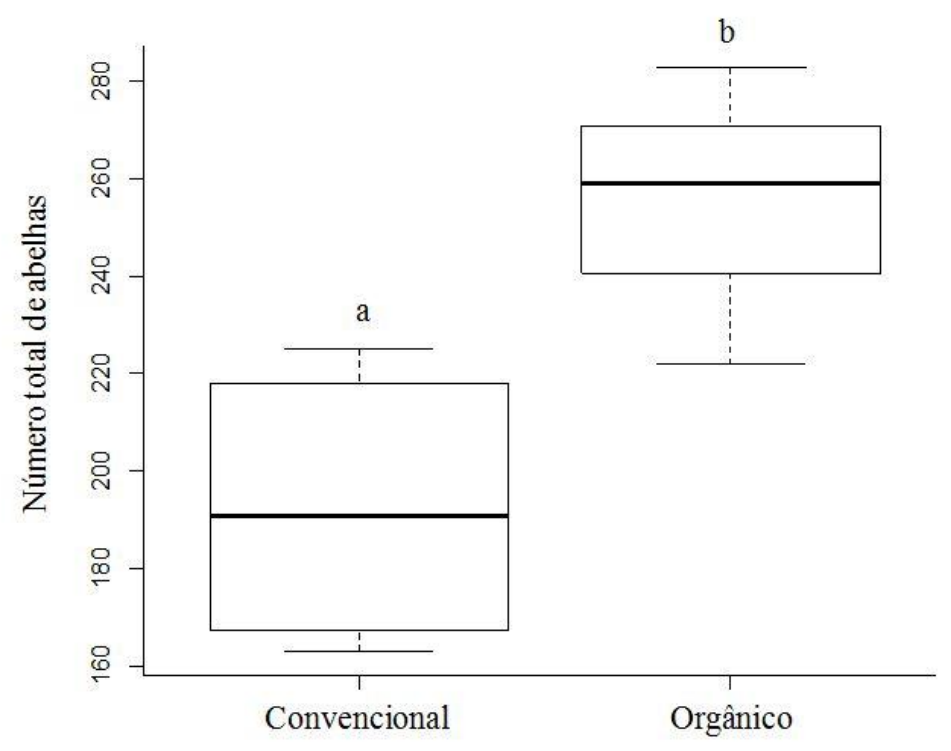

Figura 1.5 - Abundância total de abelhas coletadas em flores de aboboreira (Cucurbita pepo L.), em 2014 (julho, agosto, setembro e outubro), em propriedades orgânicas ( $n=3$ ) e convencionais $(n=4)$, localizadas no Distrito Federal. O gráfico (diagrama de caixas) representa a mediana (linha preta) e os quartis. A base representa o quartil inferior (25\%) dos menores valores, e o topo da caixa o quartil superior $(75 \%)$ dos valores observados. A caixa representa $50 \%$ de todos os valores observados. Um segmento de reta vertical conecta o topo da caixa ao maior valor observado e outro segmento conecta a base da caixa ao menor valor observado. Letras diferentes acima das caixas indicam diferenças estatísticas (GLM e Análise de Deviança $\chi^{2}=29.93$, g.l=1, p<0.001). 

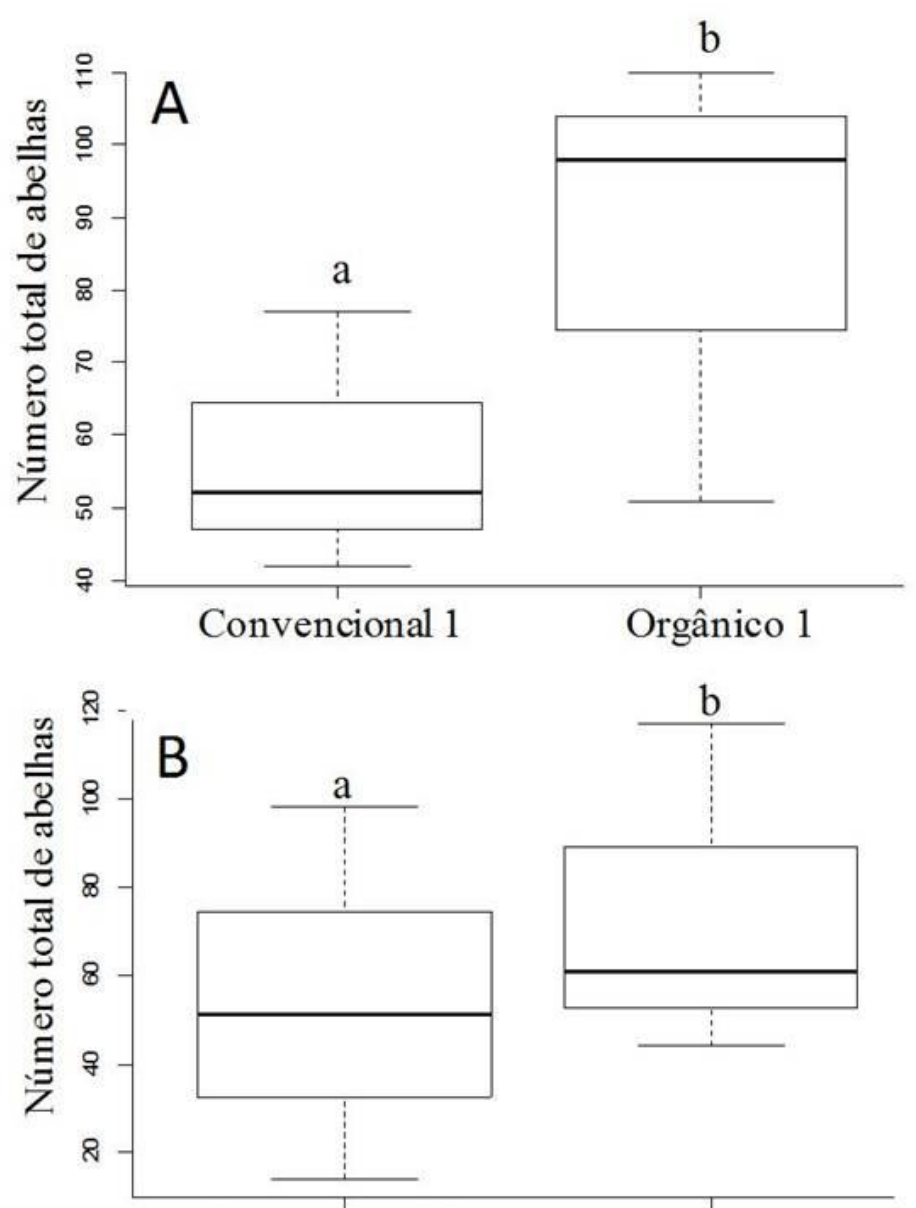

Convencional 2
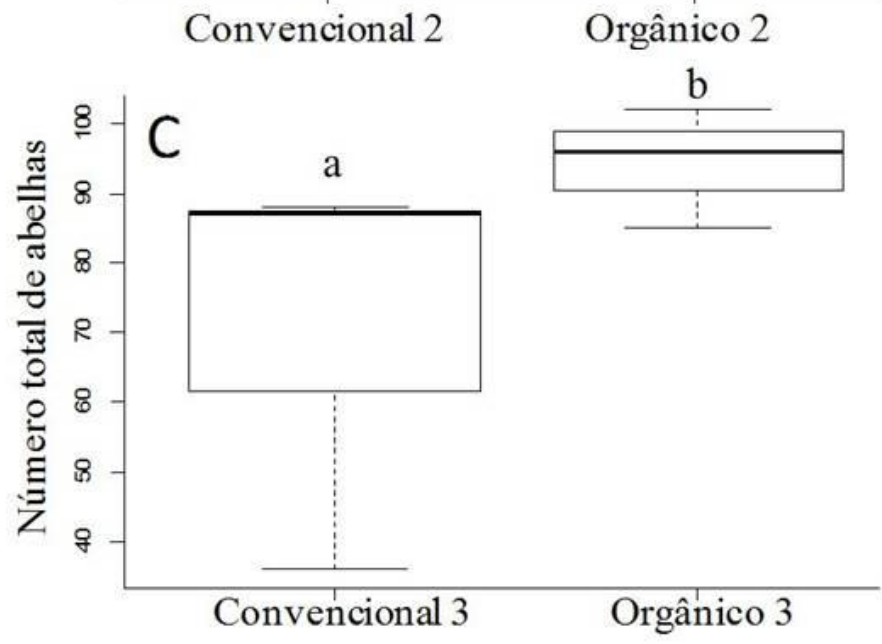

Figura 1.6 - Abundância total de abelhas coletadas em flores de aboboreira (Cucurbita pepo L.), em propriedades manejadas no sistema orgânico (O1, O2 e O3) e no sistema convencional (C1, C2, C3) em 2014. Todas as áreas estão localizadas no Distrito Federal, e foram pareadas em regiões de forma que elas estivessem em uma mesma paisagem agrícola. Letras diferentes acima das caixas indicam diferenças estatísticas (GLM e Análise de Deviança, A (O1vs.C1): $\chi^{2}=18.14$, g.l=1, p<0.001; B (O2vs.C2): $\chi^{2}=9.07$, g.l $\left.=1, \mathrm{p}<0.01 ; \mathrm{C}(\mathrm{O} 3 \mathrm{vs} . \mathrm{C} 3): \chi^{2}=10.53, \mathrm{~g} .1=1, \mathrm{p}<0.01\right)$. 


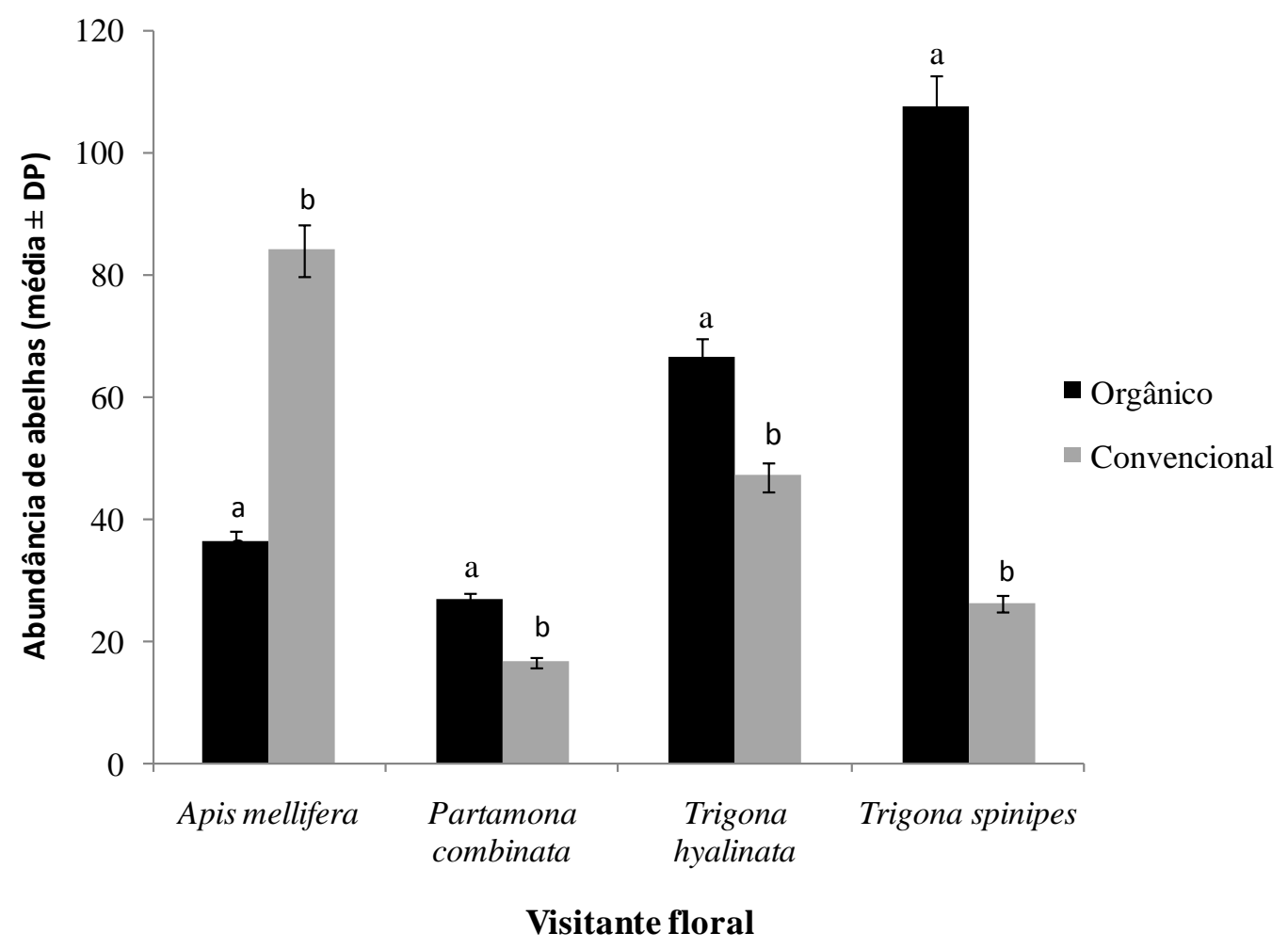

Figura 1.7 - Abundância (média \pm DP) das espécies de abelhas mais abundantes em flores de aboboreira (Cucurbita pepo L.) nos sistemas de cultivo orgânico e convencional em 2014. Letras diferentes acima das barras indicam diferenças estatísticas das espécies de abelhas nos sistemas de produção pelo Modelo Linear Generalizado (GLM). Letras diferentes acima das barras indicam diferenças estatísticas (Apis mellifera, Deviança $\chi^{2}=65.30$, g. $1=1, \mathrm{p}<0.001$; Partamona combinata, Deviança $\chi^{2}=8.40$, g.l $=1, \mathrm{p}=0.003 ;$ Trigona hyalinata, Deviança $\chi^{2}=11.46$, g.l $=1, \mathrm{p}<0.001 ;$ Trigona spinipes, Deviança $\chi^{2}=186.82$, g.l $\left.=1, \mathrm{p}<0.001\right)$.

\subsection{Caracterização das paisagens do entorno dos cultivos}

Após finalizada a caracterização da paisagem para cada propriedade foi gerado o mapa de uso e ocupação da terra de acordo com as 11 classes pré-estabelecidas, e portanto, pode-se perceber que em geral as propriedades estão inseridas em um contexto de paisagem altamente heterogêneo. (Tabela 1.3; ver Figuras 3.3 a 3.16 no Apêndice).

Os dados da caracterização da paisagem foram submetidos a uma Análise de Componentes Principais (ACP) que revelou que os pareamentos formados entre os sistemas (orgânico e convencional) se agruparam em quatro regiões geográficas distintas que coincidem com a localização geográfica das propriedades pareadas (Figura 
1.8). Em relação às 11 classes estabelecidas, os dados indicam que algumas variáveis foram mais relevantes para promover a separação dos agrupamentos: o plantio de monocultura $(\mathrm{PM})$ para o pareamento $(\mathrm{O} 1$ e $\mathrm{C} 1)$; área degradada em recuperação $(\mathrm{AD})$ para as propriedades $\mathrm{O} 3$ e C3; área urbana (AU) e reflorestamento (R) para O2 e C2; e área de pasto (AP) para a propriedade C4 (Figura 1.8).

A Análise de Componentes principais (ACP) levando em consideração a qualidade do habitat segundo a reclassificação proposta: vegetação nativa (VN); área antropizada de alta qualidade (A1); área antropizada de baixa qualidade (A2) indica que as propriedades convencionais, com exceção da C2 são caracterizadas por A1 e as propriedades orgânicas, com exceção de $\mathrm{O} 2$ são caracterizadas por A2, O2 e C2 encontram-se em áreas com maior percentagem relativa de vegetação nativa (Figura 1.9).

Neste novo cenário adotando o conceito de um gradiente de qualidade de habitat $(\mathrm{VN}>\mathrm{A} 1>\mathrm{A} 2)$ a riqueza de abelhas foi influenciada positivamente pela porcentagem (\%) de vegetação nativa ao redor dos cultivos $\left(r^{2}=0.79, p<0.01\right.$; Figura 1.10), enquanto não houve relação para a abundância de abelhas $\left(\mathrm{r}^{2}=0.24, \mathrm{p}=0.27, \mathrm{y}=292,0827\right.$ $\left.1,8665^{*} \mathrm{x}\right)$. Áreas de cultivo convencional localizadas em ambientes de melhor qualidade mostraram também maior riqueza (Figura 1.10).

Tabela 1.3 - Propriedades orgânicas e convencionais com plantios da aboboreira (Cucurbita pepo) com suas respectivas classes $(\mathrm{n}=11)$ em porcentagem $(\%)$ de acordo com a caracterização da paisagempresente em um raio de $2 \mathrm{~km}$ no entorno das áreas de cultivo. As variáveis analisadas foram: formação florestal (FF), formação savânica (FS), formação campestre (FC), área degradada em recuperação (AD) reflorestamento (R), área de plantio/hortaliça $(\mathrm{PH})$, área de plantio/monocultura $(\mathrm{PM})$, área de pasto $(\mathrm{AP})$, setor de chácaras (SC), área urbana (AU), e corpos d'água (AG),

\begin{tabular}{ccccccccccccc} 
& \multicolumn{10}{c}{ Classes (\%) estabelecidas para a caracterização da paisagem } \\
\cline { 2 - 13 } Propriedade* & FF & FS & FC & AD & R & PH & PM & AP & SC & AU & AG \\
& 17,25 & 1,33 & 2,70 & 4,49 & 0,36 & 18,41 & 54,49 & 0,00 & 0,59 & 0,00 & 0,38 \\
O1 & 16,50 & 16,35 & 19,78 & 0,50 & 3,43 & 7,40 & 7,44 & 22,25 & 0,90 & 5,28 & 0,17 \\
O2 & 7,56 & 25,69 & 2,27 & 12,63 & 0,04 & 8,44 & 17,77 & 21,11 & 3,89 & 0,00 & 0,60 \\
O3 & 18,07 & 15,65 & 0,90 & 6,59 & 0,36 & 21,59 & 35,47 & 0,00 & 0,90 & 0,00 & 0,46 \\
C1 & 17,02 & 16,94 & 19,00 & 0,99 & 1,93 & 8,15 & 7,13 & 22,45 & 0,90 & 5,31 & 0,17 \\
C2 & 9,29 & 22,46 & 2,80 & 21,44 & 0,04 & 9,18 & 6,12 & 22,06 & 6,25 & 0,17 & 0,22 \\
C3 & 4,20 & 12,57 & 25,22 & 2,30 & 0,73 & 31,35 & 0,00 & 18,21 & 5,33 & 0,00 & 0,08 \\
C4 & & &
\end{tabular}

* $\mathrm{O}=$ sistema de produção orgânico; $\mathrm{C}=$ sistema de produção convencional 


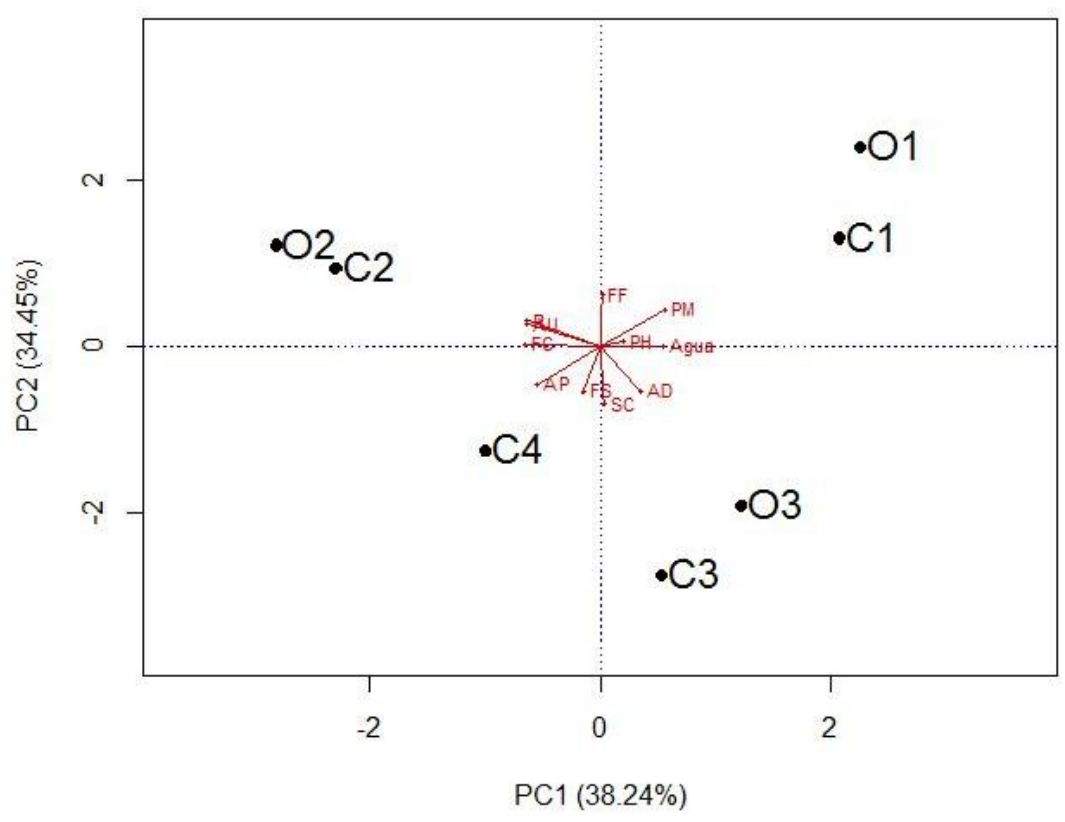

Figura 1.8 - Análise de Componentes Principais (ACP) das propriedades orgânicas $(\mathrm{O} 1, \mathrm{O} 2$ e $\mathrm{O} 3)$ e convencionais $(\mathrm{C} 1, \mathrm{C} 2, \mathrm{C} 3$ e $\mathrm{C} 4)$ a partir das 11 classes estabelecidas para a caracterização da paisagem presente em um raio de $2 \mathrm{~km}$ no entorno das áreas de cultivo, áreas localizadas no Distrito Federal, em 2014. As variáveis analisadas foram: área de plantio/hortaliça $(\mathrm{PH})$, área de plantio/monocultura $(\mathrm{PM})$, área de pasto (AP), área urbana (AU), corpos d'água (AG), formação campestre (FC), formação florestal (FF), formação savânica (FS), reflorestamento (R), setor de chácaras (SC) e área degradada em recuperação $(A D)$. Os dois primeiros componentes principais (PC1 e PC2) explicaram 72,69\% da variância.

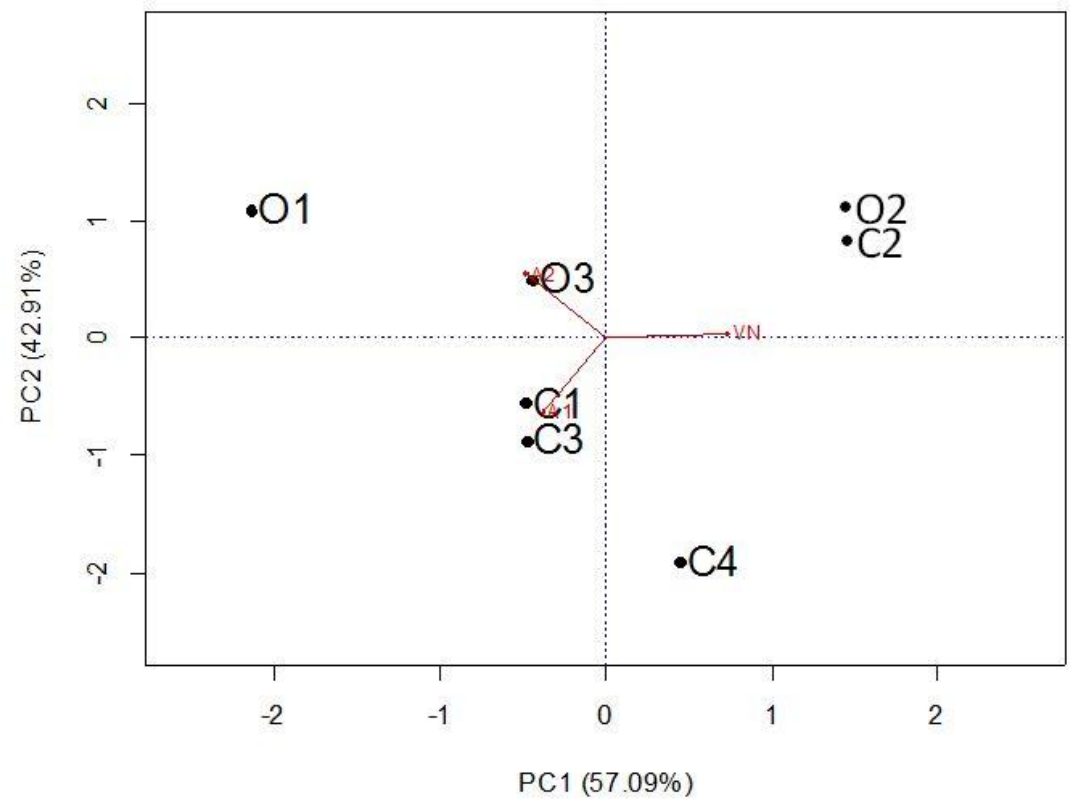

Figura 1.9 - Análise de Componentes Principais (ACP) das propriedades orgânicas $(\mathrm{O} 1, \mathrm{O} 2$ e $\mathrm{O} 3)$ e convencionais $(\mathrm{C} 1, \mathrm{C} 2, \mathrm{C} 3$ e $\mathrm{C} 4)$ das 11 classes estabelecidas para a caracterização da paisagempresente em um raio de $2 \mathrm{~km}$ no entorno das áreas de cultivo reclassificadas em três grupos: Vegetação Nativa (VN); Área antropizada de alta qualidade (A1) e Área antropizada de baixa qualidade (A2), áreas localizadas no Distrito Federal, em 2014. 


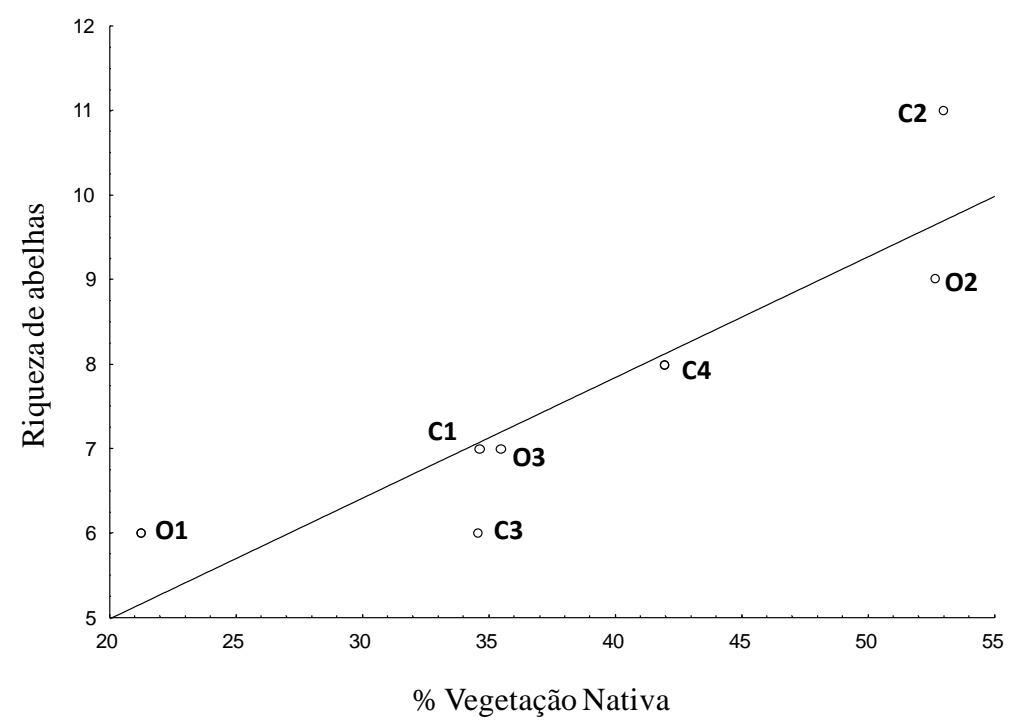

Figura 1.10 - Relação entre a riqueza de abelhas coletadas em 2014 em flores de aboboreira (Cucurbita pepo L.) e a porcentagem de vegetação nativa (\%) presente em um raio de $2 \mathrm{~km}$ no entorno das áreas de cultivo em propriedades orgânicas $(\mathrm{O} 1, \mathrm{O} 2 \mathrm{e}$ $\mathrm{O} 3)$ e convencionais $(\mathrm{C} 1, \mathrm{C} 2, \mathrm{C} 3$ e $\mathrm{C} 4)$ por meio de análise de regressão $\left(\mathrm{r}^{2}=0.79\right.$; $\mathrm{p}<0.01 ; \mathrm{y}=2,5069+0,1369 * \mathrm{x})$.. As áreas estão localizadas no Distrito Federal.

\section{DISCUSS $\tilde{O} O$}

Os resultados do presente estudo demonstram que a riqueza de abelhas visitantes florais da aboboreira, $C$. pepo, foi influenciada pela paisagem do entorno das propriedades, independentemente do tipo de sistema de produção, convencional ou orgânico. No entanto, a abundância de abelhas foi influenciada pelo tipo de manejo praticado pelas propriedades e não pela paisagem do entorno. Assim observou-se um efeito a nível local na abundância de indivíduos e um efeito a escala regional na riqueza de espécies.

Este resultado está em concordância, em parte, com uma análise multivariada feita a partir de estudos desenvolvidos em várias regiões do mundo considerando 39 culturas diferentes, inclusive a aboboreira. A análise desse conjunto de dados mostrou que a abundância de abelhas foi significativamente maior nos sistemas orgânicos do que no convencional. Contudo, a riqueza diferiu entre os tipos de manejo (Kennedy et al., 2013).

Quando as abundâncias foram comparadas entre os sistemas de produção localizados dentro da mesma região geográfica, também observaram-se as maiores abundâncias nos sistemas orgânicos. Portanto, estes resultados sugerem que o tipo de 
manejo influencia a presença de abelhas, o que pode estar relacionado com algumas práticas adotadas em áreas convencionais que são prejudiciais para as abelhas, como o uso de inseticida, eliminação de recursos alternativos (plantas espontâneas), entre outros..

Em relação ao uso de agrotóxicos existem evidências que todas as espécies de abelhas podem ser afetadas, em algum grau, pelo uso intensivo de agrotóxicos (Freitas \& Pinheiro, 2010). Muitos dos estudos de toxicidade de agrotóxicos nas abelhas são conduzidos em condições de laboratório. Na natureza as abelhas estão expostas a um conjunto de condições mais complexas em relação ao ambiente controlado de laboratório. Nestas condições efeitos bióticos e abióticos podem interagir com os inseticidas potencializando o efeito dos mesmos. Adicionalmente, no mosaico de vegetação e diferentes cultivos os insetos podem ser expostos a áreas tratadas com diversos tipos de agrotóxicos, e em diferentes dosagens e períodos de aplicação.

O crescente uso de pesticidas em lavouras agrícolas, com destaque para os neonicotinóides, foi uma das hipóteses formuladas pelos pesquisadores sobre os eventos conhecidos como "Desordem do Colapso de Colônias", que atingem as colônias de Apis mellifera. As abelhas são contaminadas pelos neonicotinóides, não apenas pelo contato tópico com o produto, mas também pela ingestão via pólen e/ou néctar contaminados. Estudos realizados nos Estados Unidos mostraram que a concentração de resíduos de diversos neonicotinóides, utilizados em plantações de abóbora (Cucurbita pepo), foram elevados tanto no pólen quanto no néctar $(73,5 \%$ e $88,8 \%$ de resíduos nas amostras, respectivamente). O período de aplicação dos produtos também influenciou nas concentrações de resíduos encontrados no pólen e néctar, sendo que os níveis mais altos de resíduos de inseticidas e seus metabólitos foram encontrados quando a pulverização foi realizada no período de floração da abóbora (Dively \& Kamel, 2012). A aplicação de inseticida nos cultivos de aboboreira do presente estudo também foi realizada durante a floração, sugerindo um fator adicional para a diferença na abundância de abelhas encontrada entre os sistemas de produção (ver Tabela 3.2 no Apêndice).

Resultados semelhantes foram encontrados em um estudo realizado em Juazeiro (BA) no Brasil (Bogdanski, 2005), onde foram medidas as taxas de visitação de polinizadores e a frutificação em maracujá (Passiflora edulis) em áreas de produção localizadas a diferentes distâncias do habitat natural (Caatinga). Esta espécie de maracujá é auto-incompatível e a polinização é feita fundamentalmente por mamangavas, Xylocopa spp. (Klein et al., 2007) que nidificam em cavidades de árvores. 
Seria de esperar, portanto, que uma fazenda próxima a uma área com vegetação nativa tivesse maiores níveis de polinização e produtividade do maracujá. No entanto, essa relação não foi encontrada, os autores justificam este resultado, em parte, pelo uso intensivo de inseticidas nos campos.

As propriedades estudadas estão localizadas em uma paisagem altamente heterogênea, com disponibilidade de recursos florais (vegetação do entorno, plantio de diversas espécies em rotação de cultura; plantas espontâneas) e locais de nidificação para as abelhas. Áreas antropizadas e os próprios campos agrícolas, podem oferecer recursos florais e de nidificação, contudo a qualidade desses recursos dependerá de práticas agrícolas (por exemplo: aplicação de inseticidas; plantio direto) Holzschuh et al., 2007).

Os resultados apresentados aqui mostram que a riqueza de abelhas foi maior em propriedades localizadas em regiões com maior porcentagem de vegetação nativa no entorno das áreas de cultivo. A riqueza encontrada nos campos convencionais foi também beneficiada pela qualidade da paisagem do entorno, medida através dos três grupos propostos [Vegetação Nativa (VN); Área antropizada de alta qualidade (A1) e Área antropizada de baixa qualidade (A2)]. Isso também foi constatado por Kennedy et $a l .$, (2013) em um estudo em vários partes do mundo com 39 culturas diferentes.

Essa relação positiva entre a proximidade de habitats naturais das áreas de cultivo e a atividade de polinizadores já havia sido constatada anteriormente em áreas de produção de melancia (Citrullus lanatus) (Kremen et al., 2002b). Entretanto um estudo conduzido sob as mesmas condições ao anterior não encontrou tal efeito (Winfree et al., 2007a). Os resultados divergentes destes estudos podem indicar fatores adicionais importantes que possam influenciar a presença de polinizadores, tal como o próprio manejo das culturas (plantios em consórcio, manejo de espontâneas e uso de inseticidas, entre outros) nas lavouras agrícolas.

As espécies de abelhas mais abundantes neste estudo, Apis mellifera, Trigona spinipes e Trigona hyalinata, também foram os visitantes florais de Cucurbita spp. mais abundantes relatados em trabalhos prévios realizados no Brasil (Cardoso, 2003; Serra, 2007; Mélo, 2010 para A. mellifera e T. spinipes e Serra, 2007 para T. hyalinata).

A espécie Melipona quinquefasciata, coletada neste estudo, não é comum em flores de Cucurbita spp. Outra espécie deste gênero, M. quadrifasciata, foi registrada previamente em dois estudos anteriores, em Minas Gerais e Alagoas, com uma frequência de 104 e 11 indivíduos, respectivamente (Serra, 2007; Mélo, 2010). Em 
relação à espécie Partamona combinata, sua presença em flores de C. pepo ainda não havia sido registrada em trabalhos anteriores. A captura de todas as espécies de uma área é praticamente impossível, portanto a curva de acumulação de espécies sempre tende a ser crescente quando as coletas continuam (Santos, 2003).

$\mathrm{Na}$ comunidade amostrada no presente trabalho as abelhas sociais foram os visitantes mais frequentes nas flores de C. pepo. O tamanho corporal e o grau de sociabilidade influenciam a capacidade de deslocamento das abelhas. Abelhas solitárias tendem a forragear em distâncias menores que abelhas sociais (Steffan-Dewenter et al., 2002; Tscharntke, 2002) já que, muitas vezes as espécies sociais conseguem explorar a paisagem de maneira mais eficiente devido à habilidade de comunicação sobre a presença de fontes de recursos (Tscharntke et al., 2005). Para Heard (1999) as abelhas sociais mantêm reservas de alimento estocadas no ninho, para alimentar além de suas próprias necessidades, toda a colônia o que resulta em intensa visitação às flores. Estas características biológicas das abelhas sociais podem explicar a superioridade numérica destas espécies nas flores de C. pepo observada neste trabalho.

Estudos em regiões tropicais com diversas culturas, inclusive com C. pepo, mostraram que as abelhas sociais eram muitas vezes meliponíneos, que em grande parte dependem de habitat natural, porque preferem construir os seus ninhos em troncos de árvores e possuem um raio de forrageamento relativamente curto (Heard, 1999; Eltz et al., 2003). A abelha Trigona spinipes, uma das espécies mais abundantes no presente estudo, é considerada uma espécie de tamanho médio, e a distância máxima de voo foi estimada em aproximadamente 900 metros (Araujo et al., 2004).

A abelha Apis mellifera foi a única espécie amostrada em todas as propriedades de estudo. Isto suporta vários relatos que A. mellifera tem uma alta capacidade de nidificar em áreas de produção agrícola, e são menos sensíveis à quantidade de habitat natural nas proximidades do que muitas espécies nativas (Steffan-Dewenter \& Kuhn 2003; Ricketts, 2004). Enquanto que as abelhas silvestres são mais impactadas pela quantidade de habitats de alta qualidade (Potts et al., 2010a).

Assim é evidente que as comunidades de abelhas podem ser influenciadas tanto pelo tipo de manejo como pelas características da paisagem (Tscharntke et al., 2005; Kremen et al., 2007; Batary et al., 2011).

A intensificação da agricultura é caracterizada em muitas partes do mundo pelo alto uso de agrotóxicos, extensas áreas de plantio, trabalho mecanizado, baixa diversidade de outros cultivos e de vegetação natural (Tscharntke et al., 2005; Meehan 
et al., 2011). Estas características dos sistemas agrícolas afetam negativamente as comunidades de abelhas silvestres e levam a serviços de polinização reduzidos para as culturas (Klein et al., 2009).

Uma forma, portanto, de aumentar a diversidade de polinizadores em paisagens agrícolas seria aumentar a heterogeneidade funcional da paisagem, ou seja, conservar e/ou aumentar os diferentes tipos de cobertura (vegetação nativa, cultivo, pastagem, etc.) que fornecem alimento, sítios de nidificação, rotas de dispersão, entre outros serviços, para a espécie ou grupos de espécies em questão (Fahrig et al., 2011). Além disto, a redução do uso de agrotóxicos, o plantio de pequenas áreas de culturas de floração diferentes, e a adoção de cercas vivas ao redor dos plantios também podem favorecer as comunidades de abelhas (Tscharntke et al., 2005; Brosi et al., 2008). Várias práticas agrícolas citadas acima foram observadas para a maioria das propriedades orgânicas do presente estudo. Outros trabalhos também mostraram que alguns polinizadores parecem ser capazes de utilizar os recursos dentro de áreas manejadas e possuem a capacidade de manter suas populações em habitats naturais a diferentes distâncias das áreas cultivadas (Klein et al., 2003a; Kremen et al., 2004; Morandin et al., 2007), o que pode sugerir que as abelhas são capazes de tolerar a fragmentação do habitat, desde que a quantidade de habitat total seja suficiente para fornecer os recursos (alimentares e de nidificação) necessários para manter suas populações.

Finalmente, as interações entre tipo de manejo e a paisagem sugerem que os benefícios locais de uma diversidade de culturas ou vegetação nativa e o manejo orgânico poderiam melhorar a qualidade dos habitats, além de proporcionar benefícios aos campos adjacentes ou nas proximidades (Holzschuh et al., 2008).

O presente trabalho representa a primeira contribuição ao conhecimento das abelhas presentes em áreas agrícolas em plantios de C. pepo na região do Distrito Federal. Futuros estudos podem contribuir para uma melhor caracterização da fauna de abelhas que ocorrem na região. Os desafios são muitos para que as áreas agrícolas se tornem locais mais seguros para a fauna de insetos como um todo, porém os resultados deste estudo indicam que as propriedades agrícolas de produção orgânica, que em geral são do tipo de manejo familiar, apresentam muitas das características positivas relacionadas a um manejo amigável aos polinizadores. 


\section{CAPÍTULO 2}

Identificação das abelhas potenciais polinizadoras da aboboreira

Cucurbita pepo L. no Distrito Federal: Comportamento de forrageamento e déficit de polinização 


\section{INTRODUÇÃO}

Polinização é o processo que envolve o transporte dos grãos de pólen desde a antera onde são produzidos até o estigma, geralmente de outra flor (Laroca, 1995). Algumas espécies de plantas se reproduzem através da autopolinização, já outras plantas necessitam de agentes polinizadores para transportar o pólen das flores masculinas para as flores femininas, como é o caso de espécies monóicas, cujo sexo é separado nas flores do mesmo indivíduo. Estes agentes polinizadores podem ser bióticos (animais) ou abióticos (vento, água). A polinização é um serviço ambiental realizado naturalmente pelos animais, dentre eles, especialmente pelas abelhas (Imperatriz-Fonseca \& Kleinert, 2004).

A aboboreira é uma planta monóica com flores masculinas e femininas (Passarelli, 2002). A flor feminina (pistilada) produz néctar, um recurso para os polinizadores, e a flor masculina (estaminada) pólen e néctar. As flores de Cucurbita spp. são amarelas e têm duração (desde antese até senescência) de apenas algumas horas, com variações no horário de abertura, que ocorre ao amanhecer, e fechamento, nas horas mais quentes do dia, entre 11:00 e 14:00h, (Nepi \& Pacini, 1993; Nepi et al., 2001), sendo essas variações influenciadas pelas condições climáticas..

Uma grande diversidade de insetos pertencentes às ordens Hymenoptera, Diptera e Coleoptera têm sido registrados visitando flores de plantas do gênero Cucurbita (Michelbacher et al., 1964; Ávila, 1987; Free, 1993; Nogueira-Couto et al., 1990; Minussi, 2003). Porém, segundo Free (1993), os insetos polinizadores mais importantes de Cucurbita spp. são as abelhas pertencentes a família Apidae.

As abelhas são um grupo diversificado, que apresentam grande variação em relação a características comportamentais e morfológicas relacionadas com a polinização, sendo pouco adequado agrupá-las em uma única unidade funcional. Entretanto, a eficiência como agentes polinizadores varia entre as espécies. O comportamento de visitarem flores de indivíduos diferentes, porém da mesma espécie, aumenta as chances de polinização cruzada (xenogamia). Espécies que não transportam o pólen em estruturas especializadas (escopa e corbícula) podem ser polinizadores mais eficientes devido a uma quantidade maior de pólen presente no corpo desses indivíduos. Espécies que não hidratam o pólen para o transporte também são mais eficientes na polinização, uma vez que o pólen seco tem maiores chances de se desprender do corpo 
da abelha e ser depositado sobre o estigma da flor (Michener, 2000). Por isso nem todo visitante floral é eficiente na polinização de qualquer cultura agrícola, e nem todas as espécies vegetais são igualmente atrativas para todos os polinizadores (Freitas, 1998b).

Alguns estudos realizados no Brasil (São Paulo, Alagoas e Minas Gerais) em plantios de Cucurbita spp. observaram que as operárias de Trigona spinipes e Apis mellifera apesar de apresentaram algumas características desfavoráveis à polinização, podem ser consideradas polinizadoras eficientes da aboboreira (Cardoso, 2003; Lattaro \& Malerbo-Souza, 2006; Serra, 2007; Mélo et al., 2010). Já um estudo realizado no México por Canto-Aguilar \& Parra-Tabla (2000) mostrou os benefícios da polinização em C. moschata realizada por uma espécie de Peponapis. Essa espécie foi quatro vezes mais eficiente na transferência do pólen do que A. mellifera.

Cerca de $70 \%$ dos 124 principais cultivos utilizados diretamente para o consumo humano são dependentes da ação de polinizadores, principalmente abelhas, para a formação de frutos e/ou sementes (Klein et al., 2007). De acordo com Vaissière et al., (2010) pode-se definir como déficit de polinização a deposição insuficiente de pólen sobre os estigmas da flor vindo a comprometer o rendimento da cultura agrícola.

Muitos cultivos que se acreditava serem polinizados em grande parte pelo vento estão sendo estudados com relação à demanda por polinizadores bióticos. Em estudo realizado na Suécia em cultivos de canola (Brassica napus L.) a polinização por insetos contribuiu para $18 \%$ da produção de sementes e para $20 \%$ do valor de mercado da produção quando comparado ao preço das amostras que foram polinizadas exclusivamente pelo vento (Bommarco et al., 2012). Outro trabalho conduzido no Piauí na espécie Ricinus communis L. (mamona) comprovou a eficiência da abelha Apis mellifera no aumento da produtividade (sementes/ha) desse cultivo (Rizzardo et al., 2007). No Ceará, Brasil, foi verificado que áreas de soja (Glycine Max (L.) Merr.) com a adição de colônias de Apis mellifera produziram 18,09\% a mais quando comparadas às áreas que foram privadas da visita de polinizadores, assim como as abelhas nativas da região aumentaram a produção em 6,34\% (Milfont et al., 2013).

Em um cenário mundial de perda de populações de insetos polinizadores muitos cultivos teriam suas produções severamente reduzidas, acarretando num déficit de oferta, ou seja, a produção não seria suficiente para abastecer a demanda global por esses produtos. Os cultivos mais vulneráveis a perda de polinizadores são os cultivos de estimulantes (por exemplo, o café), as frutas e os vegetais que possuem alto valor econômico e são muito difíceis de estocar de um ano para o outro (Gallai et al., 2009). 


\section{OBJETIVOS:}

Objetivo Geral: Estudar o comportamento de forrageamento das espécies de abelhas mais abundantes nas flores da aboboreira (Cucurbita pepo) e avaliar o impacto da polinização promovida pelas abelhas em áreas de produção orgânica e convencional no Distrito Federal.

\section{Objetivos Específicos:}

i) Identificar entre as espécies de abelhas mais abundantes nas flores da abóbora quais são seus prováveis polinizadores em sistemas orgânicos e convencionais de produção;

ii) Avaliar se existe um déficit de polinização para a aboboreira Cucurbita pepo em sistemas orgânicos e convencionais.

\section{Hipóteses:}

Com base nos resultados apresentados no Capítulo 1 desta dissertação em relação à abundância de espécies na cultura e nos dois sistemas de produção, postulam-se as seguintes hipóteses:

i) Os prováveis polinizadores de Cucurbita pepo são as espécies de abelhas: Apis mellifera e Trigona spinipes.

ii) A abóbora C. pepo apresenta déficit de polinização nas áreas de cultivo convencional de hortaliças no Distrito Federal. 


\section{MATERIAL E MÉTODOS}

\section{1. Áreas de estudo}

Os dados foram coletados em plantios comerciais de C. pepo em dez propriedades pareadas e localizadas no Distrito Federal (Figura 2.1). As propriedades foram classificadas em orgânicas $(n=5)$ e convencionais $(n=5)$, sendo de pequenos produtores rurais (manejo familiar), com exceção da Fazenda Malunga (O1) (Figura 2.1).

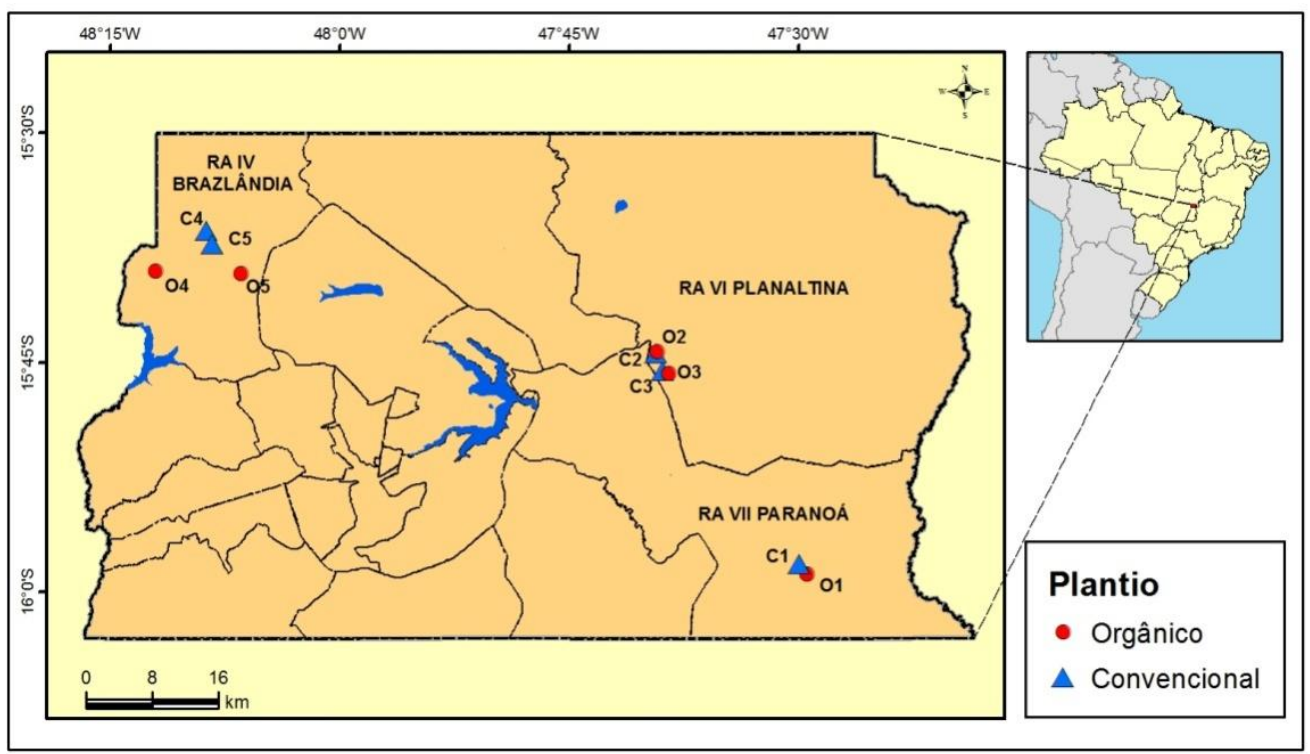

Figura 2.1 - Mapa do Distrito Federal com a localização das propriedades com plantios de abóbora (Cucurbita pepo L.) onde foi conduzido o estudo. Os círculos em vermelho representam as áreas de produção orgânica (O1 a O5), e os triângulos em azul representam as áreas de produção convencional (C1 a C5).

\subsection{Comportamento de forrageamento}

Entre os meses de julho a outubro de 2014 as amostragens foram conduzidas em sete propriedades agrícolas, sendo quatro convencionais $(\mathrm{C} 1, \mathrm{C} 2, \mathrm{C} 3$ e $\mathrm{C} 4)$ e três orgânicas (O1, O2 e 3) (Figura 2.1). A fim de padronizar o tamanho da área amostral, em todas as propriedades foram selecionadas e demarcadas áreas de 30x15m nos plantios de abóbora. 
Para a avaliação de diversidade e abundância dos visitantes florais, a área experimental $(30 \times 15 \mathrm{~m})$ foi dividida em seis parcelas de $15 \times 2 \mathrm{~m}$. Nessas parcelas, as amostragens foram realizadas entre o período de 06:00 e 12:00 h, em seis intervalos: 6:00-7:00 h; 7:00-8:00 h; 8:00-9:00 h; 9:00-10:00 h; 10:00-11:00 h e 11:00-12:00 h. Em cada intervalo, durante cinco minutos, as abelhas foram coletadas diretamente nas flores com auxílio de frascos plásticos, totalizando 30 minutos por intervalo e com um esforço total de coleta de 3horas por data de amostragem. Este método de amostragem em parcelas foi adaptado a partir do protocolo da FAO (Vaissière et al., 2010).

O comportamento das abelhas nas flores foi observado e registrado para avaliar o potencial das espécies como polinizadores de C. pepo. Para cada indivíduo observado, os seguintes comportamentos foram registrados: recurso coletado (néctar e/ou pólen); presença de grãos de pólen no corpo, locais do corpo onde o pólen ficava aderido e contato com os estigmas.

Para cada propriedade a amostragem foi realizada em três diferentes períodos do estágio fenológico da abobrinha: início da floração (45 dias), pico da floração (60 dias) e final da floração (90 dias), os dias foram contabilizados após a semeadura. Os estágios fenológicos e o tempo necessário para atingir cada um foram caracterizados seguindo Orozco (1997).

Para quantificar o recurso disponível (flores abertas) para as abelhas, em cada propriedade e data de amostragem foram amostradas três fileiras do plantio de $30 \mathrm{~m}$ de comprimento com cinco metros de distância entre elas. Com o auxílio de um contador manual, foi registrado em cada uma das fileiras o número de flores e o sexo da flor, em cada dia de amostragem.

Com o intuito de avaliar a distribuição dos recursos disponíveis para as abelhas (flores novas abertas no dia da amostragem) ao longo dos intervalos de coleta foi feito um acompanhamento da longevidade das flores e estabelecidas quatro categorias: parcialmente aberta $(\mathrm{PA}=$ fase inicial da antese, desabrochar da flor $)$, aberta $(\mathrm{A}=$ fase final da antese, flor completamente aberta), flor fechando $(\mathrm{FF}=$ fase inicial da senescência, envelhecimento da flor) e totalmente fechada $(\mathrm{TF}=$ fase final da senescência, torção em espiral da parte apical da corola) (Figura 2.2).

No pico da floração uma amostragem foi feita por propriedade, e em cada intervalo de coleta foram escolhidas aleatoriamente 20 plantas e para cada uma foi quantificado o número de flores dentro de cada uma das quatro categorias. 

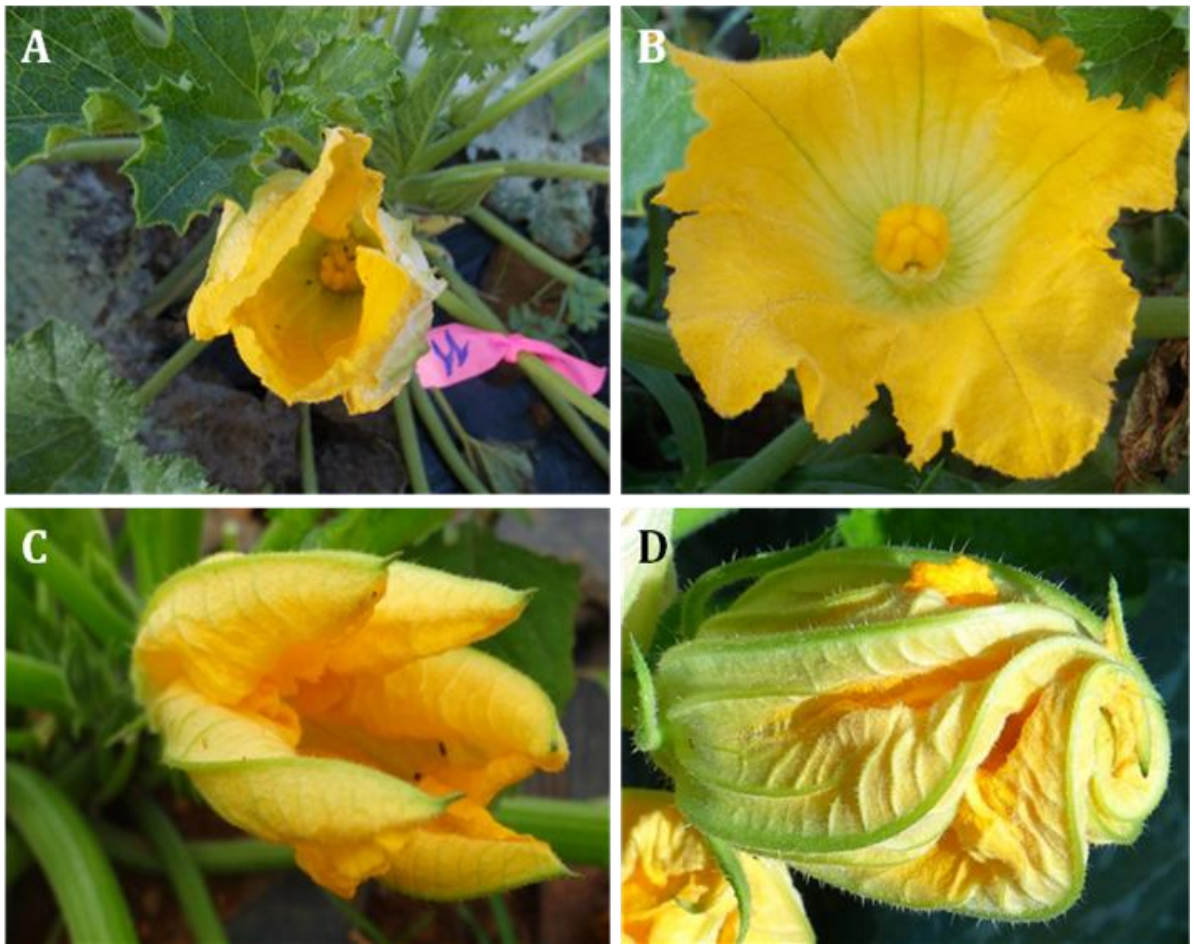

Figura 2.2 - Categorias de longevidade das flores de Cucurbita pepo. A) Parcialmente Aberta (PA); B) Aberta (A); C) Flor Fechando (FF); Totalmente Fechada (TF).

\subsection{Avaliação do déficit de polinização}

Para verificar se existe um déficit de polinização nas áreas de estudo, foram avaliadas a quantidade e qualidade de frutos formados em flores abertas a visitação das abelhas em propriedades convencionais e orgânicas de produção. Para tanto, seguindo o protocolo FAO (Vaissière et al., 2010), dentro da área experimental de 30x15m, onde foram avaliadas a abundância e riqueza de abelhas foram selecionadas aleatoriamente 30 flores femininas abertas no dia, em diferentes plantas, e marcadas com uma fita plástica (Figura 2.3A). Essa avaliação foi realizada uma vez em cada propriedade durante o pico da floração (60 dias após a semeadura). As flores permaneceram totalmente livres à visitação das abelhas. Os frutos provenientes destas flores foram colhidos verdes, seis dias após a marcação, seguindo as recomendações do protocolo FAO, ou seja, as características de comercialização utilizadas pelo produtor (Figura 2.3B e C). A qualidade dos frutos foi avaliada individualmente através de medições do 
comprimento (base do pedúnculo ao extremo oposto), diâmetro do 1/3 posterior e peso, obtido em uma balança de precisão, logo após a colheita (Figura 2.3D, E e F).
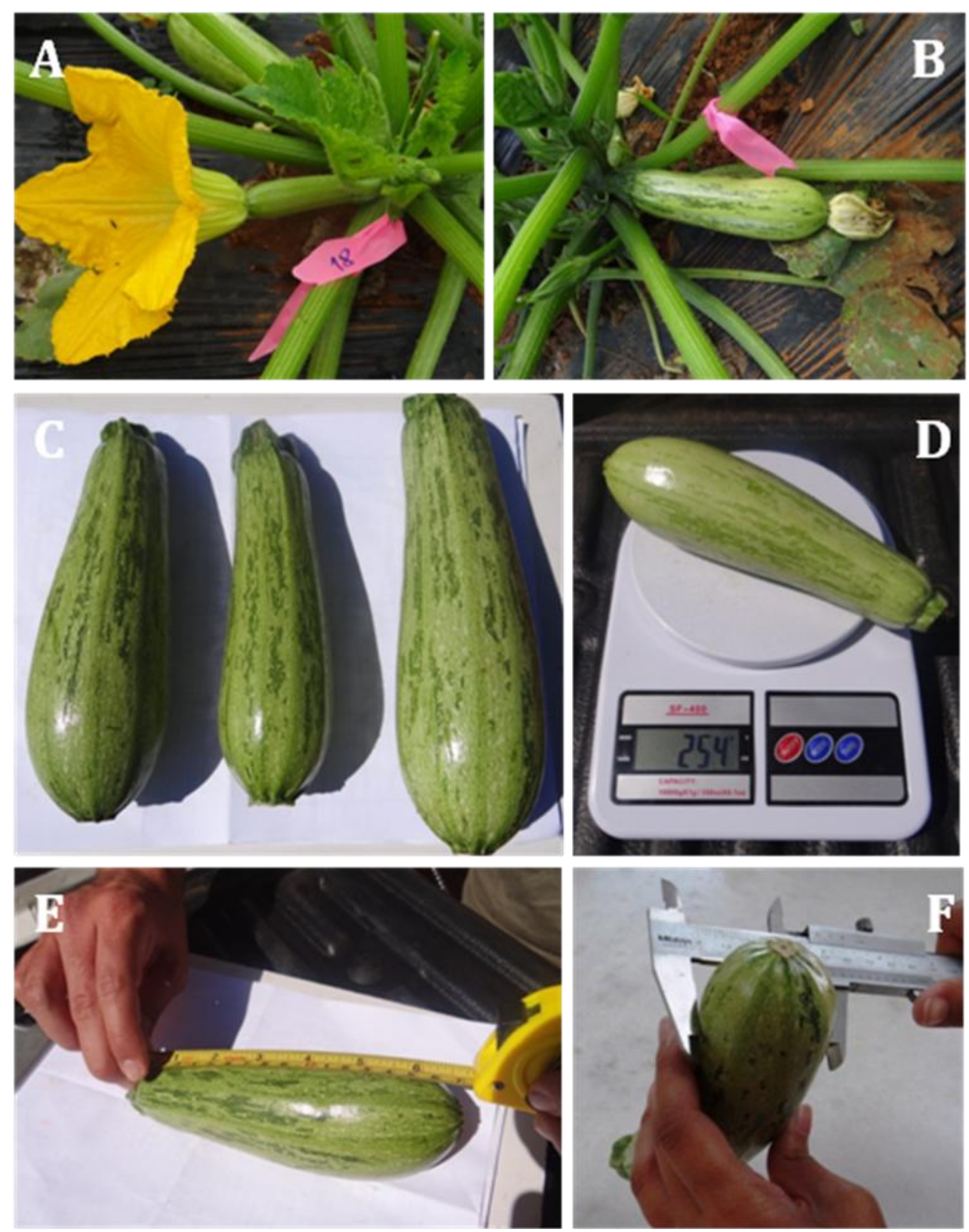

Figura 2.3 - A) Dia da marcação da flor de Cucurbita pepo para o experimento de produtividade; B e C) Frutos de C.pepo colhidos seis dias após a marcação da flor; D) Pesagem do fruto; E) Medição do comprimento do fruto; F) Medição do diâmetro do fruto. 


\subsection{Análise de dados}

Para verificar se houve diferença na abundância de abelhas ao longo dos intervalos de coleta foi utilizada uma Análise de Deviança com distribuição de erros de Poisson e função de ligação log, posteriormente a abundância de abelhas em cada intervalo de amostragem foi comparada com análise de contrastes. A abundância das espécies de abelhas mais frequentes nos diferentes intervalos de coleta em ambos os sistemas de produção (orgânico e convencional) foi avaliada por uma análise de modelo linear generalizado (GLM). Para testar a preferência das espécies de abelhas na visitação de flores masculinas ou femininas foi realizado um teste do qui-quadrado tendo como hipótese a distribuição homogênea (50\% dos indivíduos em cada tipo de flor). Foi utilizada análise de regressão simples para avaliar a influência do número de flores sobre a abundância de abelhas. As características dos frutos (peso, comprimento e diâmetro) produzidos nas propriedades de cultivo orgânico e convencional foram analisadas por meio de uma Análise de Variância (considerando tipo de propriedade). O programa R (R Core Team 2013) foi utilizado para realizar as análises estatísticas.

\section{RESULTADOS}

\subsection{Longevidade das flores de Cucurbita pepo $L$.}

No primeiro período de amostragem (06:00-07:00 h) 90,40\% das 250 flores de C. pepo observadas encontravam-se totalmente abertas à visitação de abelhas. $\mathrm{O}$ fechamento das flores iniciou-se a partir do intervalo de 09:00-10:00 h, sendo que no intervalo seguinte $(10: 00-11: 00$ h) já haviam 8,61\% $(n=23)$ de flores totalmente fechadas (Figura 2.4). As flores fechavam com o murchamento e a torção em espiral da parte apical da corola (Figura 2.2D). A proporção de flores masculinas/femininas foi de $1 / 1(45 / 45)$. 
A abundância total de abelhas foi influenciada positivamente pelo número de flores (Figura 2.5). Embora a relação entre as variáveis tenha sido significativa, o modelo estatístico mostrou baixo poder de predição $\left(r^{2}=0.24\right)$.

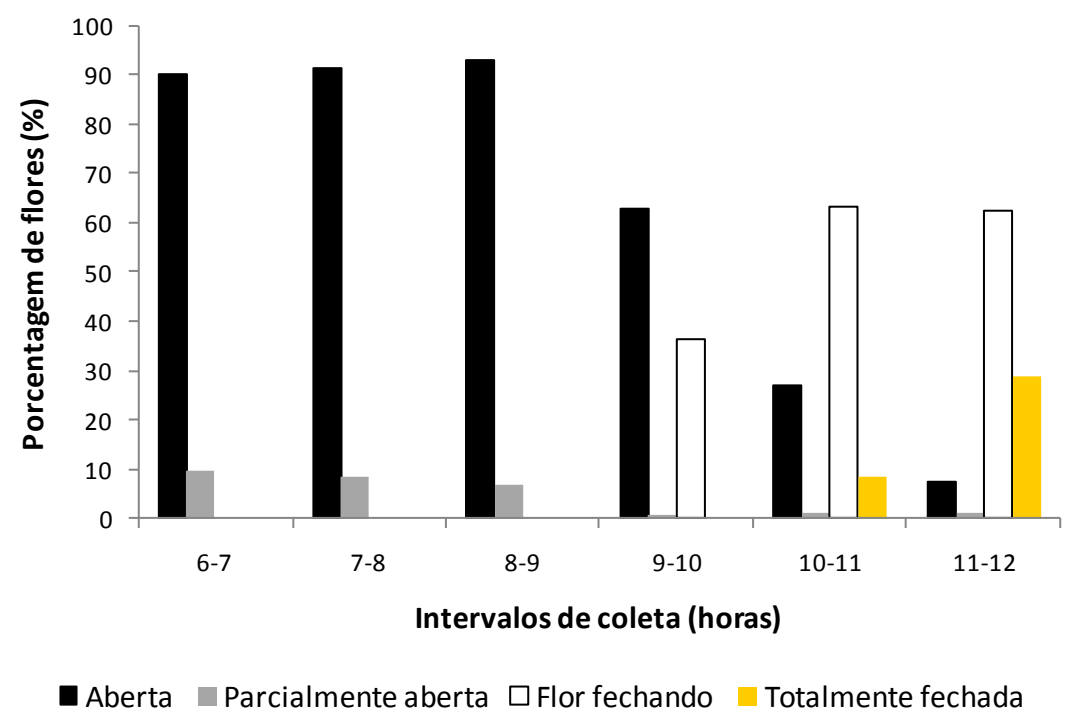

Figura 2.4 - Porcentagem de flores de Cucurbita pepo em cada categoria de longevidade, medida em função da abertura floral em seis intervalos de amostragem em uma área de produção de hortaliças no Distrito Federal, em 2014.

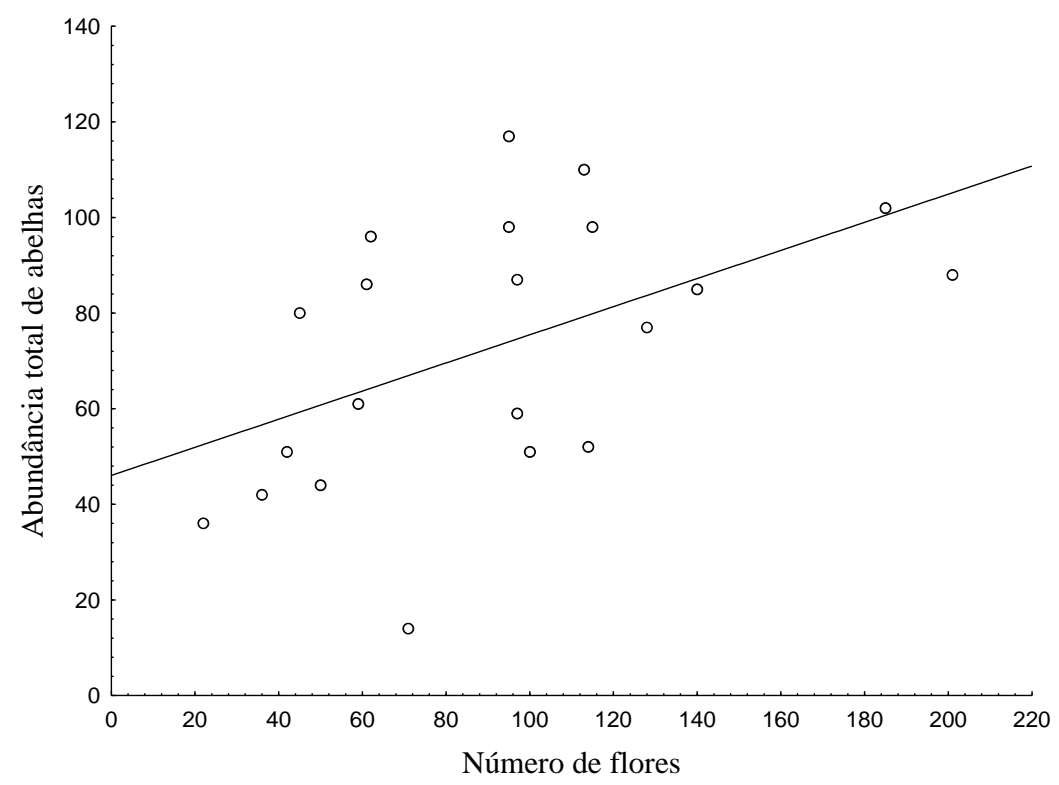

Figura 2.5 - Relação entre o número de flores abertas no dia da amostragem e a abundância total de abelhas visitantes florais observadas em cada data de coleta $(n=21)$ em três propriedades orgânicas e quatro convencionais, localizadas no Distrito Federal em 2014, $\left(r^{2}=0.24, p=0.02 ; y=46,0402+0,2942 * x\right)$. 


\subsection{Comportamento de forrageamento}

A maior atividade das abelhas ocorreu em dois intervalos de coleta (8:00-9:00 h e 9:00-10:00 h) em coincidência com períodos de máxima abertura das flores (GLM e Análise de Deviança $\chi^{2}=365.59$, g.l=5, p<0.001, Figura 2.6).

O padrão diário de forrageamento das espécies mais abundantes nas flores de $C$. pepo é apresentado nas Figuras 2.7 e 2.8. Apis mellifera foi mais abundante nos horários iniciais do dia atingindo o pico de visitação no sistema orgânico entre às 7:00-8:00 h, e no convencional no intervalo posterior (8:00-9:00 h); e decrescendo gradativamente até o final da manhã (12:00 horas) (Figuras 2.7 e 2.8). No sistema orgânico Trigona spinipes apresentou dois intervalos (8:00-9:00 h e 9:00-10:00 h; Figura 2.7) com altas taxas de visitação, sendo que, no sistema convencional, o primeiro intervalo (8:00-9:00 h) coincidiu com o pico de visitação da abelha A. mellifera. A abundância de Trigona spinipes no sistema convencional foi baixa em todos os intervalos de coleta (Figura 2.8).

A espécie Partamona combinata teve uma distribuição com pouca variação entre os horários em ambos os sistemas de manejo (Figura 2.7 e 2.8). Trigona hyalinata foi mais abundante no sistema convencional no intervalo de 9:00-10:00 h; enquanto no sistema orgânico em dois intervalos (8:00-9:00 h; 10:00-11:00 h) (Figuras 2.7 e 2.8). A maioria das espécies de abelhas foram coletadas em todos os intervalos, exceto Trigona spinipes no primeiro intervalo (6:00-7:00 h) no sistema convencional.

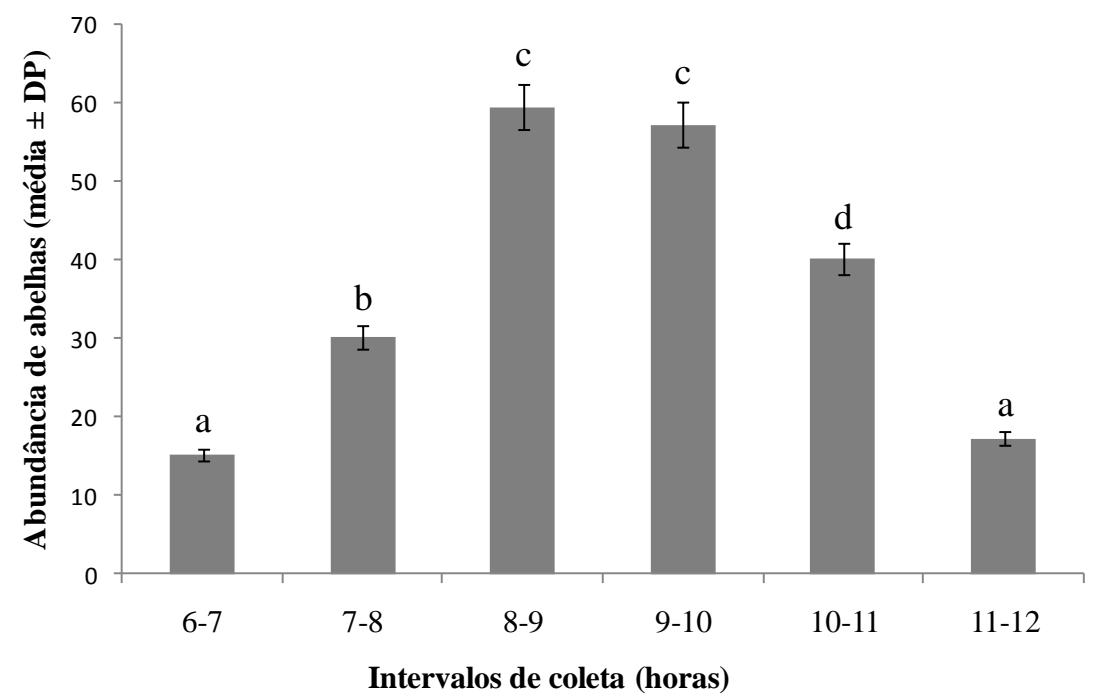

Figura 2.6 - Abundância (média \pm DP) das abelhas coletadas em flores de Cucurbita pepo nos seis intervalos de amostragem nas propriedades orgânicas e convencionais, 
localizadas no Distrito Federal em 2014. Letras diferentes acima das barras indicam diferenças estatísticas (GLM e Análise de Deviança $\chi^{2}=365.59$, g.l=5, p<0.001).

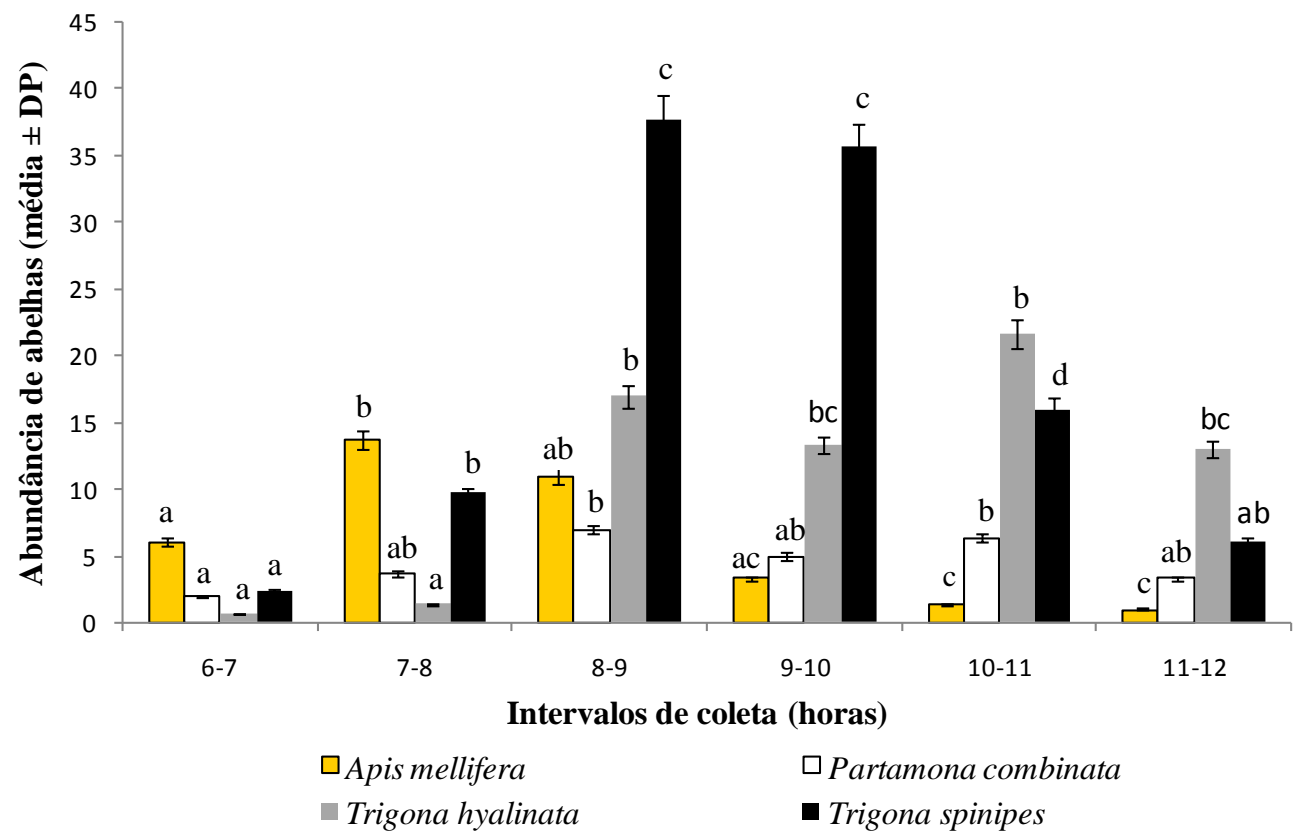

Figura 2.7- Padrão diário de forrageamento das espécies de abelhas mais abundantes (média \pm DP) coletadas em flores de Cucurbita pepo em diferentes intervalos de amostragem em propriedades orgânicas. As amostragens foram realizadas na região no Distrito Federal em 2014. Letras diferentes acima das barras indicam diferenças estatísticas entre os intervalos de coleta para uma determinada espécie (GLM e Análise de Deviança Apis mellifera: $\chi^{2}=70.95 ; g .1=5 ; p<0.001$; Partamona combinata: $\chi^{2}=12.45$; g.l=5; $\mathrm{p}=0.02$; Trigona hyalinata: $\chi^{2}=126.81 ;$ g.l=5; $\mathrm{p}<0.001 ;$ Trigona spinipes: $\chi^{2}=201.69 ;$ g.l $\left.=5 ; \mathrm{p}<0.001\right)$. 


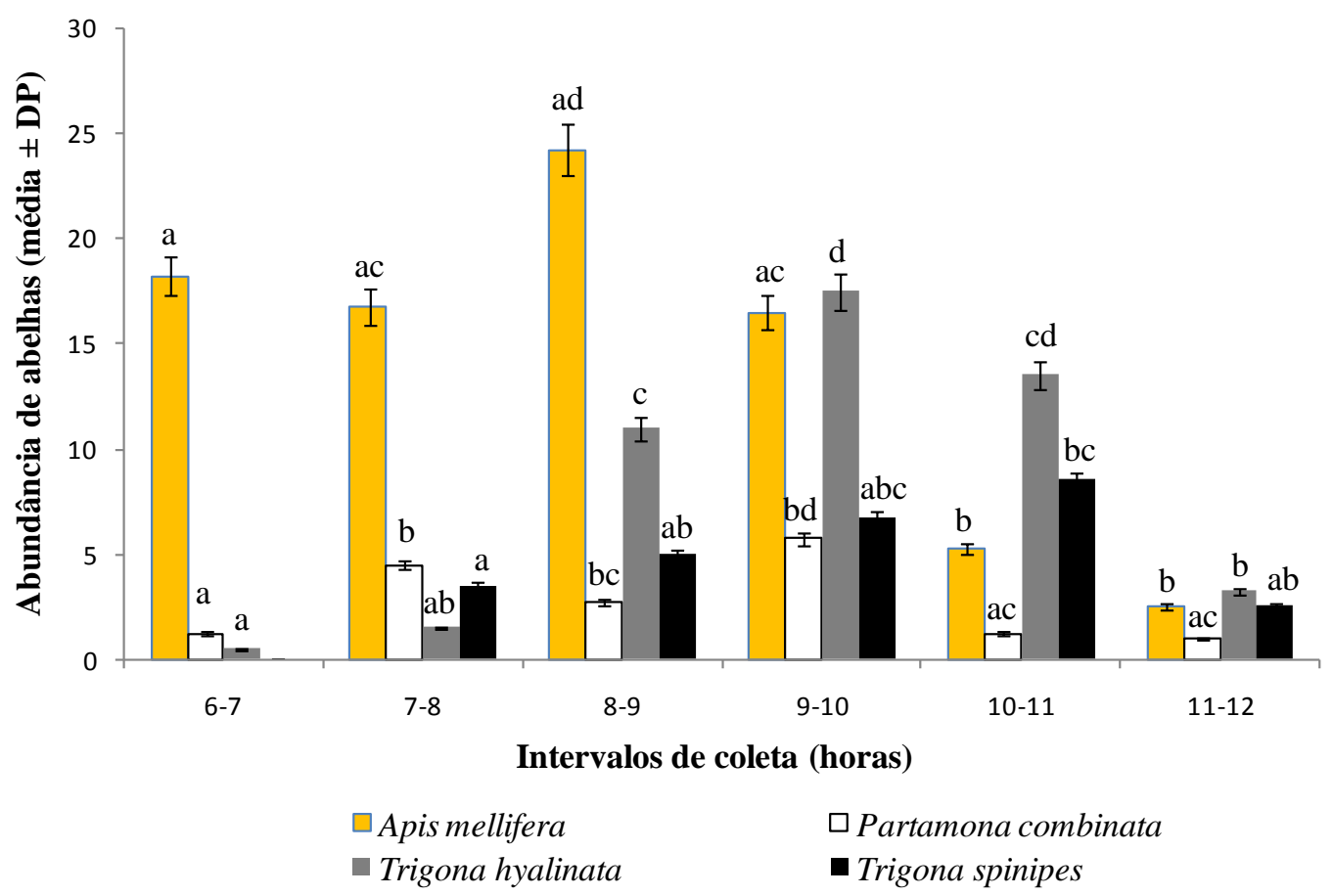

Figura 2.8 - Padrão diário de forrageamento das espécies de abelhas mais abundantes (média \pm DP) coletadas em flores de Cucurbita pepo em diferentes intervalos de amostragem em propriedades convencionais. As amostragens foram realizadas no Distrito Federal em 2014. Letras diferentes acima das barras indicam diferenças estatísticas entre os intervalos de coleta para uma determinada espécie (GLM e Análise de Deviança Apis mellifera: $\chi^{2}=119.34$; g.l=5; $\mathrm{p}<0.001 ;$ Partamona combinata: $\chi^{2}=27.80 ;$ g.l=5; $<<0.001 ;$ Trigona hyalinata: $\chi^{2}=145.47 ;$ g.l $=5 ; \mathrm{p}<0.001 ;$ Trigona spinipes: $\left.\chi^{2}=56.48 ; \mathrm{g} .1=5 ; \mathrm{p}<0.001\right)$.

Apis mellifera mostrou as maiores taxas de visitação em flores femininas $(70,11 \%)$ do que em masculinas $(29,89 \%)\left(\chi^{2}=72.00 ;\right.$ g.l $1 ; p<0.001$; Figura 2.9), mesmo com a proporção entre os sexos das flores sendo de $1 / 1$.

O comportamento de visita da Apis mellifera em flores masculinas, a procura de néctar, se dava com o posicionamento do corpo na posição vertical entre a corola e as estruturas sexuais. Nesta posição o dorso ficava voltado para as anteras, aderindo assim o pólen acidentalmente. As operárias de Apis mellifera carregaram pólen aderido ao corpo em mais de $60 \%$ dos indivíduos observados (Figura 2.10). O pólen estava localizado principalmente no dorso, mas também nas pernas e no ventre (Figura 2.11). A maioria dos indivíduos observados (55,73\%) tocara nos estigmas (Figura 2.12).

Apenas em 5\% (n=23) dos indivíduos observados registrou-se A. mellifera coletando pólen, sendo a maior procura por néctar (Figura 2.13). Em algumas ocasiões 
verificou-se indivíduos de $A$. mellifera removendo pólen de seus corpos, pousados sobre as pétalas da flor ou "dependurados" para fora da corola, presas pelas mandíbulas ao ápice de uma das pétalas da flor.

As abelhas de menor porte, T. spinipes e T. hyalinata, deslocaram-se pelas pétalas, estames ou estigmas e se dirigiram até os nectários $(93,44 \%$ e $96,39 \%$ dos indivíduos, respectivamente), não sendo possível estabelecer um padrão sequencial (Figura 2.13). As flores femininas foram as mais visitadas por estas espécies (Trigona spinipes: $\chi^{2}=133.77 ;$ g.l=1; $\mathrm{p}<0.001 ;$ Trigona hyalinata: $\chi^{2}=188.36 ;$ g.l=1; $\mathrm{p}<0.001$; Figura 2.9). Em mais de $80 \%$ dos indivíduos observados de T.spinipes e T. hyalinata o pólen aderiu-se ao corpo (Figura 2.10), localizando-se principalmente nas pernas, mas também, no dorso e no ventre (Figura 2.11). Quando estas visitavam as flores femininas, andaram sobre os estigmas (55\% dos indivíduos observados) (Figura 2.12), sendo também observados indivíduos que ficavam caminhando em movimentos circulares sobre os estigmas, e depositando assim o pólen. Estas abelhas forrageavam em grupo e monopolizam as fontes de alimento, afugentando outras espécies que tentassem pousar nas flores que ocupavam. Os indivíduos dessas espécies coletavam na maioria das visitas néctar nas flores femininas (Figura 2.13).

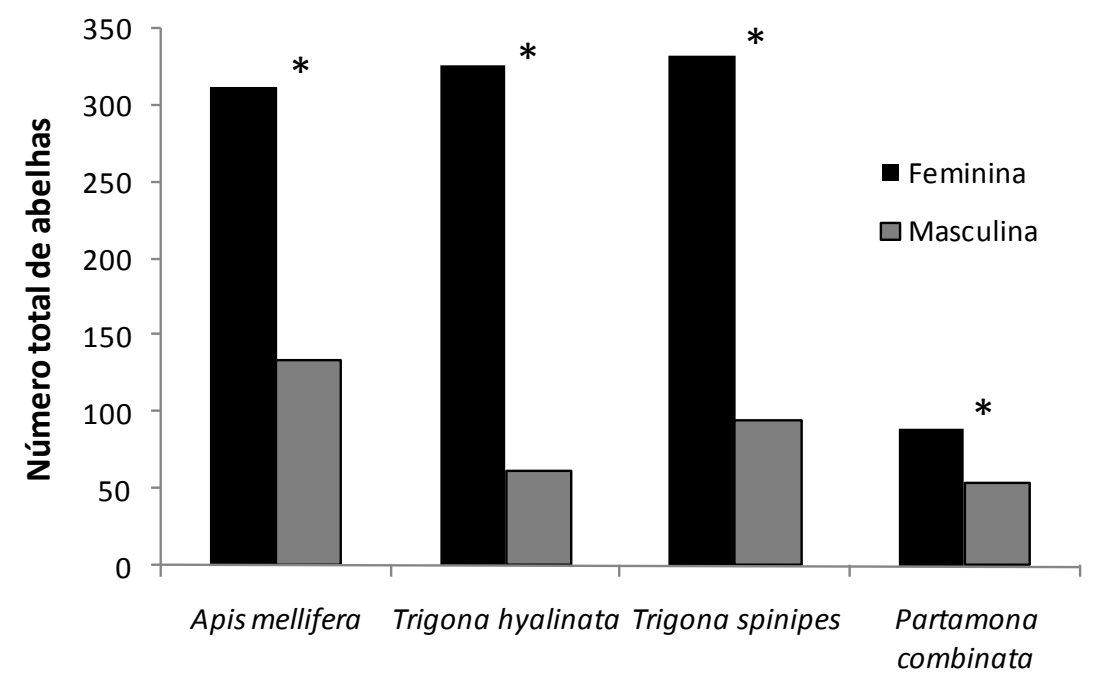

Visitante Floral

Figura 2.9 - Frequiência total das espécies de abelhas mais abundantes em flores masculinas e femininas da aboboreira Cucurbita pepo, em propriedades orgânicas e convencionais, DF, em 2014. *O asterisco significa diferenças estatísticas de acordo com o teste do Qui-quadrado $(\mathrm{p}<0.05)$. 


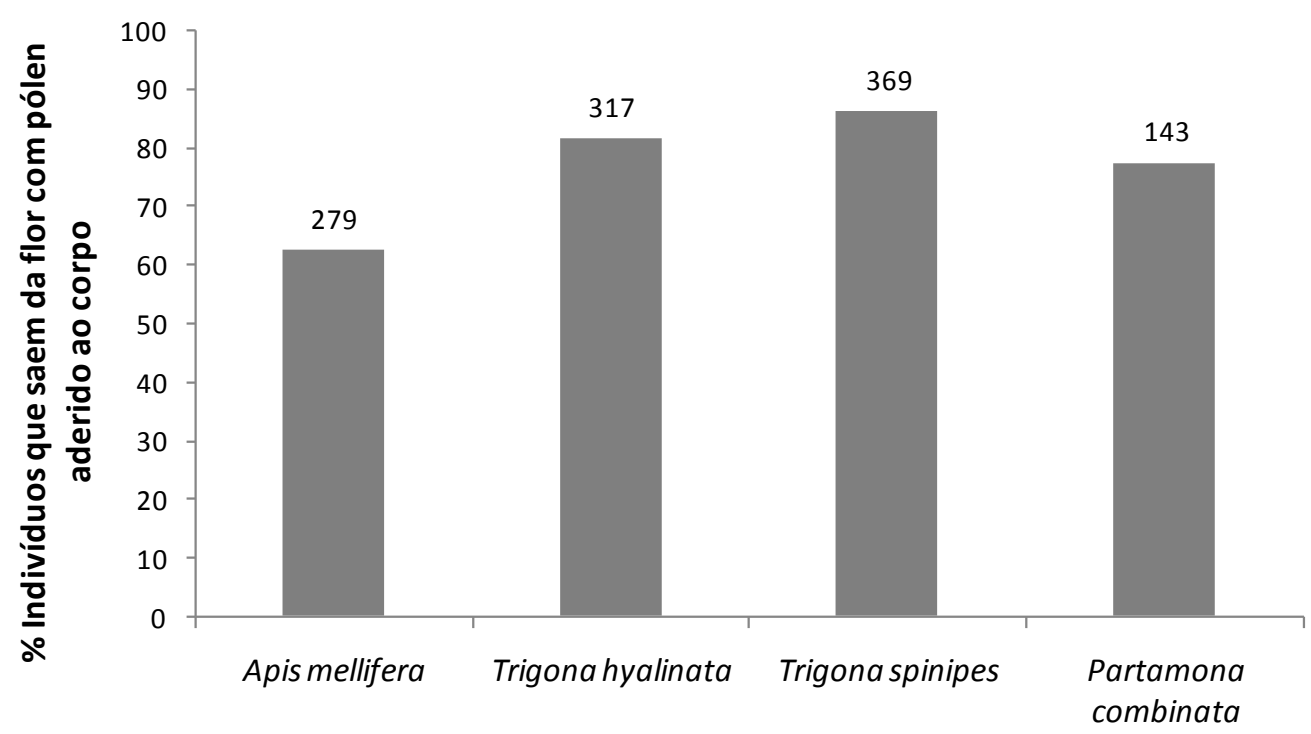

Visitante floral

Figura 2.10 - Indivíduos das espécies de abelhas mais abundantes (em porcentagem) que saem da flor de abobrinha Cucurbita pepo com grãos de pólen aderidos ao corpo. As observações foram realizadas em áreas orgânicas e convencionais de produção, DF, em 2014. O número total de indivíduos observados para cada espécie encontra-se acima das barras.

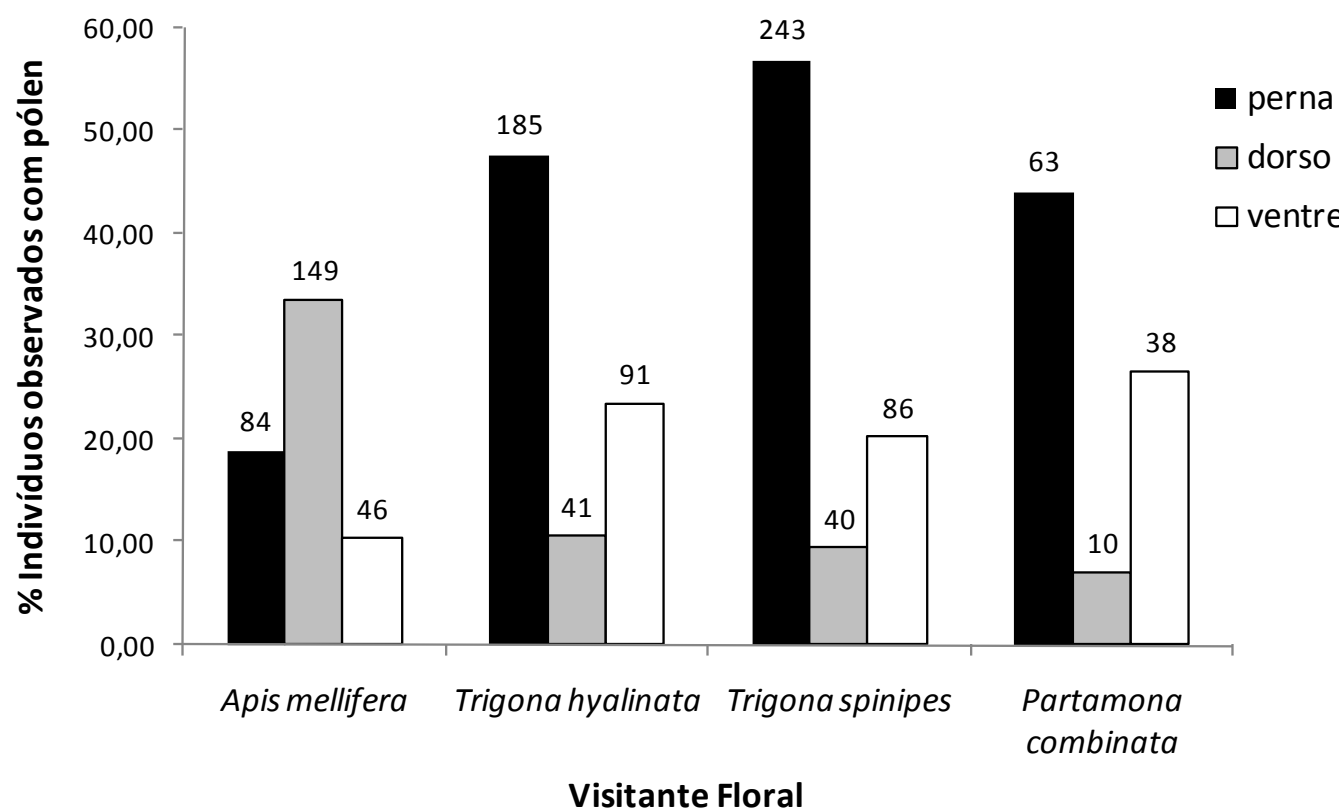

Figura 2.11 - Indivíduos das espécies de abelhas mais abundantes (em porcentagem) que saem da flor de abobrinha C.pepo com grãos de pólen aderidos em diferentes partes do corpo (perna, dorso e ventre). As observações foram realizadas em áreas orgânicas e convencionais, DF, em 2014. O número total de indivíduos observados para cada espécie encontra-se acima das barras. 


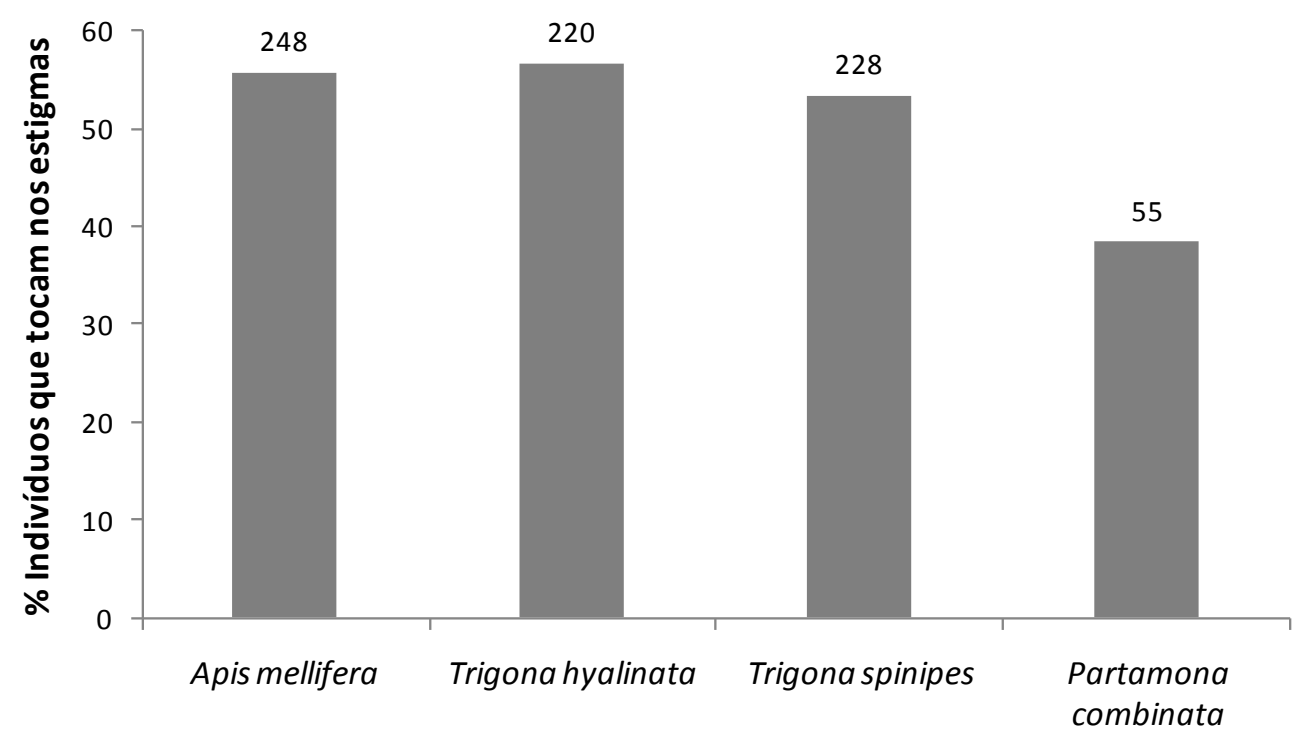

Visitante Floral

Figura 2.12 - Porcentagem de indivíduos das espécies de abelhas mais abundantes que tocam os estigmas das flores de Cucurbita pepo durante o forrageamento. As observações foram realizadas em áreas orgânicas e convencionais de produção, DF, em 2014. Os números acima das barras são os números totais de indivíduos observados.

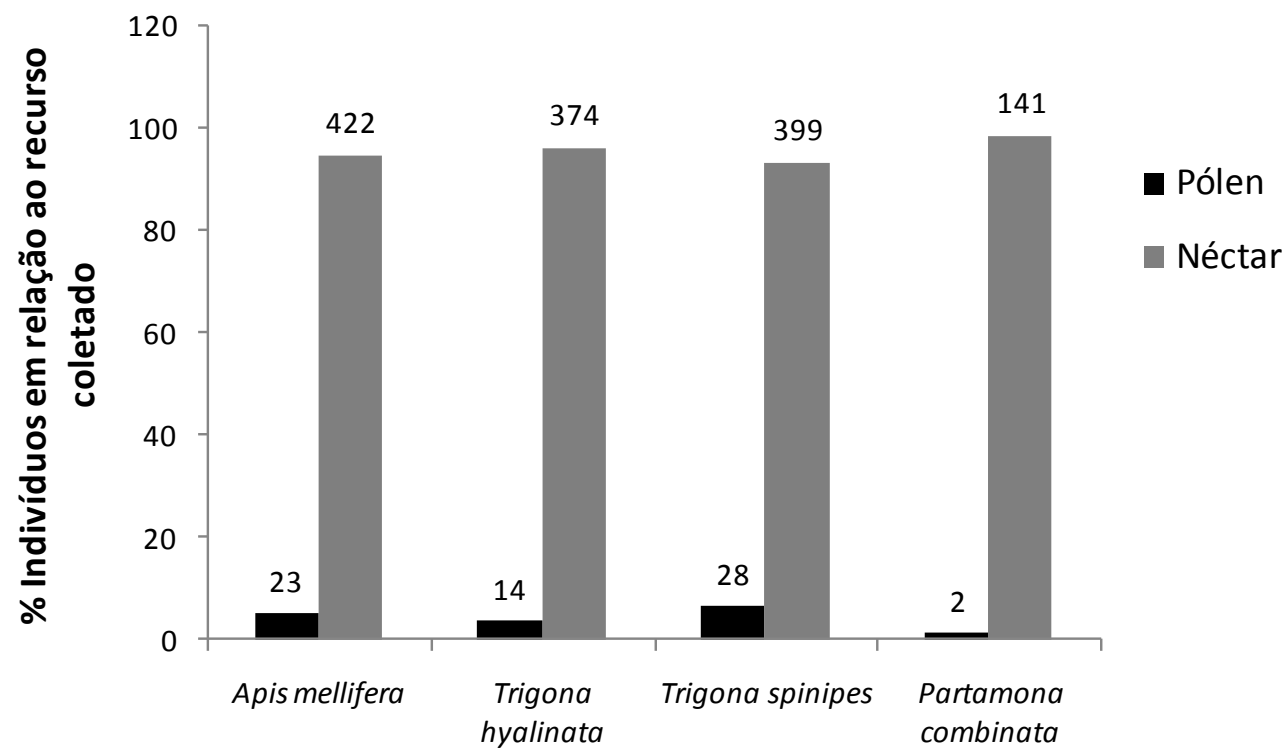

\section{Visitante floral}

Figura 2.13 - Indivíduos das espécies de abelhas mais abundantes (em porcentagem) visitantes florais de Cucurbita pepo em relação ao recurso coletado (pólen e/ou néctar). As observações foram realizadas em áreas orgânicas e convencionais de produção, DF, em 2014. O número total de indivíduos observados para cada espécie encontra-se acima das barras. 
As operárias de Partamona combinata entraram em contato com os estigmas em apenas cerca de 38,46\% dos indivíduos observados (Figura 2.12), saíam das flores com pólen aderido ao corpo principalmente às pernas e ao ventre (Figura 2.11), e visitavam mais as flores femininas $\left(\chi^{2}=8.56\right.$; g.l 1 ; $p=0.003$; Figura 2.9).

\subsection{Avaliação do déficit de polinização}

Em todas as propriedades estudadas, tanto no sistema convencional quanto no orgânico, $100 \%$ das flores de Cucurbita pepo marcadas e que receberam visitação livre das abelhas frutificaram (Tabela 2.1).

Já em relação à qualidade dos frutos, o peso diferiu entre as propriedades $(F(6,203)=27.97, \quad \mathrm{p}<0.001)$, enquanto que o diâmetro e o comprimento não apresentaram diferenças significativas (Tabela 2.4). A propriedade convencional (C1) foi a que apresentou os menores valores médios para as características dos frutos avaliadas.

Tabela 2.1 - Características agronômicas (peso, diâmetro e comprimento) dos frutos de Cucurbita pepo L. resultantes de flores femininas que permaneceram abertas a visitação de abelhas silvestres em propriedades orgânicas e convencionais, localizadas no Distrito Federal, em 2014. Letras diferentes na coluna indicam diferenças estatísticas de acordo com a Análise de Variância $(\mathrm{F}(6,203)=27.97, \mathrm{p}<0.001)$.

\begin{tabular}{ccccc}
\hline Propriedade* $^{*}$ & Peso (g) & $\begin{array}{c}\text { Diâmetro } \\
(\mathbf{c m})\end{array}$ & $\begin{array}{c}\text { Comprimento } \\
(\mathbf{c m})\end{array}$ & \%Frutificação \\
\hline O1 & $344,67 \pm 101,57 \mathrm{a}$ & $5,70 \pm 1,24$ & $17,76 \pm 3,75$ & 100 \\
O2 & $221,73 \pm 67,09 \mathrm{bc}$ & $4,77 \pm 0,68$ & $17,37 \pm 1,88$ & 100 \\
O3 & $216,40 \pm 76,64 \mathrm{bc}$ & $5,62 \pm 0,58$ & $18,53 \pm 3,32$ & 100 \\
C1 & $121,27 \pm 78,97 \mathrm{~b}$ & $3,22 \pm 1,62$ & $12,80 \pm 6,32$ & 100 \\
C2 & $204,00 \pm 92,13 \mathrm{~cd}$ & $4,5 \pm 0,84$ & $16,8 \pm 3,16$ & 100 \\
C3 & $354,83 \pm 145,98 \mathrm{a}$ & $5,24 \pm 1,37$ & $21,15 \pm 5,33$ & 100 \\
C4 & $145,80 \pm 79,95 \mathrm{~b}$ & $3,84 \pm 0,97$ & $14,71 \pm 3,39$ & 100 \\
\hline
\end{tabular}

*O=sistema de produção orgânico; $\mathrm{C}=$ sistema de produção convencional 


\section{DISCUSSÃO}

Os dados do presente trabalho indicam que Apis melifera, Trigona spinipes e Trigona hyalinata podem ser consideradas polinizadoras potenciais para a cultura de $C$. pepo no Distrito Federal. A possível eficiência da espécie A. mellifera como polinizadora da aboboreira se dá tanto por sua abundância e atividade na visitação às flores, que se inicia nas primeiras horas da manhã e se estende até o momento em que as flores começam a fechar, quanto por sua eficiência na transferência do pólen para o estigma, já que a porcentagem de visitas em que estas abelhas tocam os estigmas é alta $(55,73 \%)$. As mesmas características citadas acima para A. mellifera também se aplicam para as espécies de Trigona; que tiveram uma alta abundância nas flores de C. pepo, além dos indivíduos apresentarem pólen em seus corpos e entrarem em contato com os estigmas na maioria das visitas.

Vários estudos realizados comprovaram que o número de visitas realizadas pelas espécies de abelhas Trigona spinipes e Apis mellifera nas flores de Cucurbita spp., juntamente com o tamanho corporal e a quantidade de grãos de pólen aderido aos seus corpos foram características que as definiram como polinizadores da cultura, uma vez que esse conjunto de características resultou no aumento da frutificação (Tepedino, 1981; Alves, 2000; Nicodemo \& Nogueira-Couto, 2002). Um estudo realizado em São Paulo, também verificou que as abelhas Trigona spinipes e A. mellifera foram os principais polinizadores de C. pepo (Cardoso, 2003).

As flores de C. pepo, assim como as de outras espécies de Cucurbita, têm duração curta, mostrando que o tempo para que as flores femininas sejam fecundadas é limitado, precisando de polinizadores eficientes. A dinâmica observada para a antese e fechamento das flores de $C$. pepo é similar à observada em trabalhos préviose em outras espécies de Cucurbita. A antese das flores de C. moschata no sul do Brasil (Santa Catarina), ocorreu entre 06:30 h e 07:30 h e o fechamento entre 12:00h e 14:00h (Minussi, 2003). Outros autores observaram que as flores de C. mixta se abrem às 06:00h e fecham às 13:00h (Lattaro \& Malerbo-Souza, 2006). Trabalhos realizados em Siena, Itália, constataram que tanto as flores femininas como as masculinas de C. pepo abrem-se entre 05:00 h e 06:00 h e fecham-se entre 11:30 h e 12:30 h do mesmo dia (Nepi \& Pacini, 1993; Nepi et al., 2001).

A maior visitação das espécies de abelhas às flores femininas, observada neste estudo, pode estar relacionada à produção de néctar, pois as flores pistiladas (femininas) 
produzem néctar mais concentrado e em maior quantidade que as flores estaminadas (masculinas) (Nepi \& Pacini, 1993; Nepi et al., 2001).

As visitas de A. mellifera em ambos os sistemas de produção foi mais frequente no início da manhã sendo substituída, posteriormente, por Trigona spp. Resultados similares foram reportados por Nicodemo (2002) para cultivos de Cucurbita moschata em São Paulo, onde A. mellifera ocorreu às 8:00 h e Trigona spp. das 9:00 h às 10:00 h. Estes resultados sugerem que, na polinização de aboboreira, as abelhas desenvolvem uma estratégia de forrageamento que pode reduzir a competição entre as espécies.

Entretanto, o pico de visitação de A. mellifera no início da manhã pode ter sido influenciado pelas poucas espécies de plantas com flores abertas presentes neste período (observação pessoal, não registrada), sendo $C$. pepo um dos poucos recursos disponíveis. Após outras flores abrirem, provavelmente ocorreu um deslocamento para fontes de alimento nas áreas adjacentes. Em uma das coletas realizadas na propriedade convencional (C1), no mês de julho, em flores de C. pepo, a espécie de planta Sonchus oleraceus L. (serralha) estava florida próxima ao cultivo, e foram observados vários indivíduos de A. mellifera visitando as flores de S. oleraceus assim que essas se abriam a partir das 8:30 h, e após o fechamento às 09:30h, os indivíduos de A. mellifera voltavam a visitar as flores de $C$. pepo com uma maior frequência. Esta observação já tinha sido relatada por Passarelli (2002) que verificou a atraçãoque a flora circundante ao cultivo de $C$. máxima exerce sobre a visita de A. mellifera. Este autor verificou que as famílias Asteraceae e Fabaceae exercem uma influência negativa na polinização de C. maxima. Serra (2007) também observou que as operárias de A. mellifera visitavam Sinapis arvensis L. (mostarda-dos-campos) em inflorescências de Bidens pilosa L. (picão) e S. oleraceus (serralha), logo após visitarem flores de C. moschata. Essas espécies de crescimento espontâneo, comumente chamadas de invasoras ou ervas daninhas, geralmente estão presentes nas áreas circundantes às áreas de cultivo.

Em um estudo realizado em pradarias, as espécies de plantas que possuíam uma área total de indivíduos em florescimento maior que as demais espécies receberam significativamente mais visitas das abelhas, indicando que a abundância de flores desempenha um importante papel na distribuição de visitantes florais dentro de uma área (Weiner et al., 2011). Deste modo, é importante o conhecimento sobre a fenologia de cada cultura e do grau de dependência dos polinizadores, a fim de propor práticas agrícolas que favoreçam a presença dos polinizadores nas áreas de cultivo, para que não haja um comprometimento do rendimento das culturas.Entre outras práticas agrícolas o 
manejo das plantas espontâneas pode ser de grande importância para a eficiente polinização da aboboreira.

Além de apresentarem horários de pico de forrageamento diferentes, as principais espécies de visitantes florais registradas neste estudo mostraram diferentes padrões de uso dos recursos encontrados nas flores de aboboreira. A. mellifera utilizou as flores para coleta de néctar e pólen e Trigona spp. para coleta exclusiva de néctar.

As abundâncias de cada espécie de abelha juntamente com o comportamento favorável à polinização garantiram níveis de produtividade adequados para a cultura da aboboreira avaliada no presente estudo.

Um estudo desenvolvido com C. moschata, encontrou ausência de frutificação em flores de abóbora que receberam apenas uma visita da abelha $T$. spinipes (Serra, 2007). No mesmo trabalho o autor relata que esta ausência de frutificação está associada a uma carga de pólen insuficiente nas operárias e a maior dificuldade dessa espécie em tocar o estigma devido ao seu pequeno tamanho corporal. Nesse caso, segundo Serra (2007), ao permitir a visita de apenas um indivíduo à flor, eliminou-se o comportamento de visita em grande número, que é um padrão de forrageamento característico de $T$. spinipes.

O comportamento agressivo e monopolista (forrageando em grande número) de T. spinipes, observado neste trabalho, já tinha sido relatado anteriormente em flores de maracujá e de C. moschata (Almeida \& Laroca, 1988; Sazima \& Sazima, 1989; Serra, 2007) e também para a espécie T. hyalinata (Serra, 2007).

A porcentagem de frutificação de $100 \%$ verificada em todas as propriedades no presente estudo indica que não existe um déficit de polinizadores nas regiões estudadas.

Um trabalho conduzido em Alagoas, no Brasil, avaliando a qualidade dos frutos, utilizou as mesmas medidas adotadas no presente estudo, incluindo o número de sementes, porém constatou que a polinização manual foi tão eficaz quanto à polinização livre, não havendo diferenças estatísticas para os parâmetros de qualidade dos frutos avaliadas (Mélo, 2010). O mesmo autor encontrou uma baixa frutificação em flores de C. moschata visitadas uma a três vezes por T. spinipes, quando comparada à frutificação e qualidade do fruto obtida após quatro visitas e livre (sem restrições de visitas), sugerindo que este resultado poderia estar associado a uma carga insuficiente de pólen nas operárias, seja pelo hábito de removerem o pólen ou por terem visitado poucas flores masculinas antes de visitarem as flores femininas. 
Segundo Freitas e Paxton (1996), para ser classificado como polinizador de uma espécie vegetal, é preciso que o potencial polinizador seja: atraído pelas flores da cultura; que apresente fidelidade àquela espécie; que possua tamanho e comportamentos adequados para remover pólen dos estames e depositá-los nos estigmas, que transporte em seu corpo grande quantidade de pólen viável e compatível e que visite as flores quando os estigmas apresentam boa receptividade. Características e comportamentos observados neste trabalho para as espécies de Trigona e A. mellifera.

Portanto, o potencial de frutificação da cultura dependerá não só da produção de flores, mas também do processo de polinização e o comportamento das espécies de abelhas ao visitarem as flores masculinas e femininas. Diante dos resultados obtidos, considera-se que as espécies polinizadoras potenciais de C. pepo na região seriam Apis mellifera, Trigona spinipes e Trigona hyalinata. A identificação, criação e preservação desses insetos são relevantespara garantir bons níveis de produção para esta cultura que, obrigatoriamente, necessita de vetores bióticos que assegurem sua polinização. 


\section{CONSIDERAÇÕES FINAIS}

- A riqueza total de abelhas visitantes florais de Cucurbita pepo foi de 35 espécies, representadas pelas famílias Apidae e Halictidae. As quatro espécies mais abundantes foram: Apis mellifera, Trigona spinipes, Trigona hyalinata e Partamona combinata.

- O tipo de manejo influencia a presença de abelhas, pois a abundância foi significativamente maior para o sistema orgânico em relação ao convencional, porém a riqueza não diferiu entre os dois sistemas.

- As características da paisagem tiveram pouco impacto sobre a abundância de abelhas, entretanto a presença de áreas com vegetação nativa no entorno das fazendas mostrou uma relação diretamente proporcional com a riqueza de espécies.

- Os agentes polinizadores mais importantes de Cucurbita pepo em propriedades orgânicas e convencionais de produção no DF, foram: Apis mellifera, Trigona spinipes e Trigona hyalinata.

- Estas espécies apresentaram nas áreas estudadas, períodos de forrageamento que podem diminuir a competição por recursos entre A. mellifera e Trigona spp. o que favorece a polinização da cultura da aboboreira.

- As propriedades de produção de hortaliças, orgânicas e convencionais, localizadas no Distrito Federal não apresentaram déficit de polinizadores na cultura da aboboreira Cucurbita pepo para o período que foi conduzido o experimento.

- Embora os resultados mostrem uma eficiente ação de insetos polinizadores na cultura de aboboreira no DF alguns aspectos dos sistemas de cultivo merecem ser considerados para evitar impacto nas comunidades de abelhas polinizadoras, são estes: 1 - manutenção de áreas com vegetação nativa no entorno das áreas de produção e 2 evitar a aplicação de agrotóxicos nos períodos de maior atividade de forrageamento das abelhas (desde o amanhecer até 12:00 h).

- Adicionalmente pesquisas futuras deveriam orientar-se a estabelecer a influência de plantas espontâneas ou nativas no forrageamento dos polinizadores de aboboreira a fim de estabelecer medidas de manejo para estas espécies de plantas.

- Para uma melhor avaliação do déficit de polinização na cultura, outros experimentos utilizando outros parâmetros de qualidade dos frutos, visitantes florais e análise da paisagem poderiam ser avaliados. 
- Outro aspecto relevante para orientar trabalhos futuros refere-se a pesquisas direcionadas a estabelecer se a diferença de horários de pico de visitação entre abelhas nativas e introduzidas (A. mellifera) devem-se a estratégias para evitar a competição ou a características biológicas das mesmas (por exemplo, as espécies nativas somente são ativas a partir de uma faixa de temperatura superior às introduzidas).

\section{REFERÊNCIAS BIBLIOGRÁFICAS}

Aizen, M.A.; Harder, L.D. The Global Stock of Domesticated Honey Bees Is Growing Slower Than Agricultural Demand for Pollination. Current Biology, 19(11):915-918, 2009.

Aizen, M.A., Garibaldi, L.A., Cunningham, S.A., and Klein, A.M. How much does agriculture depend on pollinators? Lessons from long-term trends in crop production. Ann. Bot., 2009.

Almeida, M. C.; Laroca, S. Trigona spinipes (Apidae, Meliponinae): taxonomia, bionomia e relações tróficas em áreas restritas. Acta Biológica Paranaense. 17(1, 2, 3, 4): 67-108, 1988.

Alves, M. das G. V. 2000. Polinização por abelhas (Apis mellifera L.) e produção de pólen e néctar em aboboreira (Cucurbita pepo L.). Tese de Doutorado. Universidade de São Paulo, Ribeirão Preto. 120p.

Araujo, E. D.; Costa, M.; Chaud-Netto, J.; Fowler, H.G. Body size and flight distance in stingless bees (Hymenoptera:Meliponini): inference of flight range and possible ecological implications. Brazilian Journal of Biology, 64 (3B):563-568, 2004.

Ávila, C. J. 1987. Polinização e polinizadores na produção de frutos e sementes híbridas de abóbora (Cucurbita pepo L. var. melopepo). Dissertação de Mestrado. Universidade Federal de Viçosa, Minas Gerais. 56p.

Batary, P., Baldi, A., Kleijn, D. \& Tscharntke, T. Landscape-moderated biodiversity effects of agri-environmental management: a meta-analysis. Proc. R. Soc. Biol. Sci., 278, 1894-1902, 2011.

Blüthgen N.; Klein, A.M. Functional complementarity and specialisation: The role of biodiversity in plant-pollinator interactions. Basic and Applied Ecology, 12:282-291, 2011.

Bogdanski, A. 2005. The influence of landscape context on flower visitation and pollination of Passiflora edulis Sims f. flavicarpa Degener in Central Bahia, Brazil. Department of Animal Ecology and Tropical Biology, University of Wurzburg, Wurzburg. 
Bommarco, R.; Marini, L.; Vaissière, B. E. Insect pollination enhances seed yield, quality, and market value in oilseed rape. Oecologia, 169(4):1025-32,2012.

Brito, A.B. 2005. Influência de tipos de bandejas, estádios de crescimento e adubação química, no desempenho de mudas de abobrinha (Cucurbita pepo 1.). Dissertação de Mestrado. Universidade Federal do Piauí - PI. 43p.

Brosi, B.J., Armsworth, P.R. \& Daily, G.C. Optimal design of agricultural landscapes for pollination services. Conserv. Lett., 1, 27-36, 2008.

Canto-Aguilar, M.A. \& Parra-Tabla, V. Importance of conserving alternative pollinators: assessing the pollination efficiency of the squash bee, Peponapis limitaris in Cucurbita moschata (Cucurbitaceae). Journal of Insect Conservation, 4:203-210, 2000.

Cardoso, A. I. I. Produção e qualidade de sementes de abobrinha "Piramoita" em resposta à quantidade de pólen. Bragantia, 62 (1): 47 - 52, 2003.

Coffey, M.F.; Breen J. Seasonal variation in pollen and nectar sources of honey bees in Ireland. Journal of Apicultural. Research, 36:63-76, 1997.

Colwell, R. K. 2013. EstimateS, Version 9.1: Statistical Estimation of Species Richness and Shared Species from Samples. Persistent URL <purl.oclc.org.estimates>.

Crepet, W. L. Timing in the evolution of derived floral characters: upper cretaceous (turonian) taxa with tricolpate and tricolpate-derived pollen. Review of Palaeobotany and Palynology, 90(3-4):339-359, 1996.

Darolt, M.R. Cenário internacional: situação da agricultura orgânica em 2003. Disponível em: <http:// www.planetaorganico.com.br>. Acesso em: 01 out. 2013.

Dively, G.P.; Kamel, A. Insecticide Residues in Pollen and Nectar of a Cucurbit Crop and Their Potential Exposure to Pollinators. J. Agric. Food Chem., 2012, 60 (18):44494456, 2012.

Eardley, C.; Roth, D.; Clarke, J.; Buchmann, S.; Gemmil, B. Pollinators and pollination: a resource book for policy and practice. $1^{\circ}$ edição, Editora Pretoria, África do Sul: Iniciativa Africana de Polinizadores, 2006. 77p.

Eltz, T.; Bruhl, C.A.; Imiyabir, Z.; Linsenmair, K.E. Nesting and nest trees of stingless bees (Apidae:Meliponini) in lowland dipterocarp forests in Sabah, Malaysia, with implications for forest management. Forest Ecology and Management., 172, 301-313, 2003.

Faria, L. R. R.; Gonçalves, R. B. Abiotic correlates of bee diversity and composition along eastern Neotropics. Apidologie, 44(5): 547-562, 2013.

Fahrig, L.; Baudry, J.; Brotons, L.; Burel, F.G.; Crist, T.O.; Fuller, R.J.; Sirami, C.; Siriwardena, G.M.; Martin, J.L. Functional landscape heterogeneity and animal biodiversity in agricultural landscapes. Ecology letters, 14(2):101-112, 2011. 
Ferreira, J.; Pardini, R.; Metzger, J.P.; Fonseca, C.R.; Pompeu P.S.; Sparovek, G.; Louzada, J. Towards environmentally sustainable agriculture in Brazil: Challenges and opportunities for applied ecological research. Journal of Applied Ecology, 49:535-541, 2012.

Filgueira, F.A.R. Novo manual de olericultura. $2^{\circ}$ edição, Viçosa-MG, Editora UFV, 2003.

Freitas, B.M.; Pinheiro, J.N. Efeitos sub-letais dos pesticidas agrícolas e seus impactos no manejo de polinizadores dos agroecossistemas brasileiros. Oecologia Australis, 14: 282-298, 2010.

Freitas, B. M. Uso de programas racionais de polinização em áreas agrícolas. Revista Mensagem Doce, 46: 1-6, 1998a.

Freitas, B. M.; Paxton, R. J. The role of wind and insects in cashew (Anacardium occidentale) pollination in NE Brazil. Journal of Agricultural Science, 126: 319-326, 1996.

Free, J. B. 1993. Insect pollination of crops. $2^{\text {a }}$ ed. Academic Press, Londres. 684p.

Garibaldi, L.A.; Steffan-Dewenter, I.; Winfree, R.; Aizen, M.A.; Bommarco, R.; Cunningham, A.S.; Kremen, C.; Carvalheiro, L.G.; Harder, L.D.; Afik, O.; Bartomeus, I.; Benjamin, F.; Boreux, V.; Cariveau, D.; Chacoff, N.P.; Dudenho“ffer, J.H.; Freitas, B.M.; Ghazoul, J.; Greenleaf, S.; Hipólito, J.; Holzschuh, A.; Howlett, B.; Isaacs, R.; Javorek, S.K.; Kennedy, C.M.; Krewenka, K.; Krishnan, S.; Mandelik, Y.; Mayfield, M.M.; Motzke, I.; Munyuli, T.; Nault, B.A.; Otieno, M.; Petersen, J.; Pisanty, G.; Potts, S.G.; Rader, R.; Ricketts, T.A.; Rundlo"f, M.; Seymour, C.L.; Schu“epp, C.; Szentgyo"rgyi, H.; Taki, H.; Tscharntke, T.; Vergara, C.H.; Viana, B.F.; Wanger, T.C.; Westphal, C.; Williams, N.; Klein, A.M. Wild pollinators enhance fruit set of crops regardless of honey bee abundance. Science, 339:1608-1611, 2013.

Gallai, N., Salles, J.M., Settele, J., Vaissière, B.E. Economic valuation of the vulnerability of world agriculture confronted with pollinator decline. Ecological Economics, 68 (3): 810-821, 2009.

Gathmann, A.; Tscharntke, T. Foraging ranges of solitary bees. Journal of Animal Ecology, 71: 757-764, 2002.

Gemmill-Herren, B.; Ochieng, A. O. Role of native bees and natural habitats in eggplant (Solanum melongena) pollination in Kenya. Agriculture, Ecosystems and Environment, 127:31-36, 2008.

Greenleaf, S. S.; Kremen, C. Wild bee species increase tomato production and respond differently to surrounding land use in Northern California. Biological Conservation, 133(1):81-87, 2006.

Heard, T.A. The role of stingless bees in crop pollination. Annu. Rev. Entomol., 44, 183-206, 1999. 
Hoekstra, J.M., Boucher, T.M., Ricketts, T.H. \& Roberts, C. Confronting a biome crisis: global disparities of habitat loss and protection. Ecol. Lett., 8:23-29, 2005.

Hurd, P. D. Jr.; Linsley, E.G.; Whitaker, A. E. Squash and gourd bees (Peponapis, Xenoglossa) and the origin of the cultivated Cucurbita. Evolution, 25:218-234, 1971.

Heard, T.A. The role of stingless bees in crop pollination. Annu. Rev. Entomol., 44: 183-206, 1999.

Holzschuh, A.; Steffan-Dewenter, I.; Kleijn, D.; Tscharntke, T. Diversity of flowervisiting bees in cereal fields: effects of farming system, landscape composition and regional context. Journal of Applied Ecology, 44:41-49, 2007.

Holzschuh, A., Steffan-Dewenter, I. \& Tscharntke, T. Agricultural landscapes with organic crops support higher pollinator diversity. Oikos, 117:354-361, 2008.

Imperatriz-Fonseca, V. L. \& Kleinert, A. M. P. As abelhas e as iniciativas internacionais de polinizadores. Revista de tecnologia e ambiente, 10(2):45-58, 2004.

Julier, H. E.; Roulston, T. H. Wild bee abundance and pollination service in cultivated pumpkins: farm management, nesting behavior and landscape effects. Journal of economic entomology, 102(2):563-573, 2009.

Kennedy, C.M., Lonsdorf, E., Neel, M.C., Williams, N.M., Ricketts, T.H., Winfree, R., Bommarco, R., Brittain, C., Burley, A.L., Cariveau, D., Carvalheiro, L.G., Chacoff, N.P., Cunningham, S.A., Danforth, B.N., Dudenhöffer, J.H., Elle, E., Gaines, H.R., Gratton, C., Garibaldi, L.A., Holzschuh, A., Isaacs, R., Javorek, S.K., Jha, S., Klein, A.M., Krewenka, K.,Mandelik, Y., Mayfield, M.M., Morandin, L., Neame, L.A., Otieno, M., Park, M., Potts, S., Rundlöf, M., Saez, A., Steffan-Dewenter, I., Taki, H., Viana, B.F., Westphal, C., Wilson, J.K., Greenleaf, S.S.; Kremen, C. A global quantitative synthesis of local and landscape effects on wild bee pollinators in agroecosystems. Ecology Letters, 16 (5):584-599, 2013.

Klein, A.M., Mueller, C.M., Hoehn, P., Kremen, C. Understanding the role of species richness for pollination services. In: Biodiversity, Ecosystem Functioning, and Human Wellbeing: An Ecological and Economic Perspective (eds Bunker, D., Hector, A., Loreau, M., Perrings, C. \& Naeem, S.). Oxford University Press, Oxford, 195-208, 2009.

Klein, A.M.; Vaissière, B. E.; Cane, J. H.; Steffan-Dewenter, I.; Cunningham, S. A.; Kremen, C.; Tscharntke, T. Importance of pollinators in changing landscapes for world crops. Proceedings. Biological sciences / The Royal Society, 274(1608):303-313, 2007.

Klein, A., Steffan-Dewenter, I. \& Tscharntke, T. Fruit set of highland coffee increases with the diversity of pollinating bees. Proc. R. Soc. Lond. Ser. B, 270, 955-961, 2003 a.

Kremen, K.; Williams, N. M.; Aizen, M.; Gemmill-Herren, B. et al. Pollination and other ecosystem services produced by mobile organisms: a conceptual framework for the effects of land-use change. Ecology Letters, 10: 299-314, 2007. 
Kremen, C., Williams, N. M., Bugg, R. L., Fay, J. P. \& Thorp, R.W. The area requirements of an ecosystem service: crop pollination by native bee communities in California. Ecology Letters, 7: 1109-1119, 2004.

Kremen, C., Williams, N.M. \& Thorp, R.W. Crop pollination from native bees at risk from agricultural intensification. Proc. Natl Acad. Sci. USA, 99: 16812-16816, 2002 b.

Krug, C.; Alves-dos-Santos, I.; Cane, J. Visiting bees of Cucurbita flowers (Cucurbitaceae) with emphasis on the presence of Peponapis fervens Smith (Eucerini Apidae) - Santa Catarina, Southern Brazil. Oecologia Australis, 14: 128-139, 2010.

Krug, C. 2007. A comunidade de abelhas (Hymenoptera - Apiformes) da Mata com Araucária em Porto União - SC e abelhas visitantes florais da aboboreira (Cucurbita L.) em Santa Catarina, com notas sobre Peponapis fervens (Eucerini, Apidae). Universidade do Extremo Sul Catarinense - SC. 127p.

Laroca, S. Ecologia: princípios e métodos. Petrópolis: Vozes, 1995. 197p.

Lataro, L. H. \& Malerbo-Souza, D. T. Polinização entomófila em abóbora caipira, Cucurbita mixta (Cucurbitaceae). Acta Scientiarum Agronomy, 28(4):563-568, 2006.

Losey, J. E.; Vaughan, M. The Economic Value of Ecological Services Provided by Insects. BioScience, 56 (4): 311-326, 2006.

Macias-Macias, O.; Chuc, J.; Ancoa-Xiu, P.; Cauich, O.; Quezada-Euán, J.J.G. Contribution of native bees and Africanized honey bees (Hymenoptera:Apoidea) to Solanaceae crop pollination in tropical México. Journal of Applied Entomology, 133(6):456-465, 2009.

Mélo, D.B.M.; Santos, A.L.A.; Beelen, R.N.; Lira, T.S.; Almeida, D.A.S.; Lima, L.P. Polinização da abóbora (Curcubita moschata d.): um estudo sobre a biologia floral e visitantes florais no município de Satuba-Al. Revista Científica do IFAL, 1(1):47-57, 2010.

Meehan, T.D., Werling, B.P., Landis, D.A., Gratton, C. Agricultural landscape simplification and insecticide use in the Midwestern United States. Proc. Natl Acad. Sci. USA, 108:11500-11505, 2011.

Michelbacher. A. E.; Smith, R. F.; Hurd, P. D. Jr. Pollination of squashes, gourds and pumpkins. California Agriculture, 1: 2-4, 1964.

Michener, C. D. The bees of the world, 1. ed. Baltimore:The Johns Hopkins University Press, 2000.

Milfont, M. O.; Rocha, E.E.M.; Lima, A.O.N.; Freitas, B.M. Higher soybean production using honeybee and wild pollinators, a sustainable alternative to pesticides and autopollination. Environmental Chemistry Letters, 11(4):335-341, 2013. 
Minussi, L. C. 2003. Potencial de abelhas nativas polinizadoras para a agricultura intensiva no município de Santa Rosa do Sul (SC). Dissertação de Mestrado. Universidade do Extremo Sul Catarinense. 77p.

MMA (2012) Ministério do Meio Ambiente. Relatório técnico de monitoramento do desmatamento no bioma cerrado, 2002 a 2008: dados Revisados, http://siscom.ibama.gov.br/monitorabiomas/cerrado/Relatorio\%20tecnico_Monitoramen to\%20Desmate_Bioma\%20Cerrado_CSR_REV.pdf.

Montemor, K. A.; Souza, T. M. Biodiversidade de polinizadores e biologia floral em cultura de berinjela (Solanum melongena). Zootecnia Trop., 27(1):97-103, 2009.

Morandin, L.A., Winston, M.L., Abbott, V.A. \& Franklin, M.T. Can pastureland increase wild bee abundance in agriculturally intense areas? Basic Appl. Ecol., 8:117$124,2007$.

Nepi, M.; Guarnieri, M. \& Pacini, E. Nectar secretion, reabsorption, and sugar composition in male and female flowers of Cucurbita pepo. International Journal of Plant Sciences, 162 (2): 353- 358, 2001.

Nepi, M.; Pacini, E. Pollination, pollen viability and pistil receptivity in Cucurbita pepo. Annals of Botany, 72: 527-536, 1993.

Nicodemo, D. Biologia floral e polinização entomófila em moranga (Cucurbita maxima Duch, var. exposição). Monografia - Faculdade de Ciências Agrárias e Veterinárias/Universidade Estadual Paulista. Jaboticabal, 2002.

Nicodemo, D.; Nogueira-Couto, R. H. N. Biologia floral, insetos visitantes e o efeito das visitas das abelhas Apis mellifera nas flores de moranga (Cucurbita maxima Duch.) quanto a produção de frutos. In: Congresso Brasileiro de Apicultura, 14 ${ }^{\circ}$, Campo Grande, Anais..., Campo Grande, p. 4, 2002.

Nogueira-Couto, R. H.; Pereira, J. M. S.; Couto, L. A. Estudo da polinização entomófila em Cucurbita pepo (abóbora italiana). Científica, 18(1):21-27, 1990.

Orozco, L.A. 1997. Estudio de la incidencia de enfermedades fungosas em tres etapas fenologicas y su efecto en el rendimiento de tres híbridos de zucchini (Cucurbita pepo c.v.zucchini), santo tomas milpas altas sacatepequez. Universidad de San Carlos de Guatemala. 74p.

Ollerton, J.; Winfree, R.; Tarrant, S. How many flowering plants are pollinated by animals?. Oikos, 120(3):321-326, 2011.

Passarelli, L. L. Importância de Apis mellifera L. em la producción de Cucurbita maxima Duch. (Zapallito de tronco). Invest. Agr.: Prod. Prot. Veg., 17(1):5-13, 2002.

Patricio, G. B.; Grisolia, B. B.; Desuo, I. C.; Montagnana, P. C.; Brocanelli, F. G.; Gomig, E. G.; Campos, M. J. O. The importance of bees for eggplant cultivations (Hymenoptera: Apidae, Andrenidae, Halictidae). Sociobiology, Chico, Calif., US, 59(3):1037-1052, 2012. 
Perfecto, I. \& Vandermeer, J. The agroecological matrix as alternative to the landsparing/agriculture intensification model. Proc. Natl Acad. Sci. USA, 107, 5786-5791, 2010.

Petersen, J. D.; Reiners, S.; Nault, B. A. Pollination services provided by bees in pumpkin fields supplemented with either Apis mellifera or Bombus impatiens or not supplemented. PloS one, 8(7):e69819, 2013.

Potts, S.G., Biesmeijer, J.C., Kremen, C., Neumann, P., Schweiger, O. \& Kunin, W.E. Global pollinator declines: trends, impacts and drivers. Trends Ecol. Evol., 25:345-353, 2010a.

R Core Team (2013). R: A language and environment for statistical computing. R Foundation for Statistical Computing, Vienna, Austria. ISBN 3-900051-07-0, URL http://www.R-project.org/.

Ribeiro, J.F. \& Walter, B.M.T. As principais fitofisionomias do Bioma Cerrado. In Cerrado: ecologia e flora (S.M. Sano, S.P. Almeida \& J.F. Ribeiro, eds.). Embrapa Cerrados, Planaltina. p.151 -212, 2008.

Ricketts, T. H.; Lonsdorf, E. Mapping the margin: comparing marginal values of tropical forest remnants for pollination services. Ecological Applications, 23(5): 1113$1123,2013$.

Ricketts, T.H. Tropical forest fragments enhance pollinator activity in nearby coffee crops. Conserv. Biol., 18:1262-1271, 2004.

Rizzardo, R. A. G. 2007. O papel de Apis mellifera L. como polinizador da mamoneira (Ricinus communis L.): avaliação da eficiência de polinização das abelhas e incremento da produtividade da cultura. Dissertação (Mestrado em Zootecnia). Universidade Federal do Ceará, Fortaleza.

Sanderson, E.W., Jaiteh, M., Levy, M.A., Redford, K.H., Wannebo, A.V. \& Woolmer, G. The human footprint and the last of the wild. Bioscience, 52, 891-904, 2002.

Santos, A.J.S. Estimativas de riqueza em espécies. In. Cullen, J.R. L.; Valdares-Padua, C.; Rudran, R. Métodos de estudos em biologia da conservação e manejo da vida silvestre. Curitiba: UFPR, Fundação o Boticário, 2003.

Sazima, I.; Sazima, M. Mamangavas e irapuás (Hymenoptera, Apoidea): visitas, interações e conseqüências para polinização do maracujá (Passifloraceae). Revista Brasileira de Entomologia, 33(1):109-118, 1989.

Serra, B.D.V. 2007. Polinização entomófila de Cucurbita moschata Poir em áreas agrícolas nos municípios de Viçosa e Paula Cândido, Minas Gerais, Brasil. Dissertação de Mestrado. Universidade Federal de Viçosa - MG. 58p.

Silveira, F.A.; Melo, G.A.R.; Almeida, E.A.B. Abelhas Brasileiras. Sistemática e Identificação. 1.ed., Belo Horizonte: Ed. do autor, 2002. 253 p. 
Smith, A. A.; Bentley, M.; Reynolds, H. L. Wild Bees Visiting Cucumber on Midwestern U . S . Organic Farms Benefit from Near-Farm Semi-Natural Areas. Journal of Economic Entomology, 106 (1):97-106, 2013.

Souza, M.F.; Lúcio, A.D.; Storck, L.; Carpes, R.H.; Santos, P.M.; Siqueira, L. F. Tamanho da amostra para peso da massa de frutos na cultura da abóbora italiana em estufa plástica. Revista Brasileira de Agrociência, 8 (2):123-128, 2002.

Steffan-Dewenter, I.; Munzenberg, U.; Burger, C.; Thies, C. Tscharntke, T. Scaledependent effects of landscape context on three pollinator guilds. Ecology, 83(5): 1421$1432,2002$.

Steffan-Dewenter, I.; Kuhn, A. Honeybee foraging in differentially structured landscapes. Proc. R Soc. Lond. Ser. B Biol. Sci., 270, 569-575, 2003.

Tepedino, V. J. The pollination efficiency of the squash bee (Peponapis pruinosa) and the honeybee (Apis mellifera) on summer squash (Cucurbita pepo). Journal of the Kansas Entomological Society, 54: 359-377, 1981.

Tscharntke, T.; Klein, A.M.; Kruess, A.; Steffan-Dewenter, I.; Thies, C. Landscape perspectives on agricultural intensification and biodiversity - ecosystem service management. Ecology Letters, 8(8):857-874, 2005.

Vaissière, B.E.; Freitas, B.; E Gemmill-Herren, B. Protocol do detect and assess pollination deficits in crops: A handbook for its use. Global Action on Pollination Services for Sustainable Agriculture, FAO - Food and Agriculture Organization of the United Nations, Roma. 2010. 79 p.

Vaughan, M.; Skinner, M. 2008. Using Farm Bill Programs for Pollinator Conservation. Technical note 78. U.S. Department of Agriculture (USDA), Natural Resources Conservation Service (NRCS), NRCS National Plant Data, The Xerces Society Invertebrate Conservation, and S. Francisco State University.

Weiner, C. N. et al. Land use intensity in grasslands: Changes in biodiversity, species composition and specialisation in flower visitor networks. Basic and Applied Ecology, 12(4): 292-299, 2011.

Weiss, G.; Melo, G.A.R. 2007. Comportamento forrageiro de Peponapis fervens Smith (Hymenoptera, Apidae, Eucerini) em flores de Cucurbita (Cucurbitaceae). In: Congresso de Ecologia do Brasil, 8., Minas Gerais, 2007. Resumos.

Westerkamp, C.; Gottsberger, G. Review \& interpretation: diversity pays in crop pollination. Crop Science, 5(40):1209-1222, 2000.

Winfree, R.; Griswold, T.; Kremen, C. Effect of human disturbance on bee communities in a forested ecosystem. Conservation Biology, 21:213-223, 2007a.

Winfree, R. The conservation and restoration of wild bees, Annals of the New York Academy of Sciences, 1195: 69 - 197, 2010. 


\section{APÊNDICES}

Tabela 3.1 - Lista de produtos fitossanitários (data, produto e dosagem) aplicados nos cultivos de aboboreira (Cucurbita pepo) em propriedades orgânicas $(\mathrm{O} 1, \mathrm{O} 2$ e O3) e convencionais (C1, C2, C3 e C4) localizadas no Distrito Federal.

\begin{tabular}{|c|c|c|c|c|c|}
\hline Propriedade & $\begin{array}{c}\text { Data de } \\
\text { aplicação }\end{array}$ & Produto & Descrição & Grupo químico & $\begin{array}{c}\text { Dose (g ou mL/L } \\
\text { de solução) }\end{array}$ \\
\hline \multirow[t]{43}{*}{ O1 } & \multirow{3}{*}{$16 / 06 / 2014$} & Bokashi & Fertilizante orgânico & & $2000 \mathrm{~mL}$ \\
\hline & & Supa cobre & Micronutriente & & $40 \mathrm{~mL}$ \\
\hline & & Kumulus & Acaricida/Fungicida & Inorgânico & $40 \mathrm{~g}$ \\
\hline & \multirow{3}{*}{$23 / 06 / 2014$} & Bio Bok 7 & Fertilizante orgânico & & $2000 \mathrm{~mL}$ \\
\hline & & Supa cobre & Micronutriente & & $40 \mathrm{~mL}$ \\
\hline & & Kumulus & Acaricida/Fungicida & Inorgânico & $40 \mathrm{~g}$ \\
\hline & \multirow{3}{*}{$30 / 06 / 2014$} & Bio Bok 7 & Fertilizante orgânico & & $2000 \mathrm{~mL}$ \\
\hline & & Supa cobre & Micronutriente & & $40 \mathrm{~mL}$ \\
\hline & & Kumulus & Acaricida/Fungicida & Inorgânico & $40 \mathrm{~g}$ \\
\hline & \multirow{5}{*}{ 01/07/2014 } & Rocksil & Fertilizante orgânico & & $60 \mathrm{~g}$ \\
\hline & & Bio bok 3 & Fertilizante orgânico & & $5000 \mathrm{~mL}$ \\
\hline & & Cellerate & Micronutrientes & & $15 \mathrm{~mL}$ \\
\hline & & Extrato Pimenta & Inseticida/Nematicida & & $100 \mathrm{~mL}$ \\
\hline & & Bio Cab & Fertilizante & & $2000 \mathrm{~mL}$ \\
\hline & & Bio bok 7 & Fertilizante orgânico & & $2000 \mathrm{~mL}$ \\
\hline & 07/07/2014 & Supa cobre & Micronutriente & & $40 \mathrm{~mL}$ \\
\hline & & Kumulus & Acaricida/Fungicida & Inorgânico & $40 \mathrm{~g}$ \\
\hline & & Bio bok 7 & Fertilizante orgânico & & $5000 \mathrm{~mL}$ \\
\hline & & Rocksil & Fertilizante orgânico & & $60 \mathrm{~g}$ \\
\hline & 08/07/2014 & Brexil & Fertilizante foliar & & $40 \mathrm{~g}$ \\
\hline & & Ácido Bórico & & & $15 \mathrm{~g}$ \\
\hline & & Extrato Pimenta & Inseticida/Nematicida & & $100 \mathrm{~mL}$ \\
\hline & & Bio bok 3 & Fertilizante orgânico & & $5000 \mathrm{~mL}$ \\
\hline & & Rocksil & Fertilizante orgânico & & $60 \mathrm{~g}$ \\
\hline & $14 / 07 / 2014$ & Cellerate & Micronutrientes & & $15 \mathrm{~mL}$ \\
\hline & & Extrato Pimenta & Inseticida/Nematicida & & $100 \mathrm{~mL}$ \\
\hline & & Bio Cab & Fertilizante & & $2000 \mathrm{~mL}$ \\
\hline & & Bio bok 7 & Fertilizante orgânico & & $2000 \mathrm{~mL}$ \\
\hline & $15 / 07 / 2014$ & Supa cobre & Micronutriente & & $40 \mathrm{~mL}$ \\
\hline & & Kumulus & Acaricida/Fungicida & Inorgânico & $40 \mathrm{~g}$ \\
\hline & & Bio bok 7 & Fertilizante orgânico & & $5000 \mathrm{~mL}$ \\
\hline & & Rocksil & Fertilizante orgânico & & $60 \mathrm{~g}$ \\
\hline & $21 / 07 / 2014$ & Brexil & Fertilizante foliar & & $40 \mathrm{~g}$ \\
\hline & 21/07/2014 & Ácido Bórico & & & $30 \mathrm{~g}$ \\
\hline & & Bio Cab & Fertilizante & & 4 \\
\hline & & Extrato Pimenta & Inseticida/Nematicida & & $100 \mathrm{~mL}$ \\
\hline & & Dipel & Inseticida & & $30 \mathrm{~g}$ \\
\hline & (2/07/2014 & Boverril & Inseticida & & $15 \mathrm{~g}$ \\
\hline & $22 / 0 / / 2014$ & Metarril & Inseticida & & $15 \mathrm{~g}$ \\
\hline & & Trichodermil & Fungicida & & $40 \mathrm{~g}$ \\
\hline & & Bio bok 7 & Fertilizante orgânico & & $2 \mathrm{~L}$ \\
\hline & $23 / 07 / 2014$ & Supa cobre & Micronutriente & & $40 \mathrm{~mL}$ \\
\hline & & Kumulus & Acaricida/Fungicida & Inorgânico & $40 \mathrm{~g}$ \\
\hline$\overline{C 1}$ & & Manzate & Fungicida & ditiocarbamatos & \\
\hline & $30 / 05 / 2014$ & Cobre & Fungicida & Inorgânico & \\
\hline & & Nufos & Inseticida & organofosforado & \\
\hline & 06/06/2014 & Losna & Inseticida & & \\
\hline & & Nufos & Inseticida & organofosforado & \\
\hline & $11 / 06 / 2014$ & Evidence & Inseticida & neonicotinóide & \\
\hline & & Cercobim & Fungicida & benzimidazol & \\
\hline & 16/06/2014 & Ridomil & Fungicida & Fenilamida+Ditiocarbamato & \\
\hline & & Exion top & Adubo foliar & & \\
\hline & $21 / 06 / 2014$ & Boro plus & Adubo foliar & & \\
\hline & & Nufos & Inseticida & organofosforado & \\
\hline & $26 / 06 / 2014$ & Evidence & Inseticida & neonicotinóide & $1 \mathrm{~mL}$ \\
\hline & $02107 / 2014$ & Plantafol & Adubo foliar & & \\
\hline & $02 / 07 / 2014$ & Boro plus & Adubo foliar & & \\
\hline & & Evidence & Inseticida & neonicotinóide & \\
\hline & 07/07/2014 & Certero & Inseticida & benzoiluréia & \\
\hline & & Plantafol & Adubo foliar & & \\
\hline & 14/07/2014 & Exion top & Adubo foliar & & \\
\hline & $21 / 07 / 2014$ & Bravonil & Fungicida & isoftalinitrila & \\
\hline & 21/07/2014 & Nufos & Inseticida & organofosforado & \\
\hline & & Calbit C & Adubo foliar & & \\
\hline & $28 / 07 / 2014$ & Nufos & Inseticida & organofosforado & \\
\hline $\mathbf{O 2}$ & $15 / 09 / 2014$ & Dipel & Inseticida & neonicotinóide & $30 \mathrm{~g}$ \\
\hline & $30 / 06 / 2014$ & Evidence & Inseticida & neonicotinóide & $0,25 \mathrm{~g}$ \\
\hline & $07 / 07 / 2014$ & Dithane & Fungicida & ditiocarbamato & $3 g$ \\
\hline & $14 / 07 / 2014$ & Fish Fértil & Adubo foliar & & $2 \mathrm{~mL}$ \\
\hline $\mathrm{C2}$ & $21 / 07 / 2014$ & Evidence & Inseticida & neonicotinóide & $0,25 \mathrm{~g}$ \\
\hline & $28 / 07 / 2014$ & Fish Fértil & Adubo foliar & & $2 \mathrm{~mL}$ \\
\hline & $04 / 08 / 2014$ & Evidence & Inseticida & neonicotinóide & $0,25 \mathrm{~g}$ \\
\hline $\mathbf{O 3}$ & $10 / 08 / 2014$ & Bokashi & Fertilizante orgânico & & $0,2 \mathrm{~mL}$ \\
\hline & $15 / 07 / 2014$ & Evidence & Inseticida & neonicotinóide & $0,5 \mathrm{~g}$ \\
\hline & $20 / 07 / 2014$ & Sevin & Inseticida & Metilcarbamato de naftila & $1 \mathrm{~mL}$ \\
\hline C3 & $20 / 07 / 2014$ & Cobre & Adubo foliar & & \\
\hline & $14 / 08 / 2014$ & Evidence & Inseticida & neonicotinóide & $0,5 \mathrm{~g}$ \\
\hline & $04 / 09 / 2014$ & Cobre & Micronutriente & & \\
\hline & $04 / 09 / 2014$ & Cercobim & Fungicida & benzimidazol & \\
\hline C4 & $04 / 09 / 2014$ & Complex 151 & Adubo foliar & & \\
\hline & $10 / 09 / 2014$ & Actara & Inseticida & neonicotinóide & $0,5 \mathrm{~g}$ \\
\hline
\end{tabular}



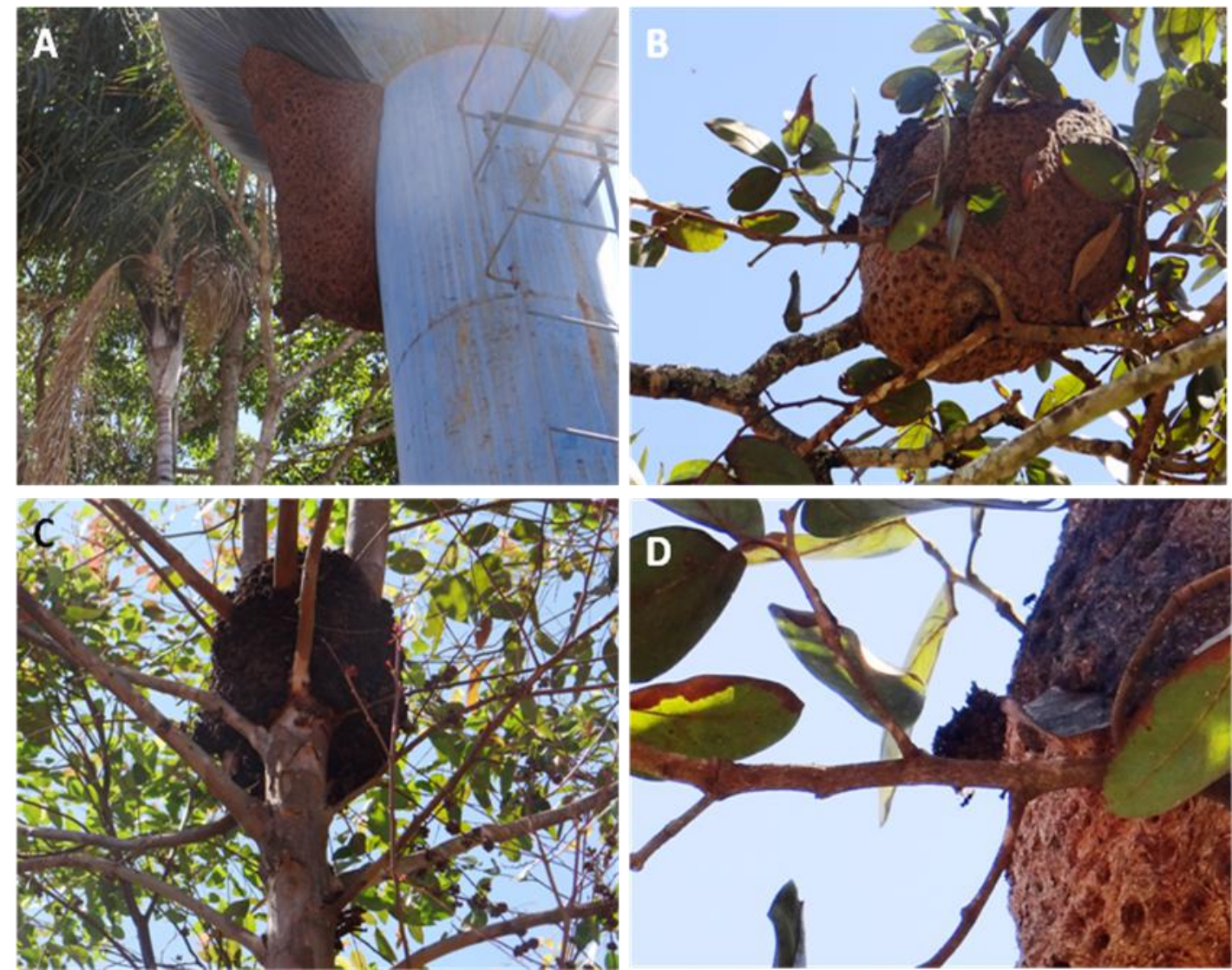

Figura 3.1 - Ninhos de abelhas encontrados nas propriedades de cultivo convencional e orgânico de aboboreira (Cucurbita pepo L.). A) Trigona hyalinata (na parede de uma caixa d'água) na propriedade O3; B) Trigona spinipes (em galho de árvore) na propriedade C2; B) Trigona spinipes (em galho de eucalipto) na propriedade O3; D) Detalhe da entrada do ninho de Trigona spinipes.

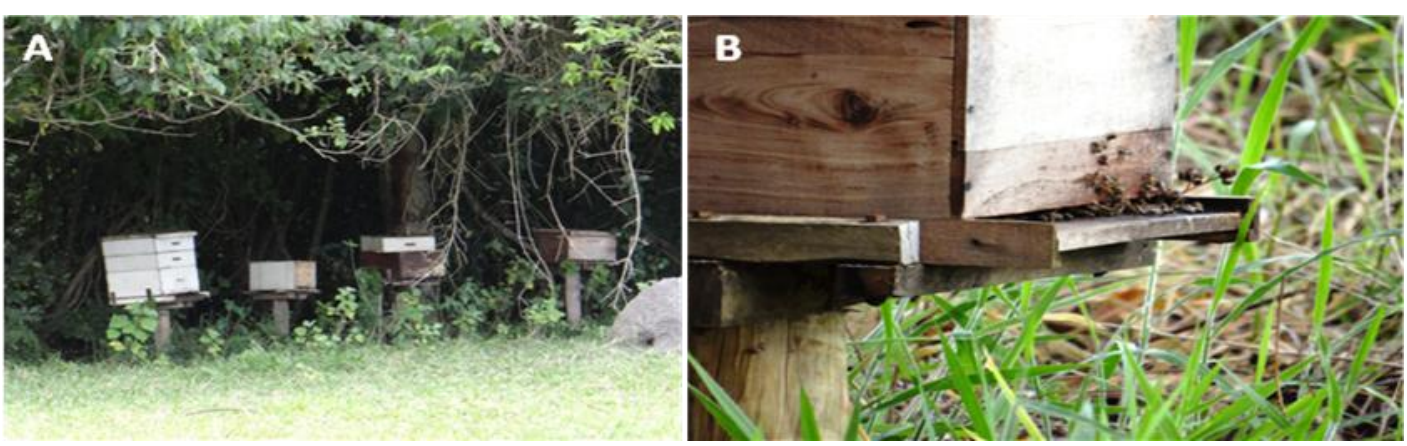

Figura 3.2 - Caixas de criação da abelha exótica Apis mellifera localizadas nas proximidades das áreas de cultivo orgânico (propriedade O1) e convencional (propriedade C1) de aboboreira (Cucurbita pepo L.), localizadas no Distrito Federal. 


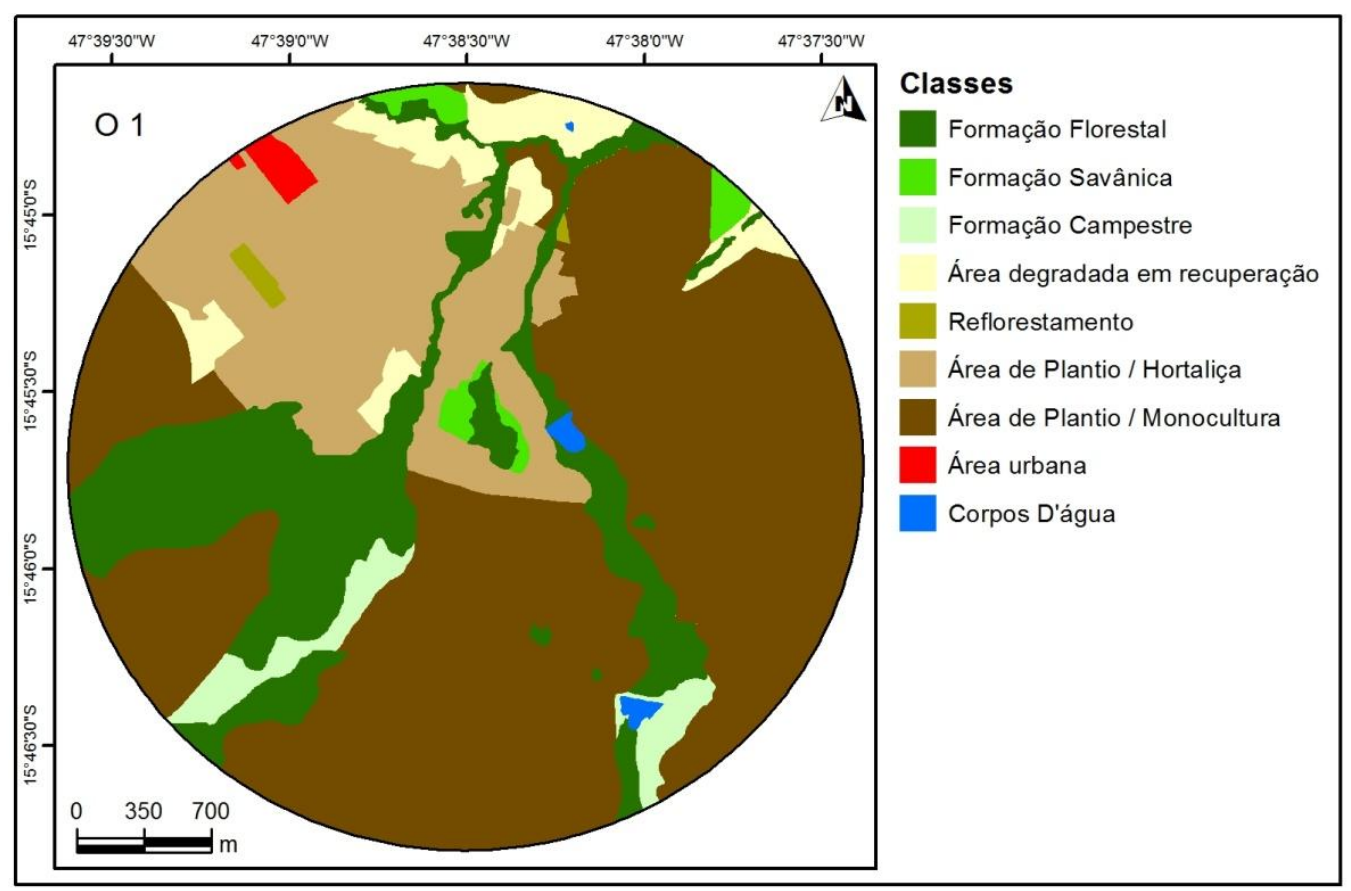

Figura 3.3 - Caracterização da paisagem do entorno em um raio de $2 \mathrm{~km}$ a partir do ponto central com as 11 classes estabelecidas. Propriedade orgânica (O1) localizada no Distrito Federal.

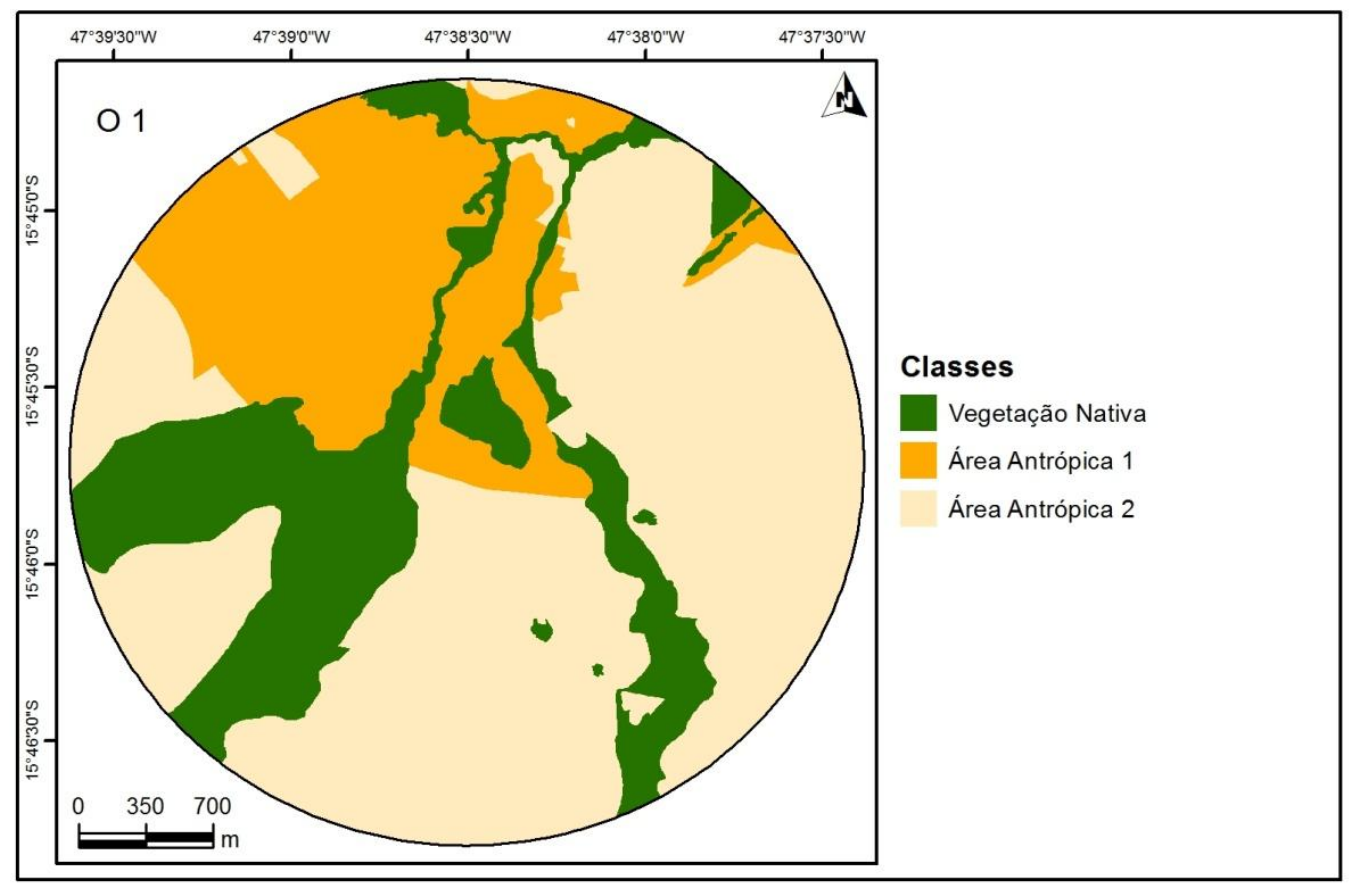

Figura 3.4 - Caracterização da paisagem do entorno em um raio de $2 \mathrm{~km}$ a partir do ponto central após a reclassificação gerando 3 classes. Propriedade orgânica (O1) localizada no Distrito Federal. 


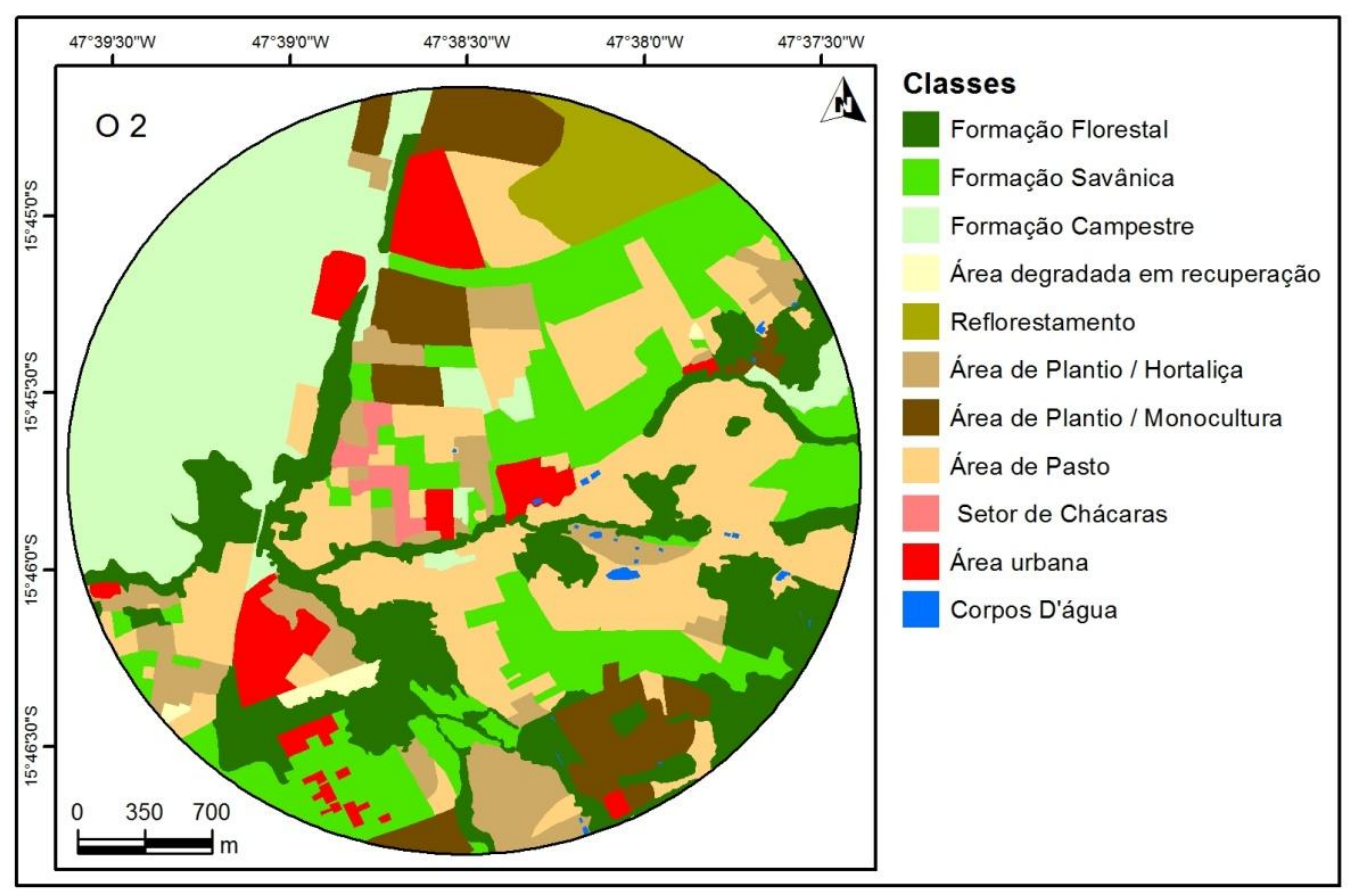

Figura 3.5 - Caracterização da paisagem do entorno em um raio de $2 \mathrm{~km}$ a partir do ponto central com as 11 classes estabelecidas. Propriedade orgânica (O2) localizada no Distrito Federal.

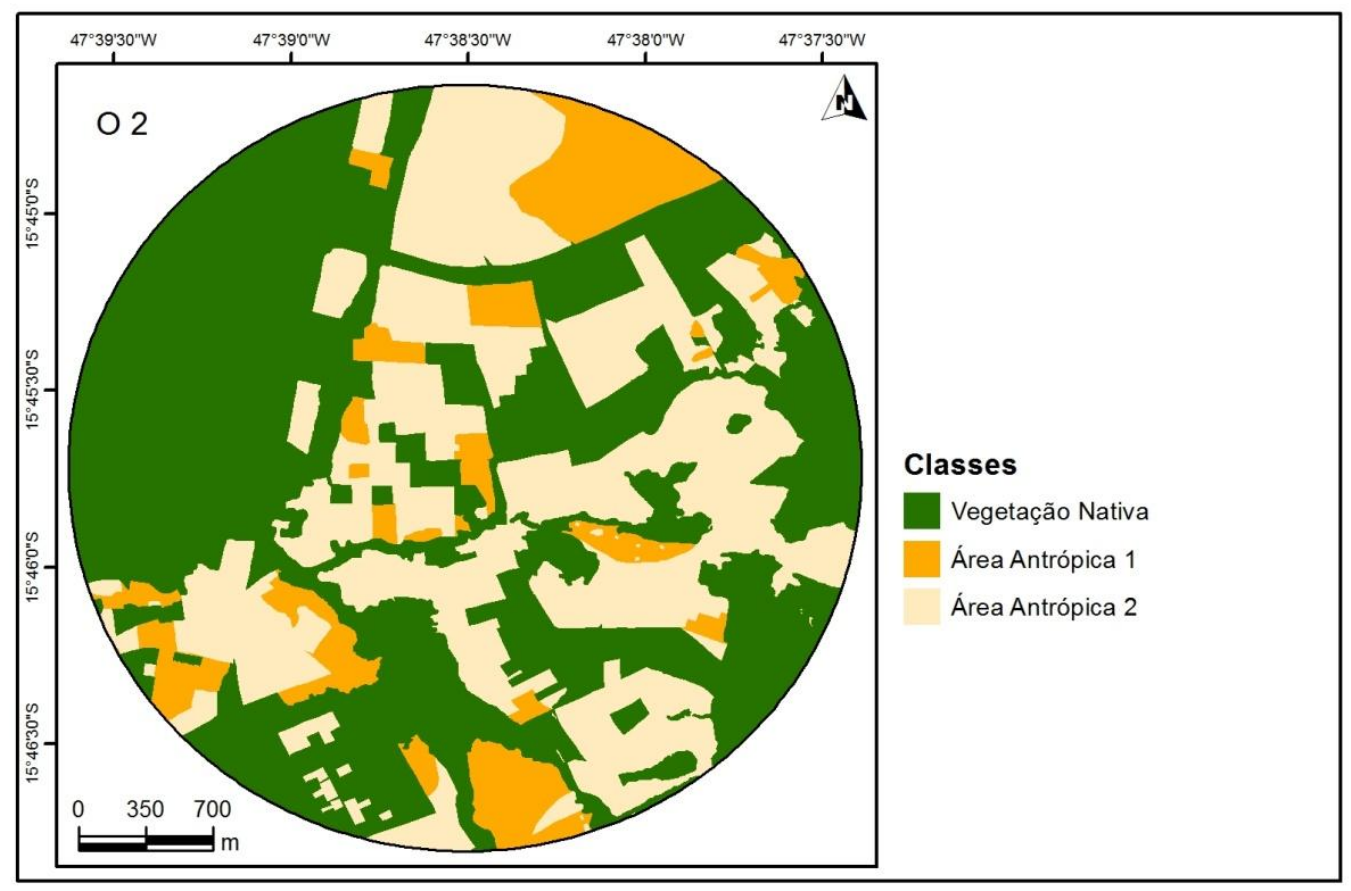

Figura 3.6 - Caracterização da paisagem do entorno em um raio de $2 \mathrm{~km}$ a partir do ponto central com as 11 classes estabelecidas. Propriedade orgânica (O2) localizada no Distrito Federal. 


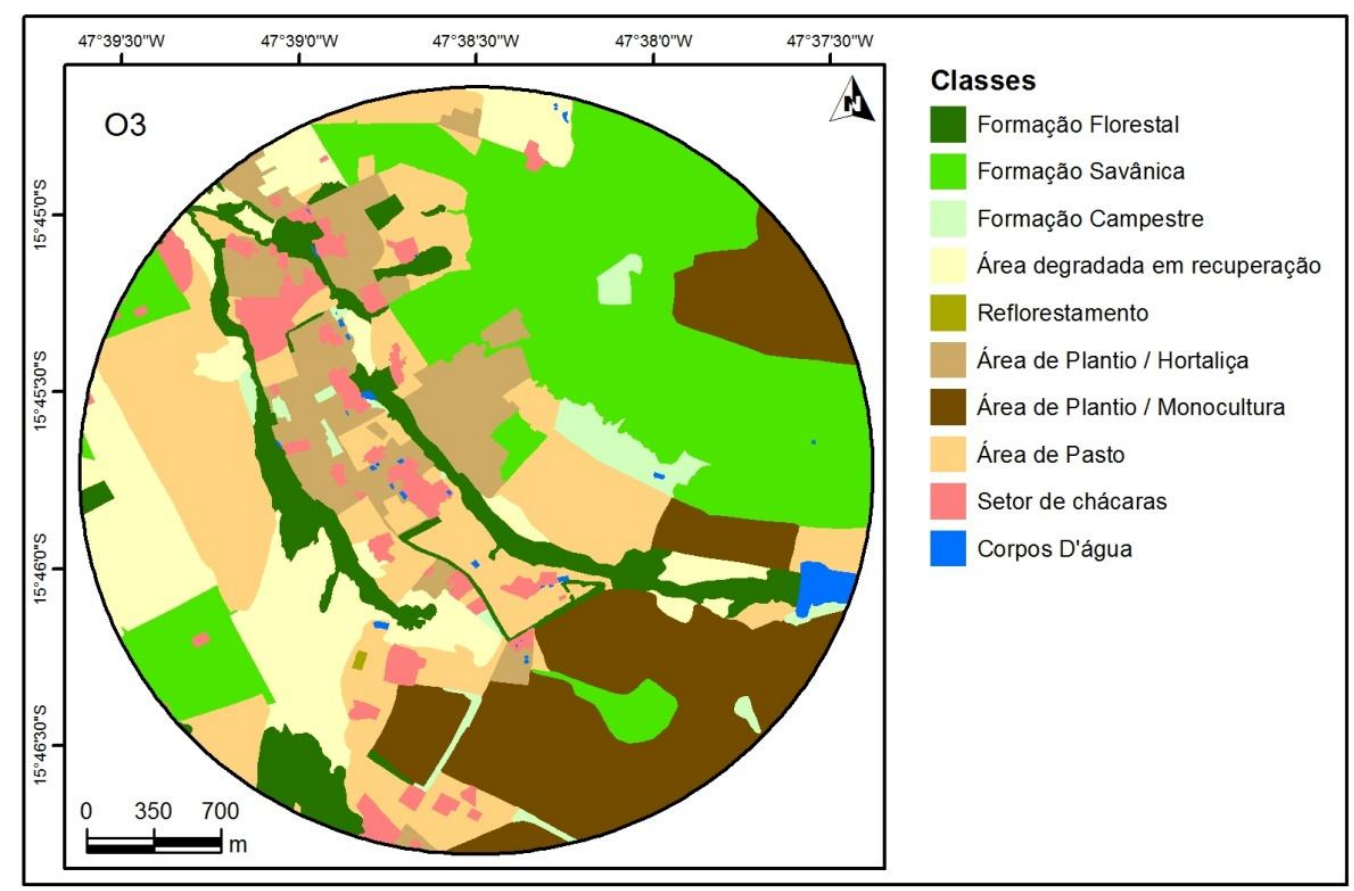

Figura 3.7 - Caracterização da paisagem do entorno em um raio de $2 \mathrm{~km}$ a partir do ponto central com as 11 classes estabelecidas. Propriedade orgânica (O3) localizada no Distrito Federal.

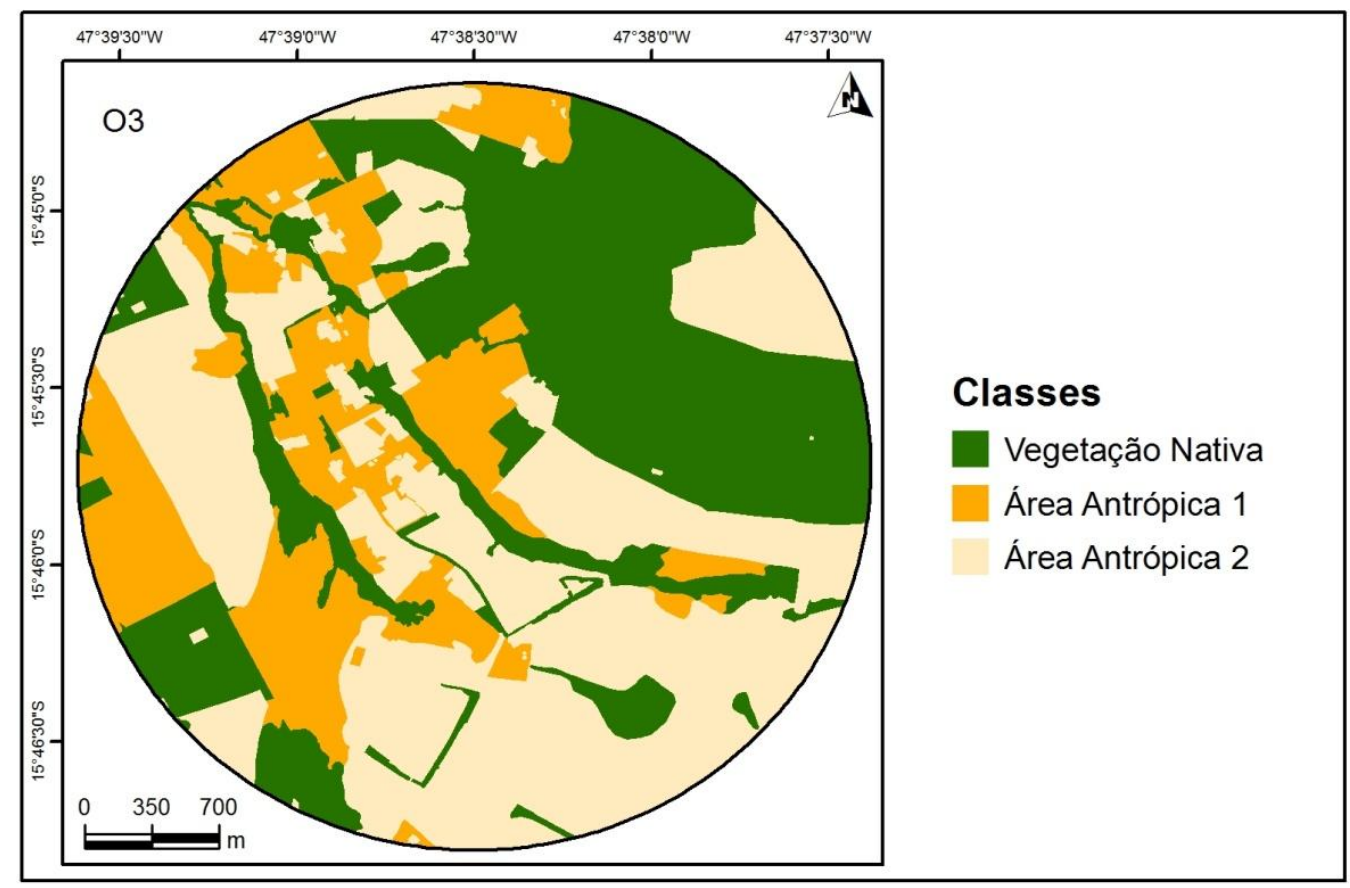

Figura 3.8 - Caracterização da paisagem do entorno em um raio de $2 \mathrm{~km}$ a partir do ponto central com as 11 classes estabelecidas. Propriedade orgânica (O3) localizada no Distrito Federal. 


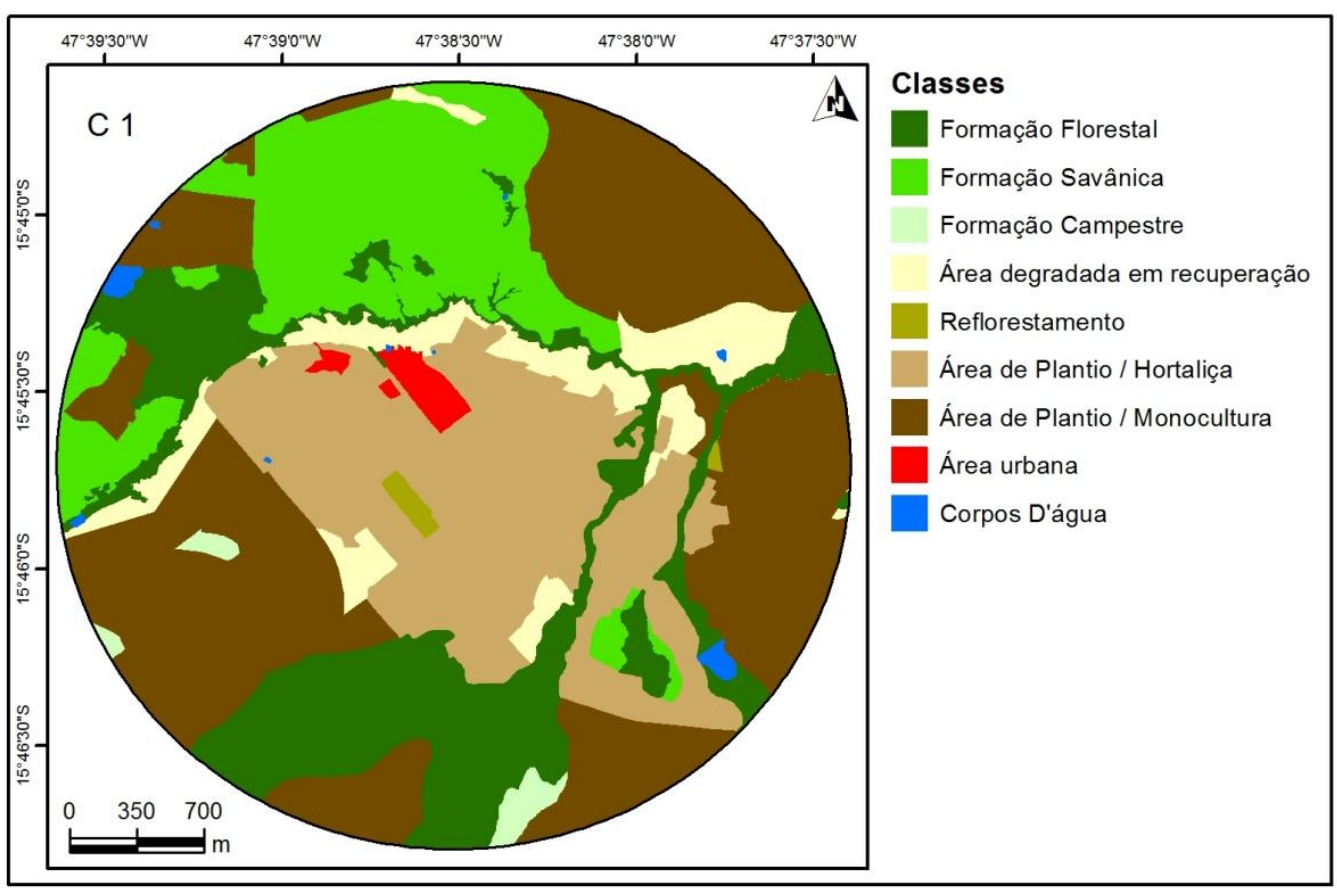

Figura 3.9 - Caracterização da paisagem do entorno em um raio de $2 \mathrm{~km}$ a partir do ponto central com as 11 classes estabelecidas. Propriedade orgânica (C1) localizada no Distrito Federal.

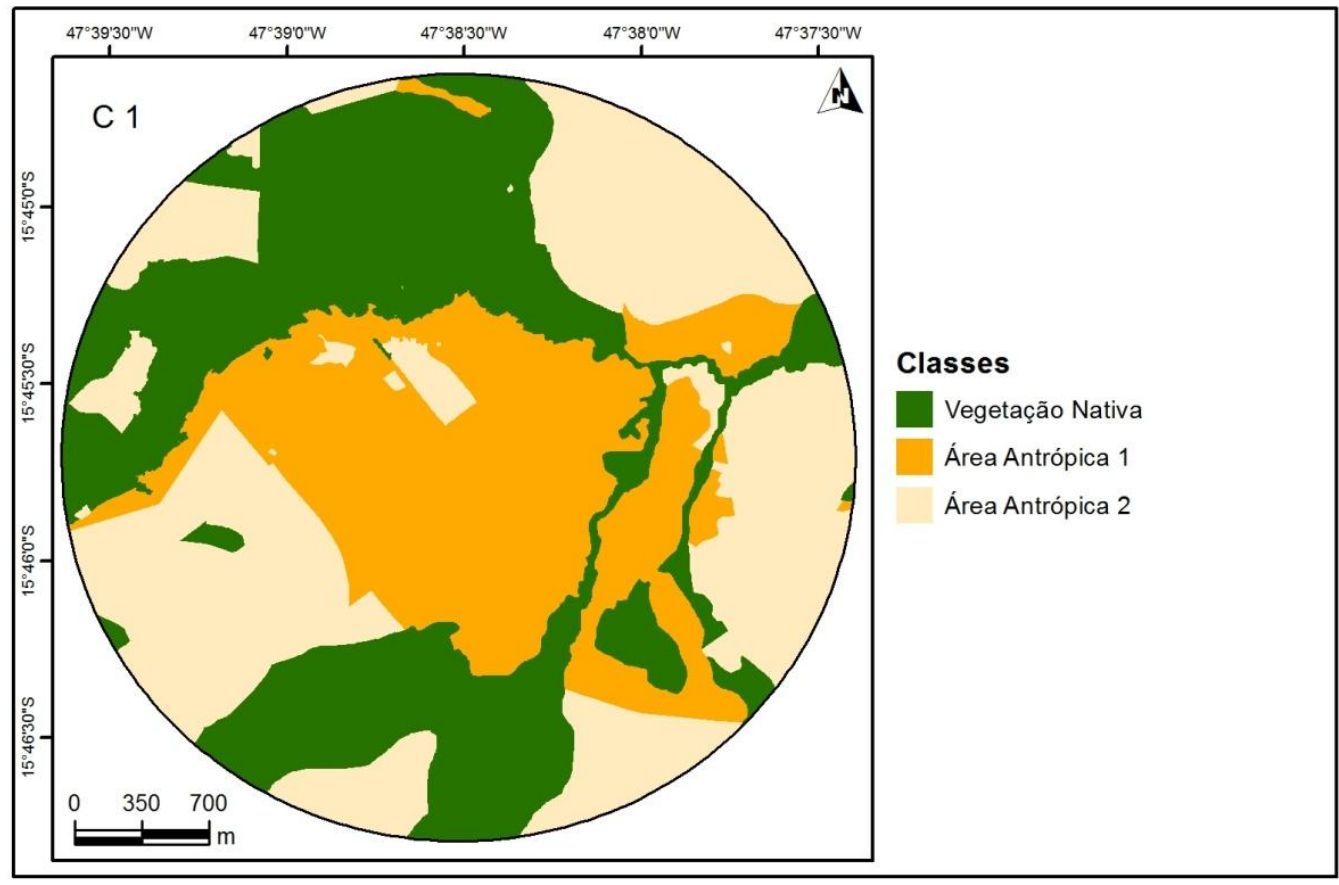

Figura 3.10 - Caracterização da paisagem do entorno em um raio de $2 \mathrm{~km}$ a partir do ponto central com as 11 classes estabelecidas. Propriedade orgânica (C1) localizada no Distrito Federal. 


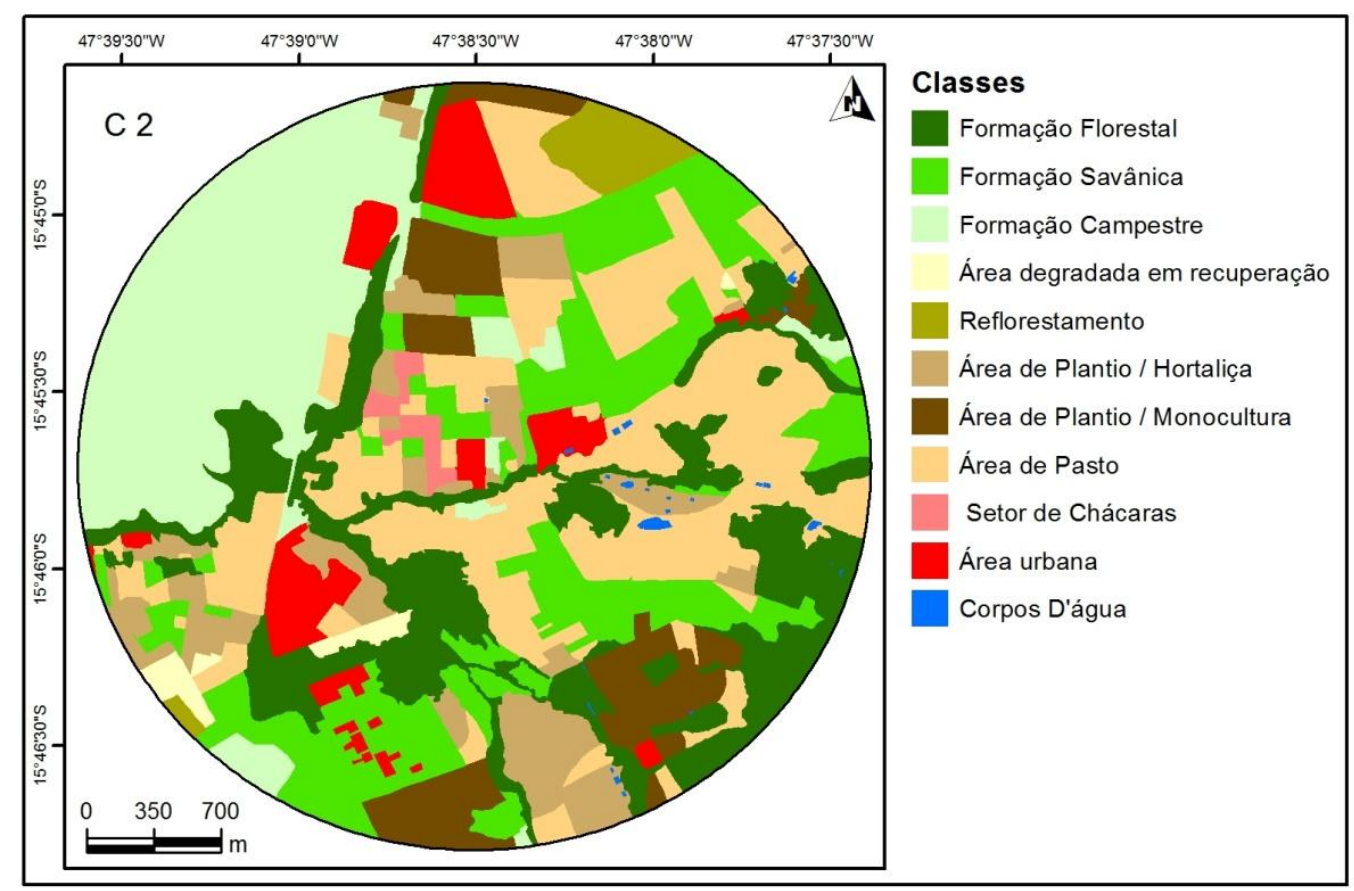

Figura 3.11 - Caracterização da paisagem do entorno em um raio de $2 \mathrm{~km}$ a partir do ponto central com as 11 classes estabelecidas. Propriedade orgânica (C2) localizada no Distrito Federal.

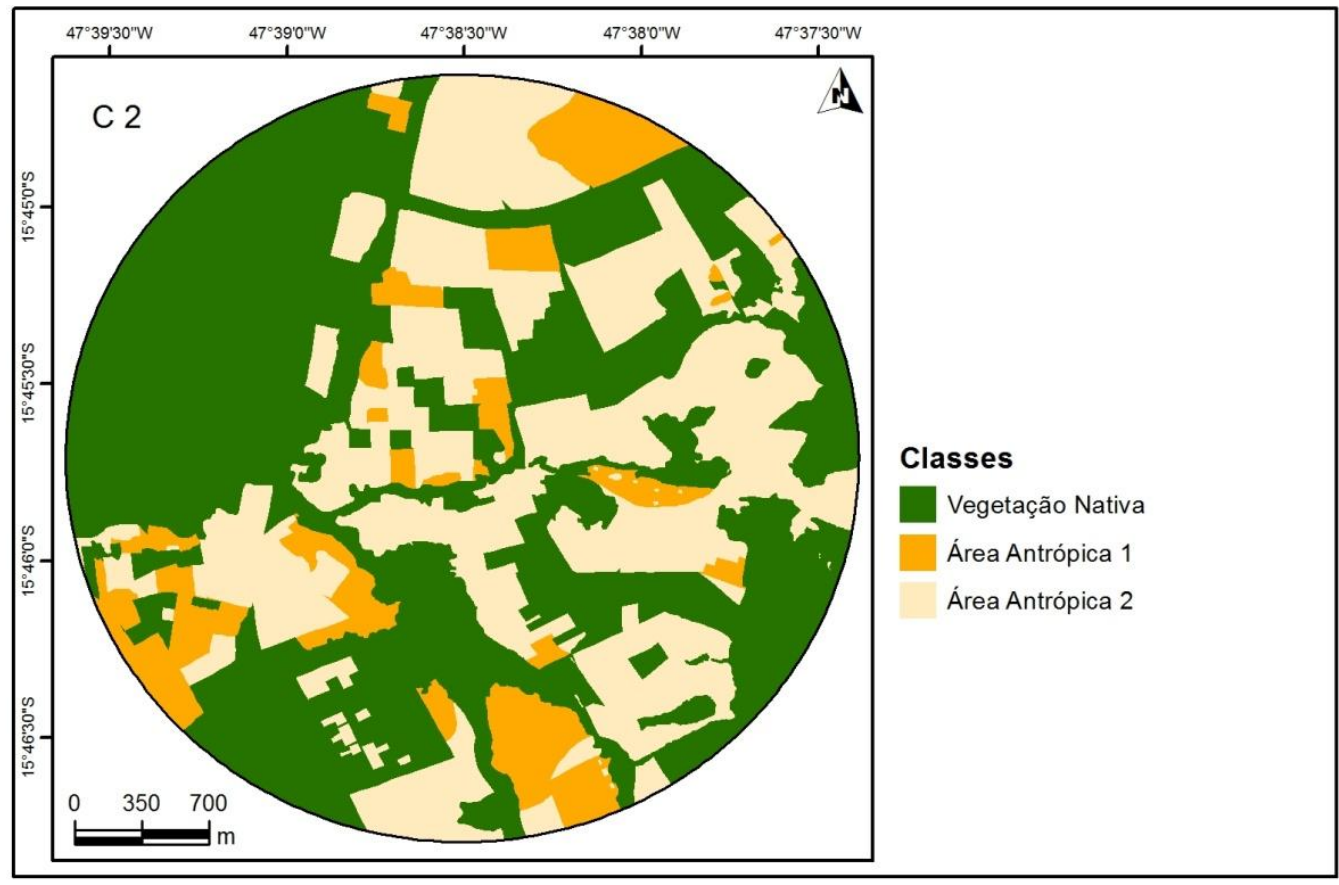

Figura 3.12 - Caracterização da paisagem do entorno em um raio de $2 \mathrm{~km}$ a partir do ponto central com as 11 classes estabelecidas. Propriedade orgânica (C2) localizada no Distrito Federal. 


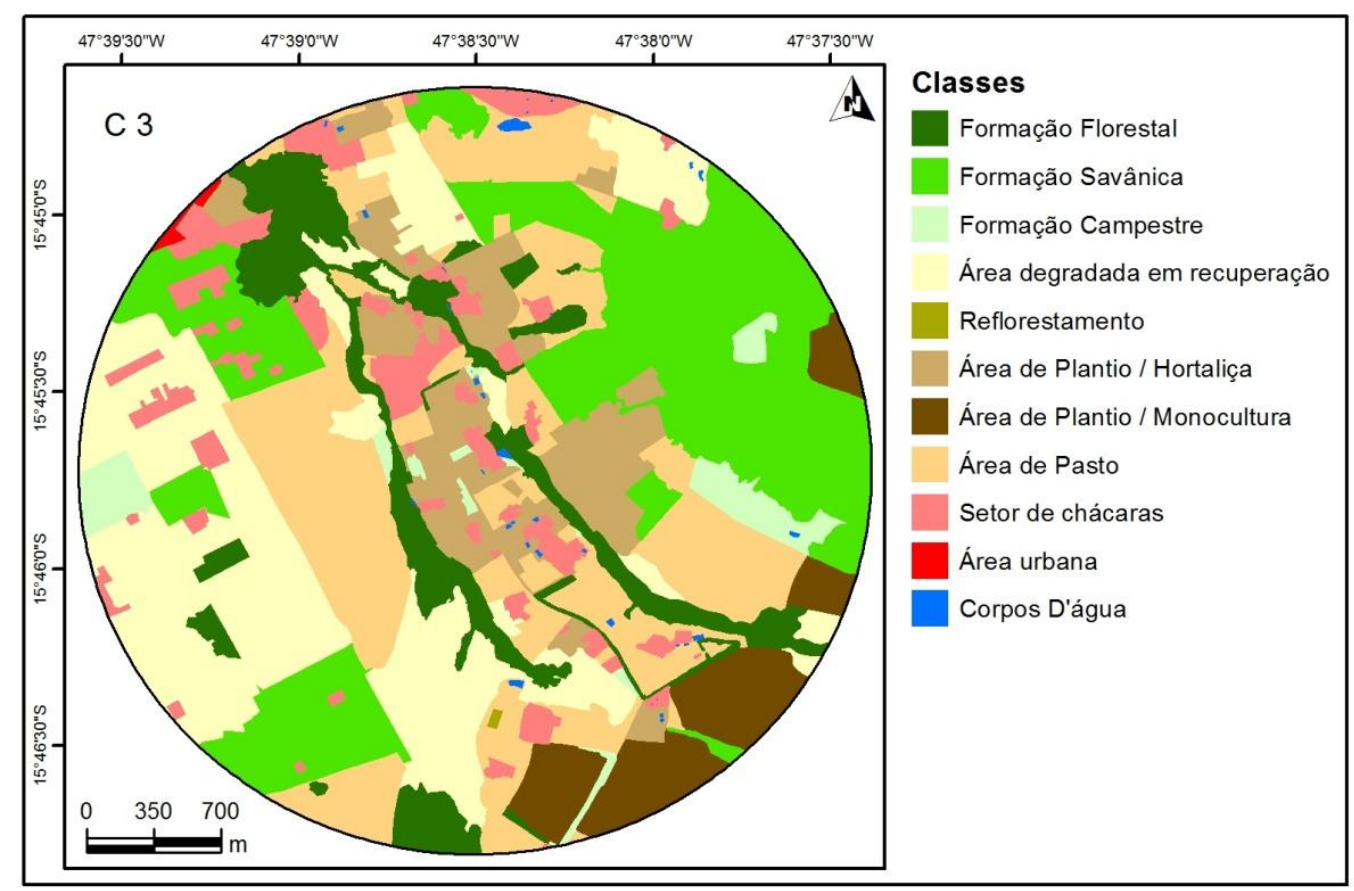

Figura 3.13 - Caracterização da paisagem do entorno em um raio de $2 \mathrm{~km}$ a partir do ponto central com as 11 classes estabelecidas. Propriedade orgânica (C3) localizada no Distrito Federal.

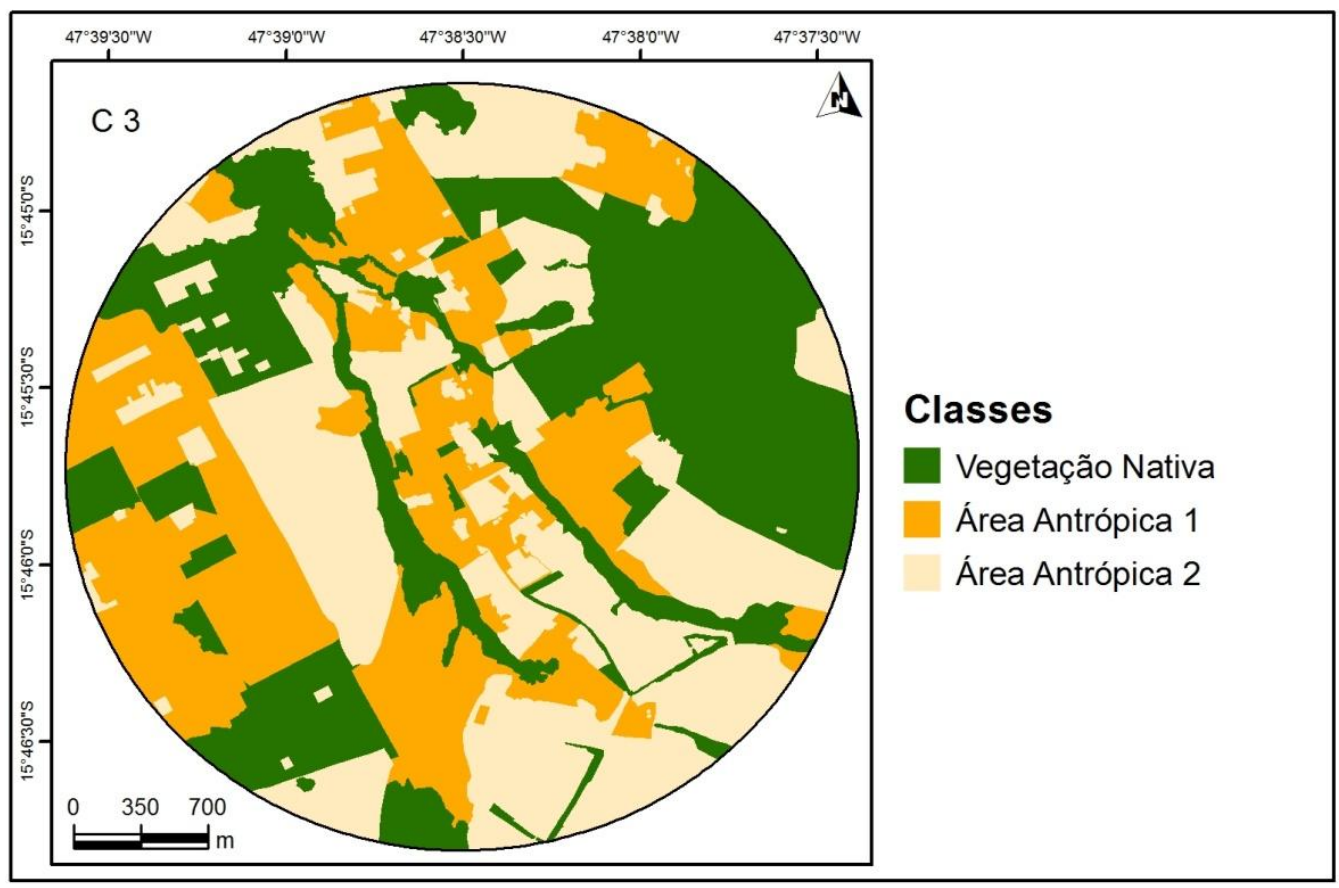

Figura 3.14 - Caracterização da paisagem do entorno em um raio de $2 \mathrm{~km}$ a partir do ponto central com as 11 classes estabelecidas. Propriedade orgânica (C3) localizada no Distrito Federal. 


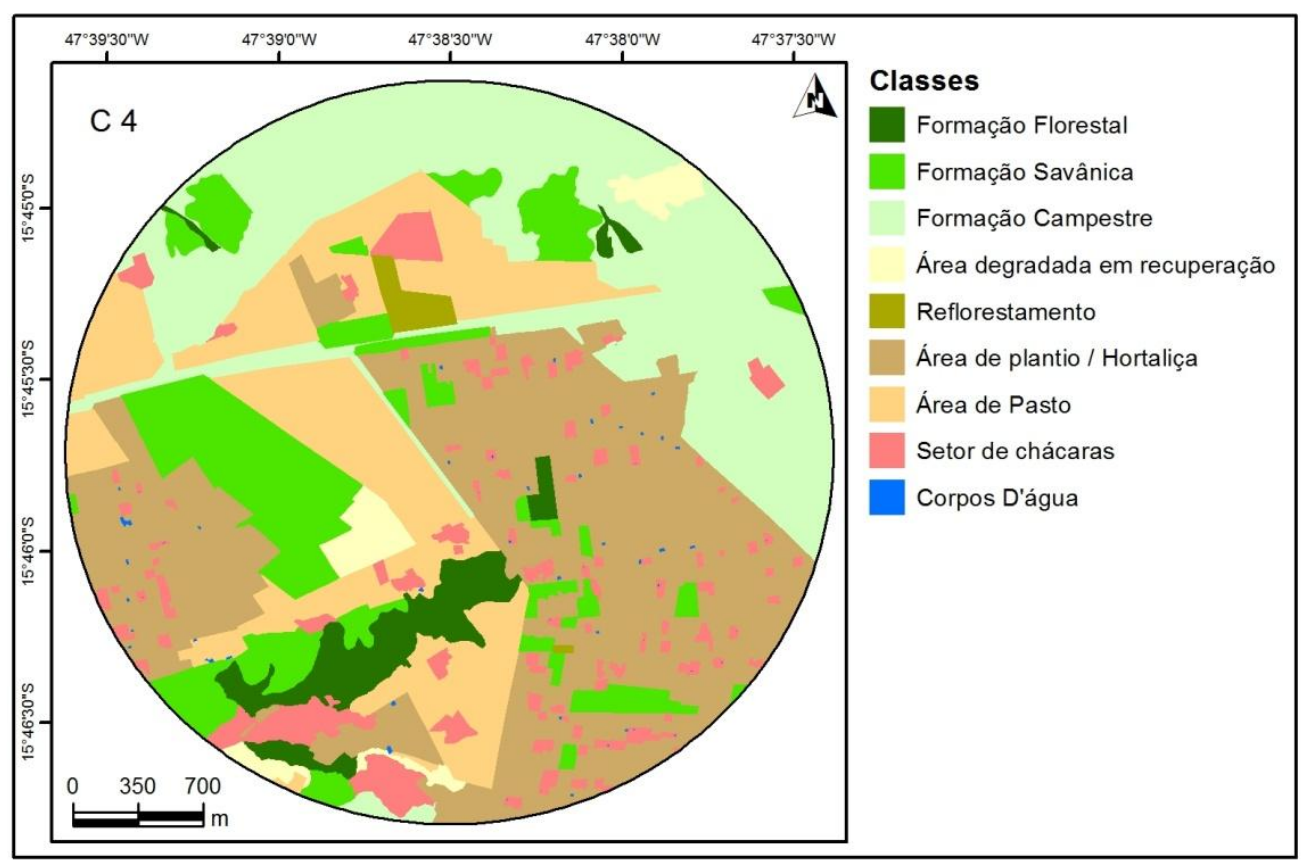

Figura 3.15 - Caracterização da paisagem do entorno em um raio de $2 \mathrm{~km}$ a partir do ponto central com as 11 classes estabelecidas. Propriedade orgânica (C4) localizada no Distrito Federal.

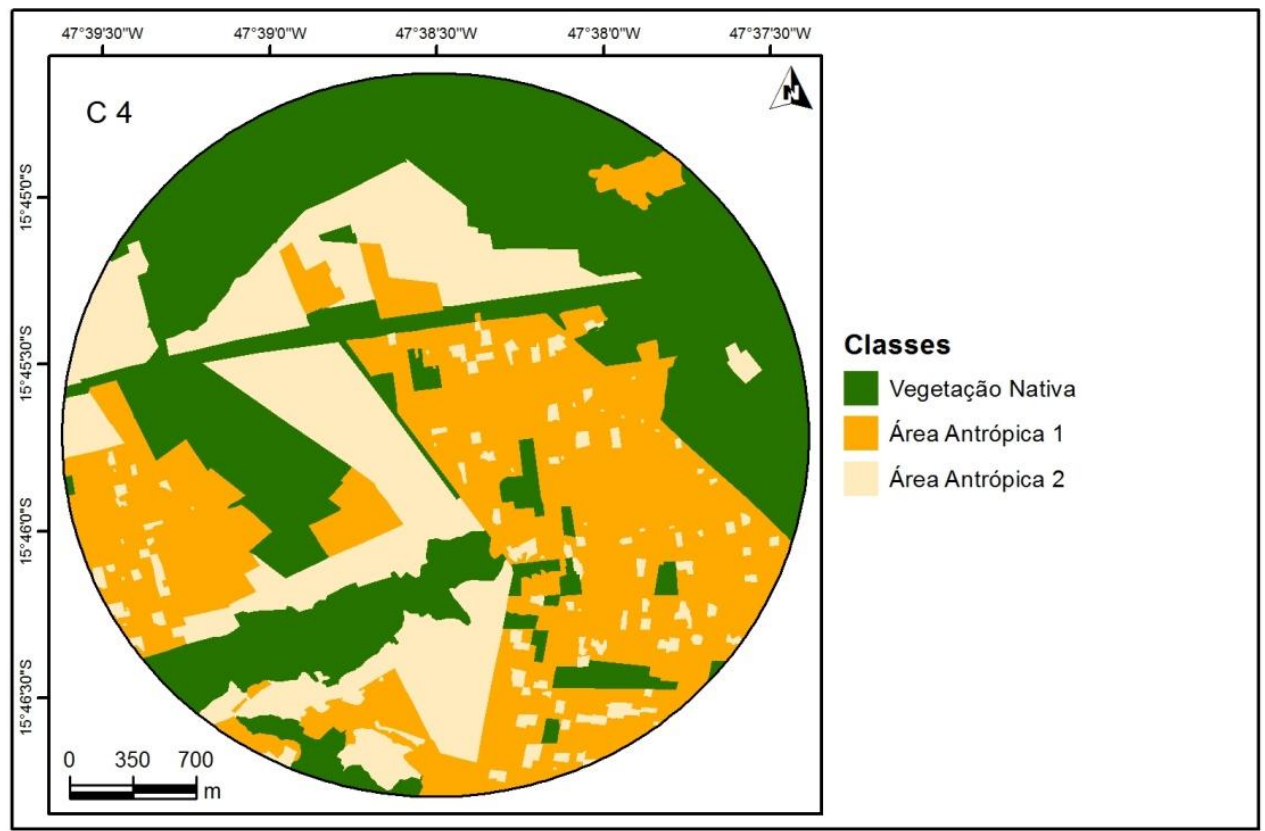

Figura 3.16 - Caracterização da paisagem do entorno em um raio de $2 \mathrm{~km}$ a partir do ponto central com as 11 classes estabelecidas. Propriedade orgânica (C4) localizada no Distrito Federal. 